\title{
MODELO PARA SIMULAÇÃO DA DINÂMICA DE NITRATO EM COLUNAS VERTICAIS DE SOLO NÃO-SATURADO
}

\section{JARBAS HONORIO DE MIRANDA}

Engenheiro Agrônomo

\author{
Orientador: Prof. Dr. SERGIO NASCIMENTO DUARTE
}

Tese apresentada à Escola Superior de Agricultura "Luiz de Queiroz", Universidade de São Paulo, para obtenção do título de Doutor em Agronomia, Área de Concentração: Irrigação e Drenagem.

P I R A C I C A B A

Estado de São Paulo - Brasil

Agosto - 2001 


\section{Dados Internacionais de Catalogação na Publicação (CIP) DIVISĀO DE BIBLIOTECA E DOCUMENTAÇĀO - Campus "Luiz de Queiroz"/USP}

Miranda, Jarbas Honorio de

Modelo para simulação da dinâmica de nitrato em colunas verticais de solo nāosaturado / Jarbas Honario de Miranda. - - Piracicaba, 2001.

79 p. : it.

Tese (doutorado) - Escola Superior de Agricultura Luiz de Queiroz, 2001.

Bibliografia.

1. Dinâmica 2. Nitrato 3. Simulação automatizada 4. Solo 5 . Solução do solo I. Titulo

CDD 631.41

Termitida a copia total ou parcial deste documento, desde que citada a fonte - 0 autor? 
"Lensamos demasiadamente e sentimos muito pouco. Necessitamos mais de humildade que de máquinas. Mais de bondade e ternura que de inteligencia. Sem isso, a vida se tornará violerita e cudo se perder á".

"A vida é mavarilhusa se você não tern medo dela."

Gharles Ghaplin

Momentos de alegria, retratam na sua ivegridade a nossa corvivênsia e comirihada, dearidamente aproveritados e saboreados. Dividimos e apraneitamos dos momentos alegres e difüceis as devidas liscoes para crescermos e aprendermos a dificil arte de viver. LPor isso, ressalto a importâsicia da sua presensa no sentido de fazer-me entender que para aplicar na prútica a teoria de viver, é preciso também aprender a arte de owir, sorriv e ter paciência ....sempre.

MTKêsia Oheira da Silwa

Dedica 
Ḿminha mãe Bunice da Sillow Miranda;

As minhas irmãs Tza e Maria Três,

Ámemória do mew pai, Losé Honorio de Mirunda; e do mew irmão, Zosé Thumbertor de Miranda.

Ofereso 


\section{AGRADECIMENTOS}

A Deus pela força e coragem para superar todas as dificuldades e momentos dificeis durante a realização desse trabalho.

Ao Prof. Dr. Sergio Nascimento Duarte, além de orientador, um amigo e incentivador para com a minha vida profissional.

Aos Professores Paulo Leonel Libardi (ESALQ/USP), Tarlei Arriel Botrel (ESALQ/USP), Mauro Aparecido Martinez (UFV), Antônio Teixeira Matos (UFV) e Vicente Gualberto (UFLA), pelas valiosas sugestões fornecidas para a conclusão do trabalho.

Ao U.S.S.L (United State Salinity Laboratories) pelo fornecimento de material de software aplicado nesse trabalho.

Às funcionárias do Laboratório de Ecologia Aplicada do Departamento de Ciências Florestais, ESALQ/USP, pela dedicação na realização das análises.

Aos Funcionários Gilmar Batista Grigolom e José Luiz Moraes Rodrigues pelo auxílio na obtenção de dados e materiais de solos utilizados nesse trabalho.

Aos Professores do Departamento de Engenharia da Universidade Federal de Lavras, Nilson Salvador e Sebastião Pereira Lopes e em especial aos Professores do Setor de Engenharia de Água e Solo, Alberto Colombo, Antônio Marciano da Silva, Elio Lemos da Silva, Geraldo Magela Pereira, Jacinto de Assunção Carvalho, Luís Artur A. Vilela e Manoel Alves de Faria, pelo companheirismo, incentivo e auxílio para a conclusão desse trabalho.

Ao Prof. Dr. Iran José Oliveira da Silva pelo apoio e incentivo durante a realização desse trabalho. 
Aos meus colegas de pós-graduação, especialmente ao Ênio Farias de França e Silva e ao Luís Carlos Timm, pelo convívio agradável e a todos aqueles que de alguma forma participaram e me ajudaram na conclusão desse trabalho, registro o meu muito obrigado.

Aos Professores do Departamento de Engenharia Rural da ESALQ/USP pelos ensinamentos e pelas oportunidades concedidas no decorrer do curso, em especial aos Professores Dr. José Antonio Frizzone e Dr. Marcos Vinícius Folegatti.

À bibliotecária Eliana Maria Garcia pelas correções realizadas.

Ao CNPq pela concessão da bolsa de estudos.

À Escola Superior de Agricultura "Luiz de Queiroz" pelos conhecimentos adquiridos durante a realização do curso. 


\section{SUMÁRIO}

\begin{tabular}{|c|c|c|}
\hline & & Página \\
\hline LISTA & FIGURAS & . \\
\hline ISTA & DE QUADROS . & xiii \\
\hline ESU & & xiv \\
\hline UMM & ARY & $x v i$ \\
\hline 1 & INTRODUÇÃO ..... & 1 \\
\hline 2 & REVISÃO DE LITERATURA........ & 4 \\
\hline 2.1 & 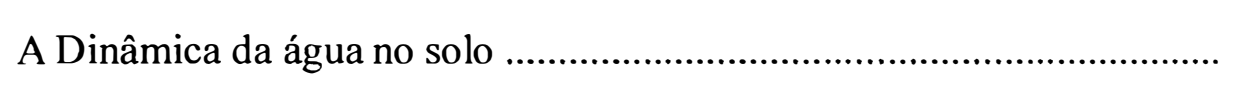 & 4 \\
\hline 2.1 .1 & 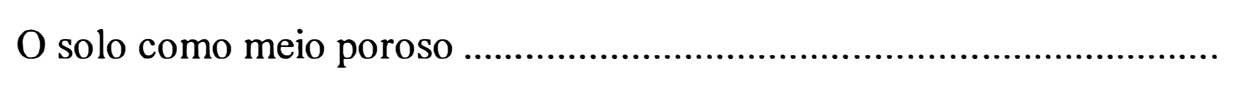 & 4 \\
\hline 2.1 .2 & A lei de Darcy ........................ & 4 \\
\hline 2.1 .3 & Condutividade Hidráulica ............. & 6 \\
\hline 2.2 & Dinâmica dos solutos .............. & 9 \\
\hline 2.2 .1 & Utilização de modelos para avaliação da dinâmica dos solutos ................. & 10 \\
\hline 2.2 .2 & Equação de transporte de solutos ... & 12 \\
\hline 3 & MATERIAL E MÉTODOS ..... & 17 \\
\hline 3.1 & Desenvolvimento do modelo ............... & 17 \\
\hline 3.1 .1 & Etapas de processamento do modelo & 19 \\
\hline 3.1.1.1 & Processamento da variação de umidade nas células da coluna .................. & 19 \\
\hline 3.1 .1 .2 & Processamento da variação da concentração de nitrato nas células da & 21 \\
\hline 3.2 & Condução do experimento em laboratório ...... & 26 \\
\hline 3.2 .1 & Características do solo ............ & 26 \\
\hline
\end{tabular}


3.2.2 Determinação das curvas de eluição e obtenção dos parâmetros de transporte do nitrato

3.2.2.1 Preparo da solução de nitrato ............................................................. 28

3.2.2.2 Aplicação da solução na coluna de solo .................................................... 28

3.2.2.3 Obtenção dos parâmetros de transporte pelo modelo CXTFIT ................ 30

3.2.3 Aplicação da solução na coluna segmentada ........................................... 30

3.3 Análise de sensibilidade do modelo ...................................................... 34

$4 \quad$ RESULTADOS E DISCUSS ÃO ...................................................... 36

4.1 Validação do modelo comparando o perfil de umidade simulado em relação à média das três medições ........................................................... $\quad 36$

4.2 Simulação do perfil de umidade em relação às três repetições ................ 38

4.3 Validação do modelo comparando o perfil de concentração de nitrato simulado em relação à média das três medições ...................................... $\quad 40$

4.4 Simulação do perfil de nitrato em relação às três repetições ..................... 42

4.5 Influência da variação dos parâmetros de entrada do modelo na simulação da umidade do solo na coluna e concentração de nitrato .......

4.5.1 Análise de sensibilidade dos parâmetros de simulação na representação do perfil de umidade ........................................................................... 45

4.5.2 Análise de sensibilidade dos parâmetros de simulação na representação do perfil de concentração de nitrato

4.6 Análise de sensibilidade do modelo supondo a aplicação de uma solução de concentração superior à concentração do solo ........................ 57

4.7 Recomendações finais ...................................................................... 65

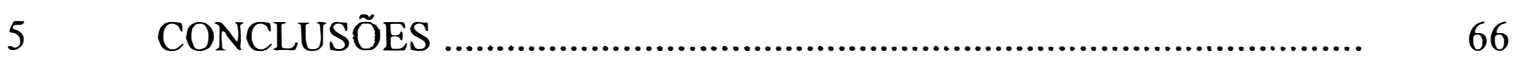

REFERÊNCIAS BIBLIOGRÁFICAS ............................................................. 67

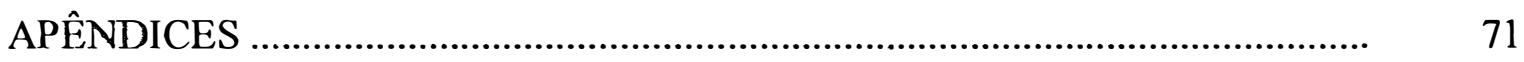




\section{LISTA DE FIGURAS}

Página

1 Fluxograma do modelo proposto

2 Sub-rotinas do modelo proposto

3 Tela inicial (a) e Tela de entrada e saída de resultados do modelo (b) ............ 25

4 Esquema para a coleta de solução que atravessa a coluna de solo, para a elaboração das curvas de eluição

5 Representação gráfica da concentração de nitrato em função da condutividade elétrica da solução

6 Curvas de eluição obtidas para o Solo 1 (a), Solo 2 (b) e Solo 3 (c)

7 Coluna utilizada para aplicar a solução e determinação da concentração de nitrato em cada anel (a) e representação esquemática da aplicação da solução de nitrato na coluna com um dosador (b)

8 Representação do perfil de umidade média de três repetições obtido em laboratório e pelo modelo para os solos: Solo 1 (a), Solo 2 (b) e Solo 3 (c) ..

9 Representação do perfil de umidade obtido em laboratório em 3 repetições e pelo modelo para os solos: Solo 1 (a), Solo 2 (b) e Solo 3 (c)

10 Representação do perfil de concentração de nitrato obtido em laboratório em relação à média de 3 repetições e pelo modelo para os solos: Solo 1 (a), Solo 2 (b) e Solo 3 (c)

11 Representação do perfil de concentração de nitrato obtido em laboratório em 3 repetições e simulado pelo modelo para os solos: Solo 1 (a), Solo 2 (b) e Solo 3 (c) 
12 Representação esquemática da análise de sensibilidade do modelo em relação à simulação do perfil de umidade do solo na coluna, aplicando de $90 \%$ a +90 \% de variação nos parâmetros de entrada, condutividade hidráulica do solo saturado e umidade volumétrica do solo saturado para 0 Solo 2

13 Representação do perfil de umidade simulado para o Solo 2 comparado com outras duas simulações aumentando e reduzindo de $90 \%$ o parâmetro de entrada umidade volumétrica do solo

14 Representação do perfil de umidade simulado para o Solo 2 comparado com outras duas simulações aumentando e reduzindo de $90 \%$ o parâmetro de entrada saturado condutividade hidráulica do solo saturado

15 Representação esquemática da análise de sensibilidade do modelo em relação à simulação do perfil de umidade do solo na coluna, aplicando de 90 \% a +90 \% de variação nos parâmetros de entrada, vazão do gotejador e umidade inicial do solo que preencheu a coluna para o Solo 2

16 Representação do perfil de umidade simulado para o Solo 2 comparado com outras duas simulações aumentando e reduzindo de $90 \%$ o parâmetro de entrada vazão do gotejador

17 Representação do perfil de umidade simulado para o Solo 2 comparado com outras duas simulações aumentando e reduzindo de 90 \% o parâmetro de entrada umidade inicial do solo que preenche a coluna

18 Representação esquemática da análise de sensibilidade do modelo em relação à simulação da concentração de nitrato, aplicando de -90 \% a +90 \% de variação nos parâmetros de entrada, condutividade hidráulica do solo saturado e umidade volumétrica do solo saturado para o Solo 2

19 Representação do perfil de concentração de nitrato simulado para o Solo 2 comparado com outras duas simulações aumentando e reduzindo de $90 \%$ o parâmetro de entrada condutividade hidráulica do solo saturado ....

20 Representação do perfil de concentração de nitrato simulado para o Solo 2 comparado com outras duas simulações aumentando e reduzindo de $90 \%$ o parâmetro de entrada umidade volumétrica do solo saturado

21 Representação esquemática da análise de sensibilidade do modelo em relação à simulação da concentração de nitrato, aplicando de $-90 \%$ a +90 \% de variação nos parâmetros de entrada, dispersividade e fator de retardamento para o Solo 2 
22 Representação do perfil de concentração de nitrato simulado para o Solo 2 comparado com outras duas simulações aumentando e reduzindo de $90 \%$ o parâmetro de entrada dispersividade

23 Representação do perfil de concentração de nitrato simulado para o Solo 2 comparado com outras duas simulações aumentando e reduzindo de $90 \%$ o parâmetro de entrada fator de retardamento

24 Representação esquemática da análise de sensibilidade do modelo em relação à simulação da concentração de nitrato, aplicando de $-90 \%$ a +90 \% de variação nos parâmetros de entrada, vazão do gotejador e umidade inicial do solo que preencheu a coluna para o Solo 2

25 Representação do perfil de concentração de nitrato simulado para o Solo 2 comparado com outras duas simulações aumentando e reduzindo de $90 \%$ o parâmetro de entrada vazão do gotejador

26 Representação do perfil de concentração de nitrato simulado para o Solo 2 comparado com outras duas simulações aumentando e reduzindo de $90 \%$ o parâmetro de entrada umidade inicial do solo que preenche a coluna

27 Representação esquemática da análise de sensibilidade do modelo em relação à simulação da concentração de nitrato, aplicando de $-90 \%$ a +90 \% de variação nos parâmetros de entrada, condutividade hidráulica do solo saturado e umidade volumétrica do solo saturado, aplicando-se uma solução de 2.000 ppm, para o Solo 2

28 Representação do perfil de concentração de nitrato simulado para o Solo 2, aplicando-se uma solução de 2.000 ppm, comparado com outras duas simulações aumentando e reduzindo de $90 \%$ o parâmetro de entrada condutividade hidráulica do solo saturado

29 Representação do perfil de concentração de nitrato simulado para o Solo 2, aplicando-se uma solução de 2.000 ppm, comparado com outras duas simulações aumentando e reduzindo de $90 \%$ o parâmetro de entrada umidade volumétrica do solo saturado

30 Representação esquemática da análise de sensibilidade do modelo em relação à simulação da concentração de nitrato, aplicando de $-90 \%$ a +90 \% de variação nos parâmetros de entrada, dispersividade e fator de retardamento, aplicando-se uma solução de 2.000 ppm, para o Solo 2 
31 Representação do perfil de concentração de nitrato simulado para o Solo 2 , aplicando-se uma solução de 2.000 ppm, comparado com outras duas simulações aumentando e reduzindo de 90 \% o parâmetro de entrada dispersividade

32 Representação do perfil de concentração de nitrato simulado para o Solo 2 , aplicando-se uma solução de 2.000 ppm, comparado com outras duas simulações aumentando e reduzindo de 90 \% o parâmetro de entrada fator de retardamento

33 Representação esquemática da análise de sensibilidade do modelo em relação à simulação da concentração de nitrato, aplicando de $-90 \%$ a +90 \% de variação nos parâmetros de entrada, vazão do gotejador e umidade inicial do solo que preencheu a coluna, aplicando-se uma solução de 2.000 ppm, para o Solo 2

34 Representação do perfil de concentração de nitrato simulado para o Solo 2 , aplicando-se uma solução de 2.000 ppm, comparado com outras duas simulações aumentando e reduzindo de 90 \% o parâmetro de entrada vazão do gotejador

35 Representação do perfil de concentração de nitrato simulado para o Solo 2, aplicando-se uma solução de 2.000 ppm, comparado com outras duas simulações aumentando e reduzindo de $90 \%$ o parâmetro de entrada umidade inicial do solo que preenche a coluna 


\section{LISTA DE QUADROS}

Página

1 Características Físico-Hídricas dos três solos submetidos à simulação

2 Parâmetros da curva de retenção, segundo o modelo de Genuchten (1980) dos três solos submetidos à simulação

3 Parâmetros de transporte do nitrato: velocidade da água nos poros (v), coeficiente de dispersão (D), fator de retardamento (R) e dispersividade $(\lambda)$, dos três solos submetidos à simulação 


\title{
MODELO PARA SIMULAÇÃO DA DINÂMICA DE NITRATO EM COLUNAS VERTICAIS DE SOLO NÃO-SATURADO
}

\author{
Autor: JARBAS HONORIO DE MIRANDA \\ Orientador: Prof. Dr. SERGIO NASCIMENTO DUARTE
}

\section{RESUMO}

A agricultura realizada de forma intensiva está sempre visando acréscimos de produtividade, mas geralmente com pouca atenção dedicada a possíveis impactos aos recursos naturais. Visando atingir altas produtividades das culturas e alimentar as expectativas da sociedade, o uso de fertilizantes, herbicidas e pesticidas tem aumentado no decorrer dos anos. Os produtos químicos vêm se tornando um dos mais importantes problemas no que diz respeito à poluição ambiental, pela contaminação tanto da superfície do solo como também de fontes de água. Acrescenta-se ainda o fato de haver perdas econômicas consideráveis devido ao movimento dos mesmos para fora do alcance da zona radicular. Nesse sentido, esse trabalho teve como objetivo desenvolver e avaliar um modelo computacional aplicado para simulação da dinâmica de solutos no solo por meio de soluções numéricas de equações diferenciais que descrevem esse transporte. O modelo matemático implementado consiste na solução de duas equações diferenciais parciais de segunda ordem, ou seja, a equação do movimento de água no solo, que descreve a variação da distribuição de umidade e a equação do transporte de solutos, permitindo estimar as mudanças na concentração de solutos no solo com o tempo. Pelos resultados obtidos, o modelo apresentou um bom ajuste das 
concentrações de nitrato assim como dos perfis de umidade simulados com relação aos medidos em condições de laboratório em uma coluna de solo não-saturado. A análise de sensibilidade do modelo revelou que o mesmo é bastante sensivel a variações nos parâmetros de entrada umidade volumétrica do solo saturado, vazão do emissor de solução e condutividade hidráulica do solo saturado, tanto para a simulação da concentração de nitrato quanto para a simulação do perfil de umidade. 


\title{
MODEL FOR NITRATE DISPLACEMENT SIMULATION IN VERTICAL COLUMNS OF NON-SATURATED SOIL
}

\author{
Author: JARBAS HONORIO DE MIRANDA \\ Adviser: Prof. Dr. SERGIO NASCIMENTO DUARTE
}

\section{SUMMARY}

Agriculture performed in an intensive way is always searching for increased productivity, generally with limited attention dedicated to possible impacts on natural resources. Seeking to reach high crop yields and to satisfy society's expectations, the use of fertilizers, herbicides, and pesticides have been increasing in the passing years. Chemical products are becoming one of the most important problems when regarding environmental pollution both in soil surface contamination and water source contamination. In addition there is also considerable economic losses due to the movement of chemical products outside of the root zone. In that sense, this study has as an object developing and evaluating a computational model for solute displacement simulation in soil based on numerical solutions of differential equations describing this displacement. The mathematical model consists of the solution of two second order partial differential equations, the soil water movement equation, that describes variation in soil moisture distribution and the solute transport equation, which together provide solute concentration changes in the soil over time. By the obtained results, the model presents a good agreement in nitrate concentrations as well as soil moisture profile when compared with the results obtained on a vertical column of non-saturated soil in 
laboratory conditions. The sensibility analysis reveals that both simulated profiles, nitrate concentration and soil moisture, are very sensitive to variations in the following input parameters: volumetric saturated soil moisture content, solution discharge by the emitter, and saturated hydraulic soil conductivity. 


\section{INTRODUÇÃO}

A agricultura realizada de forma intensiva está sempre visando acréscimos de produtividade, mas geralmente com pouca atenção dedicada a possíveis impactos aos recursos naturais. Visando atingir altas produtividades das culturas e alimentar as expectativas da sociedade, o uso de fertilizantes, herbicidas e pesticidas tem aumentado no decorrer dos anos. Com isso, o entendimento dos processos de transporte no solo dessas substâncias químicas auxiliam na redução da sua lixiviação para as camadas subsuperficiais.

Os produtos químicos vêm se tornando um dos mais importantes problemas no que diz respeito à poluição ambiental, pela contaminação tanto da superfície do solo como também de fontes de água. Acrescenta-se ainda o fato de haver perdas econômicas consideráveis devido ao movimento dos mesmos para fora do alcance da zona radicular. Segundo Dodds (1998), quando os fertilizantes são deslocados para partes inferiores do perfil do solo, tornam-se inviáveis para a extração pelas plantas e um grande risco de contaminação para as águas subterrâneas. Por outro lado, esses produtos agroquímicos podem alojar-se na zona radicular e serem lixiviados para sistemas de drenagem e para o lençol freático gerando problemas de contaminação em poços e minas de água.

As águas oriundas da chuva ou da irrigação, nesse caso, tanto via fertirrigação ou pela utilização de águas salinas, são maneiras pelas quais os solutos são aplicados e transportados através do solo. O processo de escoamento superficial e a infiltração podem contribuir com a movimentação dos solutos no perfil do solo, pois tratam do movimento da solução do solo. No segundo caso, as substâncias químicas podem ser transportadas até os horizontes mais profundos do solo. 
Diante disso, a contaminação por nitrato e pesticidas tem-se tornado um sério problema ambiental visto que áreas agrícolas possuem diferentes graus de exploração e potencial de poluição do lençol freático, dependendo do tipo de solo, geologia, clima e o mais importante do manejo das práticas agrícolas (Singh, 1995). O principal fator que afeta a perda de nitrogênio no campo é a lixiviação causada basicamente pelo fluxo de água no perfil do solo e a quantidade de $\mathrm{NO}_{3}{ }^{-}$disponível para lixiviação.

A contaminação de aqüíferos por nitrato está se estendendo por muitas razões, principalmente devido ao acréscimo do uso de fertilizantes inorgânicos na agricultura e a disposição de material orgânico sobre e abaixo da superfície agriculturável. A baixa eficiência de fertilizantes nitrogenados em condições tropicais tem sido atribuída ao grande potencial de perdas, sendo a lixiviação, a denitrificação e a volatilização da amônia os mecanismos mais importantes.

Qualquer que seja a forma de nitrogênio mineral introduzida no solo, tende a passar à forma orgânica, seja pela absorção por microorganismos, seja pela absorção por plantas. O nitrogênio orgânico, por sua vez, após a morte dos seres vivos de que faz parte, passará à forma mineral. A passagem de nitrogênio de formas orgânicas para formas inorgânicas denomina-se mineralização, que ocorre pelas seguintes etapas: N-orgânico $\rightarrow$ N-Amínico $\rightarrow$ N-Amoniacal $\rightarrow$ N-nitrito $\rightarrow$ N-Nitrato. A transformação inversa chama-se imobilização (Mello at al., 1984).

$\mathrm{O}$ nitrato é um poluente comum da água e trata-se da forma mais susceptível de percolação porque é um ânion, e portanto, não é atraído pelas partículas do solo (Schwab et al., 1993). A menos que $\mathrm{NO}_{3}{ }^{-}$seja removido da solução do solo por alguns processos, tais como, imobilização, absorção pela planta ou denitrificação, ele está livre para percolar abaixo da zona radicular da cultura (Blackmer, 1987).

Quando se lida com o movimento simultâneo de água e solutos no solo considera-se que o transporte do soluto é conseqüência da conveç̧ão, ou seja, o fluxo de massa (movimento laminar ou viscoso da solução do solo) e da difusão (movimentação térmica dos solutos dentro da solução). O entendimento desses dois componentes do 
processo de transporte, que ocorrem simultaneamente, é fundamental para o estabelecimento de práticas de manejo para o controle de movimento de sais (Bresler, 1981). Nos espaços interagregados, o fluxo de massa constitui o principal mecanismo de transporte de nitrogênio no solo (Santos, 1986), enquanto, nos espaços intra-agregados, em razão da maior resistência hidráulica, o movimento do nitrogênio processa-se principalmente por difusão.

De acordo com o entendimento das teorias que descrevem os processos físicos e químicos que ocorrem no solo, aliado às técnicas de resoluções numéricas de equações e aos recursos computacionais disponíveis, é possível, utilizando modelos de simulação, prever os riscos de contaminação e impactos que um determinado componente químico pode causar ao meio solo-água e às plantas. Técnicas recentes de manejo da fertirrigação com o uso de extratores de solução do solo também podem ser otimizadas pelo maior conhecimento da dinâmica dos solutos no solo.

Dentro deste contexto os modelos de simulação podem vir a propiciar ao técnico um melhor acompanhamento dos processos que ocorrem no solo, pois permitem que uma ampla faixa de alternativas sejam levadas em consideração e desta forma testadas e comparadas. Um grande número de modelos de simulação têm sido difundidos na última década, visando descrever o movimento de solutos através do perfil do solo, e o que se observa é que existe uma grande dificuldade em envolver todos os parâmetros pertinentes ao meio ambiente, para que o modelo possa realmente predizer o processo de deslocamento e retenção dos solutos na natureza.

Nesse sentido, esse trabalho teve como objetivo desenvolver e avaliar um modelo computacional aplicado para simulação da dinâmica de solutos no solo por meio de soluções numéricas de equações diferenciais que descrevem esse transporte. $O$ modelo simulará não só a distribuição da água como também a distribuição do nitrato presente em uma solução, aplicada em uma coluna vertical de solo. Além disso o estudo desenvolvido fornecerá subsídios e informações para modelagem computacional aplicada à dinâmica dos solutos no solo, necessárias a pesquisas posteriores que venham a ser desenvolvidas considerando outros fatores como a absorção e precipitação, entre outros. 


\section{REVISÃO DE LITERATURA}

\subsection{A Dinâmica da água no solo}

\subsubsection{O solo como meio poroso}

O termo solo refere-se à camada externa e agriculturável da superfície da terra, cuja origem é determinada pela ação de processos fỉsicos, químicos e biológicos na rocha, dando origem a um material natural, sólido e poroso que abriga em seus poros quantidades variáveis de solução. As diferentes ações desses processos resultam em tipos distintos de solos, os quais, apresentam uma disposição diferente com relação a esse espaço poroso e que por sua vez formam canais naturais, de onde se originam as interações entre a água e as partículas sólidas do solo, resultando em forças de atração e fixação da água no solo, diminuindo a sua energia em relação à água livre.

\subsubsection{A Lei de Darcy}

O engenheiro hidráulico Henry Darcy em 1856, por meio de observações de infiltração de solução em colunas de areia homogênea em condições de saturação, após uma série de experimentos, obteve a seguinte relação (eq. 1), na qual, a água em estado líquido move-se na existência de um gradiente de potencial nos diferentes pontos de um sistema, no sentido do maior para o menor potencial.

$$
q=-K_{0} \frac{\partial \phi t}{\partial z}
$$

em que 
$\mathrm{q}=$ vetor de densidade de fluxo de água no solo, $\mathrm{L} \mathrm{T}^{-1}$;

$\mathrm{K}_{\mathrm{o}}=$ condutividade hidráulica do solo saturado, $\mathrm{L} \mathrm{T}^{-1} ; \mathrm{e}$

$\frac{\partial \phi \mathrm{t}}{\partial \mathrm{z}}=$ gradiente do potencial total da solução na direção vertical, adimensional.

O potencial total de um ponto é determinado pela eq. 2 .

$\phi \mathrm{t}=\phi_{\mathrm{p}}+\phi_{\mathrm{g}}$

em que

$\phi_{\mathrm{p}}=$ componente de carga de pressão hidrostática, $\mathrm{L} ; \mathrm{e}$

$\phi_{\mathrm{g}}=$ componente de carga gravitacional, $\mathrm{L}$.

Porém, as condições de interesse e mais comuns para a aplicação dos conceitos de transporte de água e solutos, não é a de condição de saturação. O primeiro trabalho que se tem notícia que apresenta uma equação que quantifica o movimento da solução em condição de solo não saturado, é o de Buckingham (1907) ${ }^{1}$ citado por Libardi (1995), no qual este movimento é descrito de acordo com a eq. 3. Neste caso o potencial total é obtido pela soma entre o potencial de posição e o potencial matricial, sendo este último conhecido como o resultado de um potencial denominado de capilar, de tensão, de sucção ou de pressão negativa (Reichardt, 1996).

$$
\mathrm{q}=-\mathrm{K}(\theta) \frac{\partial \phi \mathrm{t}}{\partial \mathrm{z}}
$$

em que

$K(\theta)=$ condutividade hidráulica do solo não-saturado, $L T^{-1}$; e

' BUCKINGHAM. Studies of the movement of soil moisture. USDA Bur. Soil Bull. 38. US. Government Printing Office, Washington D.C., 61 p., 1907. 
$\frac{\partial \phi \mathrm{t}}{\partial \mathrm{z}}=$ gradiente do potencial total da solução na direção vertical, adimensional.

No qual o potencial total de um ponto é determinado pela eq. 4.

$\phi t=\phi_{\mathrm{m}}+\phi_{\mathrm{g}}$

em que

$\phi_{\mathrm{m}}=$ componente matricial, $\mathrm{L} ; \mathrm{e}$

$\phi_{\mathrm{g}}=$ componente de carga gravitacional, $\mathrm{L}$.

A equação de Darcy-Buckingham substituída na equação da continuidade (eq.5) fornece a equação de Richards (eq.6).

$\frac{\partial \theta}{\partial \mathrm{t}}=-\frac{\partial \mathrm{q}}{\partial \mathrm{z}}$

em que

$\theta=$ umidade volumétrica, $\mathrm{L}^{3} \mathrm{~L}^{-3} ; \mathrm{e}$

$\mathrm{t}=$ tempo, $\mathrm{T}$.

$\frac{\partial \theta}{\partial \mathrm{t}}=\frac{\partial}{\partial \mathrm{z}}\left[\mathrm{K}(\theta) \frac{\partial \phi \mathrm{t}}{\partial \mathrm{z}}\right]$

\subsubsection{Condutividade Hidráulica}

A condutividade hidráulica pode ser definida como sendo o coeficiente de proporcionalidade apresentado pela equação de Darcy, o qual expressa a "facilidade" com que determinado fluido se desloca no meio, mostrando-se dependente das características do meio e do fluído. Libardi (1995) e Martinez (1989) citam que as principais características da matriz do solo que interferem na condutividade hidráulica 
são a distribuição de diâmetro dos poros, a tortuosidade, a superfície específica e a porosidade. As principais características do fluído são a massa específica e a viscosidade dinâmica.

Mualem (1976), utilizando parâmetros que envolviam a umidade do solo relacionados com os efeitos de capilaridade e valores de condutividade hidráulica obtidos no ponto de saturação, desenvolveu um modelo para prever o valor da condutividade hidráulica do solo não saturado. O principal aspecto a ser observado é que os valores determinados para a condutividade hidráulica no ponto de saturação, atingem os valores máximos para esse parâmetro pois, os poros do solo estão completamente preenchidos com água, ao passo que em pontos de não saturação a presença de ar nos poros impede de certa forma o movimento da água fazendo com que a condutividade hidráulica decresça de forma exponencial (Reichardt, 1996).

Segundo Genuchten (1980), as estimativas de condutividade hidráulica do solo não saturado são difíceis de serem obtidas, principalmente devido à grande variabilidade apresentada no campo. Segundo Stankovich \& Lockington $(1995)^{2}$ citados por Oliveira (1999), vários modelos têm sido propostos para se calcular a condutividade hidráulica em meio não saturado a partir da relação entre a umidade e o potencial mátrico descrito pela curva de retenção de umidade. Vogel (2001) relata que a escolha do modelo analítico para a obtenção da curva de retenção de água no solo pode afetar significativamente a determinação da condutividade hidráulica obtida por um dos modelos estatísticos de distribuição de tamanho de poros. Uma razão para isso é que a função para predizer a condutividade hidráulica é extremamente sensível a pequenas mudanças no ajuste da curva de retenção próximo à saturação. Esta sensibilidade é a maior causa das diferenças obtidas algumas vezes na função da condutividade hidráulica pelos modelos de Brooks \& Corey (1964) and Genuchten (1980), que têm sido largamente empregados em simulações que descrevem a infiltração de água no solo. Essas diferenças tornam-se mais evidentes para solos de textura fina os quais exibem

\footnotetext{
${ }^{2}$ STANKOVICH, J.M.; LOCKINGTON, D. A. Brooks-Corey and van Genuchten soil-water retention models. Journal of Irrigation and Drainage Engineering, New York, v. 121, n. 1, p. 1-7, 1995.
} 
uma extrema não-linearidade na função de $\mathrm{K}(\theta)$ próximo à saturação, principalmente quando o modelo de Genuchten é utilizado.

No caso desse modelo foram utilizadas equações derivadas de Mualem (1976) para predizer a condutividade hidráulica relativa $(\mathrm{Kr})$, por meio de parâmetros da curva de retenção de água no solo. O parâmetro " $\omega$ " é denominado saturação efetiva e reflete de forma adimensional o conteúdo de água no solo (eq.7). Enfim, para a determinação da condutividade hidráulica relativa $(\mathrm{Kr})$ há necessidade de se determinar o potencial de retenção de água pelo solo (eq.8), de acordo com parâmetros da curva de retenção.

De posse do valor da condutividade hidráulica relativa do solo (eq.9) pode-se então determinar o valor da condutividade hidráulica do solo não saturado como um produto da condutividade hidráulica relativa e saturada (eq.10).

$$
\omega=\frac{\theta-\theta_{\mathrm{r}}}{\theta_{\mathrm{s}}-\theta_{\mathrm{r}}}
$$

em que

$\theta=$ umidade volumétrica do solo na condição inicial, $\mathrm{L}^{3} \mathrm{~L}^{-3}$;

$\theta_{\mathrm{r}}=$ umidade volumétrica residual do solo, $\mathrm{L}^{3} \mathrm{~L}^{-3} ; \mathrm{e}$

$\theta_{\mathrm{S}}=$ umidade volumétrica do solo no ponto de saturação, $\mathrm{L}^{3} \mathrm{~L}^{-3}$.

$\omega=\left[\frac{1}{1+\left(\alpha \phi_{\mathrm{m}}\right)^{\mathrm{n}}}\right]^{\mathrm{m}}$

em que

$\mathrm{m}, \mathrm{n}$ = parâmetros de regressão da equação; adimensional; e

$\alpha=$ parâmetro com dimensão igual ao inverso da tensão, $\mathrm{L}^{-1}$. 


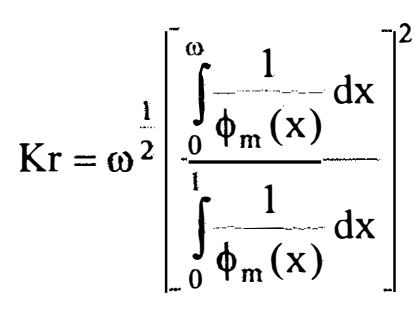

em que

$\mathrm{Kr}=$ condutividade hidráulica relativa, $\mathrm{L} \mathrm{T}^{-1}$.

$\mathrm{Kr}=\frac{\mathrm{K}(\theta)}{\mathrm{Ko}}$

em que

$\mathrm{Ko}=$ condutividade hidráulica do solo saturado, $\mathrm{L} \mathrm{T}^{-1}$.

\subsection{Dinâmica dos solutos}

O transporte de solutos através de camadas superficiais do solo por percolação da água é um fenômeno de considerável interesse na agricultura, hidrologia e em aplicações ambientais. O fluxo de água no solo pode ser descrito pela lei de Darcy, porém, essa descrição não é o suficiente para a consideração do movimento de solutos no solo, devido a uma série de outros fatores que devem ser levados em consideração. A aproximação tradicional do movimento de água e soluto consiste em considerar o solo como uma unidade homogênea e daí aplicar a situações de campo os resultados obtidos e validados em colunas em laboratório (Biggar \& Nielsen, 1962).

Os estudos da dinâmica dos solutos não proporcionam somente um meio de determinação do fluxo no solo, mas devem dar uma explicação física do fenômeno que ocorre na percolação, na troca e adsorção de íons, para o movimento de fertilizantes minerais e outros sais (Nielsen, 1961). 


\subsubsection{Utilização de modelos para ava liação da dinâmica dos solutos}

Tendo em vista o grande número de variáveis que envolvem e dificultam a avaliação de um sistema que se deseja monitorar no que diz respeito ao transporte dos solutos no solo em diferentes situações, a utilização de modelos torna-se desejável pela rapidez, precisão dos resultados obtidos e por permitir que um grande número de fatores e efeitos sejam contabilizados.

Dentre estes modelos podem-se citar: LEACHM (Hutson \& Wagenet, 1992), LEACHC (Hutson \& Wagenet, 1992), RZWQM (Singh, 1995), HYDRUS (Vogel, 1996), DRAINAGE-N (Kumar, 1997), PF (Montas, 1997), PARTLE (Shirmohammadi, 1998), GLEAMS (Stone, 1998), SIMASS (Costa, 1998), MTSES (Oliveira, 1999), entre vários outros.

Apresentando um modelo bidimensional para simular o transporte de solutos a partir da infiltração de uma solução salina emitida de uma fonte puntiforme, Bresler (1975) aplicou a técnica de diferenças finitas para resolução numérica das equações de convecção e difusão/dispersão. O modelo foi testado com sucesso, em condições de laboratório, para um tempo de infiltração de 160 minutos.

O modelo LEACHM utiliza também uma solução numérica das equações de Richards, da convecção e da dispersão, muito embora apresentando seu uso especificamente para solos homogêneos, o que dificulta estratégias de simulação em condições de campo. O modelo LEACHC é nada menos do que um aperfeiçoamento do modelo LEACHM, unidimensional e que foi utilizado para prever o movimento de cloretos no solo (Hutson \& Wagenet, 1992). Entretanto este modelo apresentou-se pouco sensível às variações de distribuição do tamanho de poros e com sensibilidade moderada às variações de densidade global e de condutividade hidráulica (Holden, 1996).

O modelo RZWQM (Root Zone Water Quality Model) foi previamente projetado para simular fluxo de água e sofreu modificações no sentido de simular especificamente concentrações e perdas de nitrato. Baseia-se em teorias químicas e equações cujos componentes são controlados por parâmetros ambientais tais como temperatura do solo, $\mathrm{pH}$, umidade e salinidade do solo e elementos como tamanho da população de microorganismos no solo. O modelo RZWQM também foi utilizado por 
Kumar (1998), simulando concentrações de nitrato em água de drenagem subsuperficial decorrentes de aplicações de esterco suíno em lavoura de milho. Os dados obtidos foram utilizados para avaliar a aplicação do modelo. Os resultados globais desses estudos indicaram que o modelo RZWQM é capaz de simular várias taxas de aplicações de esterco em diferentes condições de clima e solo.

O modelo HYDRUS é um modelo unidimensional projetado para simular o fluxo de água e solutos, usando técnicas de elementos finitos para resolver numericamente as equações de Richards para fluxo de água e equações do tipo convecção e dispersão para o movimento dos sais.

O modelo DRAINAGE-N (Kumar, 1997) foi desenvolvido a partir do modelo DRAINAGE com o objetivo de simular concentrações de nitrato no escoamento de água dos drenos. Para a calibração do modelo foram obtidos dados de campo durante os anos de produção 1984, 1986, 1987, 1990 e 1991, no estado de Iowa-EUA. De maneira geral os resultados obtidos permitiram concluir que o modelo apresentou um bom desempenho para simulação de concentrações e perdas de nitrato por escoamento de água pelos drenos.

De acordo com o trabalho realizado por Shirmohammadi (1998), foram considerados aspectos hidrológicos e perdas de nutrientes para avaliação da aplicabilidade do modelo GLEAMS na simulação de concentrações de nitrato e fósforo na saída de drenos. Nesse trabalho, de acordo com alguns algorítimos desenvolvidos para a simulação de perdas dos nutrientes, desenvolveu-se um sub-modelo denominado PARTLE, que em associação com o GLEAMS permitiu razoáveis estimativas de perdas de fósforo via drenagem dos solos testados.

No Brasil pouco se tem feito para aprimorar e testar modelos numéricos que simulem o movimento de solutos (Ferreira \& Martinez, 1997). Botrel (1988) desenvolveu e testou em condições de campo um modelo numérico computacional que permitia estimar a distribuição espacial da água em solos sob fontes puntiformes. O modelo descrevia o bulbo molhado com a técnica de células múltiplas cilíndricas e utilizava a equação de Darcy para descrever o fluxo da água em solo não saturado e o princípio da conservação de massa para estimar a variação de umidade. Testes de campo 
realizados com um período de aplicação de três horas e tempo de redistribuição de até 72 horas, após o início da aplicação revelaram que os perfis de distribuição de água observados apresentaram-se semelhantes aos simulados pelo modelo.

Costa (1998) desenvolveu o modelo SIMASS capaz de simular o transporte unidimensional de água e soluto no solo sob condições de escoamento não permanente. $\mathrm{O}$ modelo foi testado com sucesso em colunas de solo saturado.

Oliveira (1999) desenvolveu um modelo matemático para simular o transporte de água e soluto no solo e o transporte de solutos e sedimentos no escoamento superficial, no qual, as equações diferenciais foram resolvidas numericamente pelo método de diferenças finitas. $\mathrm{O}$ movimento de água no solo e o escoamento superficial foram os processos simulados pelo modelo que apresentaram os menores desvios em relação aos dados experimentais.

\subsubsection{Equação de Transporte de solutos}

Segundo Genuchten e Wierenga (1986), vários modelos teóricos têm sido desenvolvidos ao longo dos anos para descrever o transporte de solutos no solo. $\mathrm{O}$ sucesso desses modelos porém depende em grande parte da capacidade em se quantificar os parâmetros de transporte, que são variáveis de entrada para esses modelos. Os parâmetros mais importantes são o fluxo do fluido, o coeficiente de dispersão e o de adsorção ou de troca no caso de interações entre o soluto e o solo. Existem vários modelos para determinação dos coeficientes de dispersão e fator de retardamento pela distribuição da concentração de solutos observada.

O fluxo de massa refere-se ao movimento passivo de íons dissolvidos com a solução do solo. Na ausência de difusão, água e o íon dissolvido movem-se na mesma taxa. O fluxo de massa de um determinado soluto pode ser determinado pela eq. 11 .

$\mathrm{J}_{\mathrm{m}}=\mathrm{qC}$

em que 
$\mathrm{J}_{\mathrm{m}}=$ fluxo de massa do soluto no solo, $\mathrm{M} \mathrm{L}^{-2} \mathrm{~T}^{-1}$;

$\mathrm{q}=$ fluxo de água, $\mathrm{L} \mathrm{T}^{-1} ; \mathrm{e}$

$\mathrm{C}=$ concentração do soluto na solução do solo, $\mathrm{M} \mathrm{L}^{-3}$.

A difusão é um processo espontâneo que resulta do movimento natural térmico de íons e moléculas dissolvidos. O transporte de difusão nos solos tende a diminuir os gradientes de concentrações, e em analogia com a lei de Fick, pode ser descrito por:

$$
J_{\mathrm{d}}=-\theta \mathrm{D}_{\mathrm{m}} \frac{\partial \mathrm{C}}{\partial \mathrm{X}}
$$

em que

$\mathrm{J}_{\mathrm{d}}=$ fluxo de difusão do soluto no solo, $\mathrm{M} \mathrm{L}^{-2} \mathrm{~T}^{-1}$;

$\theta=$ umidade volumétrica, $\mathrm{L}^{3} \mathrm{~L}^{-3}$;

$\mathrm{D}_{\mathrm{m}}=$ coeficiente de difusão molecular do soluto na solução do solo, $\mathrm{L}^{2} \mathrm{~T}^{-1}$; e $\mathrm{X}=$ distância, $\mathrm{L}$.

Devido ao caminho tortuoso percorrido pelo fluxo da solução do solo, o valor de Dm nos solos é menor que o coeficiente de difusão em água pura (Do), podendo ser determinado por:

$$
D_{m}=D_{0} \tau
$$

em que

$\tau=$ fator de tortuosidade, adimensional.

O processo de dispersão deve-se às variações de velocidade da água nos poros. Existem portanto variações devido à resistência da matriz do solo bem como devido ao avanço da frente de molhamento. Portanto, o movimento de dispersão resulta 
do fato de que a velocidade do fluido dentro de poros individuais e entre poros de diferentes formas, tamanhos e direções, desvia-se da velocidade média da água nos poros.

$\mathrm{J}_{\mathrm{h}}=-\theta \mathrm{D}_{\mathrm{h}} \frac{\partial \mathrm{C}}{\partial \mathrm{X}}$

em que

$\mathrm{J}_{\mathrm{h}}=$ fluxo de dispersão do soluto no solo, $\mathrm{M} \mathrm{L}^{-2} \mathrm{~T}^{-1}$; e

$D_{h}=$ coeficiente de dispersão mecânica, $L^{2} T^{-1}$ (Bear, 1972).

Esse coeficiente é geralmente assumido como sendo uma função da velocidade do fluido, cujo valor pode ser obtido pela relação entre o fluxo de água no solo e a umidade volumétrica.

$\mathrm{D}_{\mathrm{h}}=\lambda \mathrm{v}^{\mathrm{n}}$

em que

$\lambda=$ dispersividade do meio poroso, $\mathrm{L}$;

$\mathrm{v}=$ velocidade da água no poro $(\mathrm{q} / \theta), \mathrm{L} \mathrm{T}^{-1} ; \mathrm{e}$

$\mathrm{n}=$ constante empírica, aproximadamente igual a 1,0 .

De acordo com Oliveira (1999), dada a similaridade entre dispersão e difusão, os coeficientes $D_{h}$ e $D_{m}$ são freqüentemente considerados aditivos e ao resultado dá-se o nome de coeficiente de dispersão hidrodinâmica.

$\mathrm{D}=\mathrm{D}_{\mathrm{m}}+\mathrm{D}_{\mathrm{h}}$

em que 
$\mathrm{D}$ = coeficiente de dispersão hidrodinâmico longitudinal, $\mathrm{L}^{2} \mathrm{~T}^{-1}$ (Bear, 1972).

Outros nomes freqüentemente utilizados para D são coeficiente de difusão aparente e coeficiente de difusão-dispersão (Hillel, 1980), enquanto que o nome de coeficiente de dispersão hidrodinâmica algumas vezes tem sido reservado apenas para $D_{h}$.

Portanto o fluxo de solutos no solo pode ser definido pela eq. 17.

$\mathrm{J}_{\mathrm{s}}=\mathrm{J}_{\mathrm{dh}}+\mathrm{J}_{\mathrm{m}}$

em que

$\mathrm{J}_{\mathrm{dh}}=$ fluxo de difusão-dispersão, $\mathrm{ML}^{-2} \mathrm{~T}^{-1}$.

Combinando as eqs. 11 e 12 obtém-se a expressão para o fluxo de solutos no solo (eq.18):

$\mathrm{J}_{\mathrm{s}}=-\theta \mathrm{D} \frac{\partial \mathrm{C}}{\partial \mathrm{X}}+\mathrm{qC}$

em que

$\mathrm{J}_{\mathrm{s}}=$ fluxo de solutos no solo, $\mathrm{ML}^{-2} \mathrm{~T}^{-1}$.

Substituindo a eq. 18 na equação da continuidade obtém-se a eq.19. Deste modo a equação de transporte de solutos pode ser obtida (eq.20):

$$
\frac{\partial}{\partial t}(\theta C+\rho S)=-\frac{\partial J_{s}}{\partial X}
$$

$$
\frac{\partial}{\partial \mathrm{t}}(\theta \mathrm{C}+\rho \mathrm{S})=\frac{\partial}{\partial \mathrm{X}}\left(\theta \mathrm{D} \frac{\partial \mathrm{C}}{\partial \mathrm{X}}-\mathrm{qC}\right)
$$


em que

$\mathrm{S}=$ concentração adsorvida (massa de soluto por unidade de massa de solo), $\mathrm{M} \mathrm{M}^{-1}$;

$\rho=$ densidade global do solo; e

$\mathrm{t}=$ tempo, $\mathrm{T}$.

Para linearizar a adsorção e o fluxo dinâmico de água em um perfil de solo homogêneo, assume-se que $\theta$ e q são constantes no tempo e no espaço, e a partir da eq. 20 , obtém-se a eq. 21 .

$\mathrm{R} \frac{\partial \mathrm{C}}{\partial \mathrm{t}}=\mathrm{D} \frac{\partial^{2} \mathrm{C}}{\partial \mathrm{X}^{2}}-\mathrm{v} \frac{\partial \mathrm{C}}{\partial \mathrm{X}}$

Sendo:

$\mathrm{R}=1+\frac{\rho \mathrm{k}}{\theta}$

em que

$\mathrm{R}=$ fator de retardamento, adimensional; $\mathrm{e}$

$\mathrm{k}=$ coeficiente empírico de distribuição (se não há interação entre o soluto e o solo, $\mathrm{k}$ assume o valor igual a zero), $\mathrm{M}^{-1} \mathrm{~L}^{3}$. 


\section{MATERIAL E MÉTODOS}

\subsection{Desenvolvimento do Modelo}

O modelo computacional foi desenvolvido no Departamento de Engenharia Rural da ESALQ/USP em linguagem de programação Visual Basic 5.0. O modelo matemático implementado consiste na solução de duas equações diferenciais parciais de segunda ordem, ou seja, a equação do movimento de água no solo, que descreve a variação da distribuição de umidade e a equação do transporte de solutos, que permite estimar as mudanças na concentração de solutos no solo. Estas equações são resolvidas numericamente em um sistema de volumes finitos, uma após a outra, a cada incremento de tempo " $\Delta \mathrm{t}$ " de simulação.

Os parâmetros de entrada necessários à simulação são:

- Umidade inicial do solo na coluna, $\mathrm{L}^{3} \mathrm{~L}^{-3}$;

- Parâmetros da curva de retenção segundo o modelo de Genuchten (1980);

- Condutividade hidráulica do solo saturado, $\mathrm{L} \mathrm{T}^{-1}$;

- Intervalo de tempo de aplicação da solução, T;

- Vazão do gotejador, $\mathrm{L}^{3} \mathrm{~T}^{-1}$;

- Diâmetro da coluna, L;

- Altura das células cilíndricas da coluna seccionada $(\Delta Z), \mathrm{L}$;

- Intervalo de tempo, T;

- Número de células da coluna;

- Concentração de nitrato na solução a ser aplicada, $\mathrm{ML}^{-3}$;

- Concentração inicial de nitrato na coluna, $\mathrm{ML}^{-3}$;

- Coeficiente de difusão do nitrato em água pura, $\mathrm{L}^{2} \mathrm{~T}^{-1}$;

- Dispersividade, L; e

- Fator de retardamento, adimensional. 
Após a simulação o modelo apresenta os seguintes parâmetros de saída:

- Umidade em cada célula da coluna, $\mathrm{L}^{3} \mathrm{~L}^{-3} ; \mathrm{e}$

- Concentração de nitrato em cada célula da coluna no intervalo de tempo, $\mathrm{ML}^{-3}$.

O modelo também disponibiliza outros parâmetros para consulta:

- Saturação efetiva $\omega$, adimensional;

- Condutividade hidráulica nos pontos da coluna, $\mathrm{L} \mathrm{T}^{-1}$;

- Potencial matricial em cada ponto da coluna, L;

- Condutividade hidráulica média entre os pontos da coluna, $\mathrm{L} \mathrm{T}^{-1}$;

- Fluxo de água entre os pontos da coluna, $\mathrm{L} \mathrm{T}^{-1}$

- Variação de fluxo entre os pontos da coluna no intervalo de tempo, $\mathrm{L} \mathrm{T}^{-1}$;

- Variação de umidade entre os pontos da coluna no intervalo de tempo, $\mathrm{L}^{3} \mathrm{~L}^{-3}$;

- Fluxo de massa entre os pontos da coluna, $\mathrm{M} \mathrm{L}^{2} \mathrm{~T}^{-1}$;

- Variação da concentração de nitrato em cada ponto da coluna no intervalo de tempo, $\mathrm{M} \mathrm{L}^{-3}$;

- Fluxo do soluto entre os pontos da coluna, $\mathrm{ML}^{2} \mathrm{~T}^{-1} ; \mathrm{e}$

- Massa de sal, em cada ponto da coluna, M.

O modelo abrange as seguintes etapas de processamento:

a) Inicialmente o modelo calcula o fluxo de água entre as células da coluna para um determinado intervalo de tempo;

b) Após a obtenção dos valores de fluxo o modelo calcula o transporte de solutos entre as células da coluna;

c) Em seguida determina qual a variação de volume da solução e a massa de solutos em cada célula da coluna, dentro do intervalo de tempo, devido ao deslocamento da solução na coluna; e

d) Atingindo o tempo total de simulação o modelo apresenta os valores de umidade e de concentração de nitrato em cada célula da coluna, com opção de gravar os resultados. 
A seguir serão mostrados todos os passos e fórmulas utilizadas na simulação.

\subsubsection{Etapas de processamento do modelo}

\subsubsection{Processamento da variação de umidade nas células da coluna}

No início do processamento dos dados visando a resolução das equações diferenciais por volumes finitos, no primeiro intervalo de tempo, o modelo determina o valor da saturação efetiva, descrita na eq.7.

Na seqüência encontra o valor da condutividade hidráulica do solo nãosaturado, cuja função $K(\theta)$ é obtida a partir da condutividade hidráulica do solo saturado, Ko, e dos parâmetros da curva de retenção de água no solo, de acordo com o modelo de Mualem (1976) e Genuchten (1980), eq. 23.

$K(\theta)=K_{0} \ell\left[1-\left(1-\omega^{1 / m}\right)^{m}\right]^{k}$

em que

$\mathrm{K}(\theta)=$ condutividade hidráulica do solo não saturado, $\mathrm{L} \mathrm{T}^{-1}$

$\mathrm{Ko}=$ condutividade hidráulica do solo saturado, $\mathrm{L} \mathrm{T}^{-1} ; \mathrm{e}$

$\ell=$ parâmetro empírico, aproximadamente igual a 0,5 para a maioria dos solos.

$\mathrm{Na}$ superfície superior da primeira célula, onde está sendo aplicada a solução de nitrato, o modelo considera que os valores da condutividade hidráulica e da umidade inicial, correspondem ao ponto de saturação.

Em seguida o modelo determina o potencial mátrico, obtido pela eq. 24 :

$\psi=\frac{\left(\omega^{1 / m}-1\right)^{1 / n}}{\alpha}$ 
Com os valores obtidos do potencial mátrico adicionados ao potencial gravitacional de cada ponto, considerados na metade de cada célula da coluna, determina o gradiente de potencial, e com isso estima o fluxo de água entre todas as células da coluna (eq.25), considerando os valores de $K(\theta)$ médios entre as células.

$$
\mathrm{q}==-\overline{\mathrm{K}}(\theta) \frac{\Delta \phi \mathrm{t}}{\Delta \mathrm{Z}}
$$

em que

$\mathrm{q}$ = fluxo de água entre os pontos da coluna, $\mathrm{L} \mathrm{T}^{-1}$;

$\Delta \phi \mathrm{t}=$ diferença do potencial total, $\mathrm{L} ; \mathrm{e}$

$\Delta \mathrm{Z}=$ altura de cada anel da coluna, $\mathrm{L}$.

De posse dos valores de fluxo de água, e estando no primeiro intervalo de tempo de simulação, o modelo determina qual a variação de umidade que ocorreu em cada ponto da coluna, cujo valor é obtido pela eq. 26.

$$
\Delta \theta=\frac{\Delta \mathrm{q} A \Delta \mathrm{T}}{\mathrm{V}}
$$

em que

$\Delta \theta=$ variação de umidade nas células da coluna, $\mathrm{L}^{3} \mathrm{~L}^{-3}$;

$\Delta q=$ diferença entre o fluxo que entrou e saiu da célula, $\mathrm{L} \mathrm{T}^{-1}$;

$\mathrm{A}=$ seção transversal da coluna, $\mathrm{L}^{2}$;

$\Delta \mathrm{T}=$ intervalo de tempo simulado, $\mathrm{T} ; \mathrm{e}$

$\mathrm{V}=$ volume de cada anel da coluna, $\mathrm{L}^{3}$.

Essa variação de umidade será acrescida respectivamente a cada célula da coluna, quando o modelo iniciar o segundo intervalo de tempo de processamento e assim por diante, até atingir o tempo total de simulação 


\subsubsection{Processamento da variação da concentração de nitrato nas células da coluna}

Uma vez processado os valores de fluxo de água entre as células da coluna, inicia-se, então, a determinação da concentração de nitrato em cada célula. $O$ primeiro valor a ser obtido é o fluxo de massa, que é resultado do produto entre o fluxo de água entre os anéis da coluna, já obtido, e a concentração de nitrato na solução do solo que preenche a coluna.

Conforme visto anteriormente, o processamento do modelo baseia-se na discretização da coluna em volumes finitos, portanto, a diferença de concentração $(\Delta C)$, utilizada para a determinação do fluxo de difusão-dispersão, é determinada dentro de cada simulação, no respectivo intervalo de tempo. Para se obter o fluxo do soluto entre as células da coluna é necessário determinar o fluxo de difusão-dispersão (eq.29) que depende dos parâmetros, descritos nas eqs. 27 e 28. A eq. 27 é uma expressão empírica citada por Oliveira (1999).

$D_{m}=\left(\frac{\bar{\theta}^{10 / 3}}{\theta s^{2}}\right)$ Do

em que $\bar{\theta}$ é a umidade média entre células consecutivas.

$$
\begin{aligned}
& \mathrm{D}=\mathrm{D}_{\mathrm{m}}+\left(\frac{\lambda \mathrm{q}}{\bar{\theta}}\right) \\
& \mathrm{J}_{\mathrm{dh}}=\mathrm{D} \overline{\bar{\theta}} \frac{\Delta \mathrm{C}}{\Delta \mathrm{Z}}
\end{aligned}
$$

O fluxo total de soluto entre as células da coluna é aditivo, ou seja, é o somatório entre o fluxo de massa e o fluxo de difusão-dispersão.

Para o modelo realizar os procedimentos de simulação da concentração em volumes finitos é necessário determinar a quantidade de massa de soluto que se 
movimenta, ou seja, a quantidade de soluto que "entra" e "sai" em cada célula da coluna. Para se determinar essa quantidade de acordo com o fluxo de soluto determinado anteriormente e no intervalo de tempo que se está simulando, determina-se qual a quantidade de massa de soluto que é adicionada em cada célula da coluna (eqs. 30, 31 e 32).

Nesse sentido a determinação da vazão de massa é determinada por:

$Q_{m}=J_{s} A$

em que

$\mathrm{Q}_{\mathrm{m}}=$ vazão de massa, $\mathrm{M} \mathrm{T}^{-1}$.

A passagem de massa do soluto entre células é definida por:

$\mathrm{E}_{\mathrm{m}}=\mathrm{Q}_{\mathrm{m}} \Delta \mathrm{T}$

em que

$E_{m}=$ passagem de massa do soluto entre células, $M$.

A determinação da variação de massa que ocorrerá em cada célula após um determinado intervalo de tempo, fica definida por:

$\Delta m=\frac{E_{m(i-1)}-E_{m(i)}}{R}$

em que

$\Delta \mathrm{m}=$ variação de massa do soluto em cada célula da coluna, $M$

$E_{m(i-1)}=$ passagem de massa na face anterior da célula, $M$; e

$E_{m(i)}=$ passagem de massa na face posterior da célula, $M$. 
O modelo, após realizar a simulação no primeiro intervalo de tempo, irá realizar para o segundo intervalo de tempo e assim por diante até completar o tempo total de simulação. O processo de simulação pode ser observado pelo fluxograma e as respectivas sub-rotinas mostrados nas Figuras 1 e 2, respectivamente. A Figura 3 apresenta a tela inicial e a tela de entrada de dados e saída dos resultados do modelo proposto.

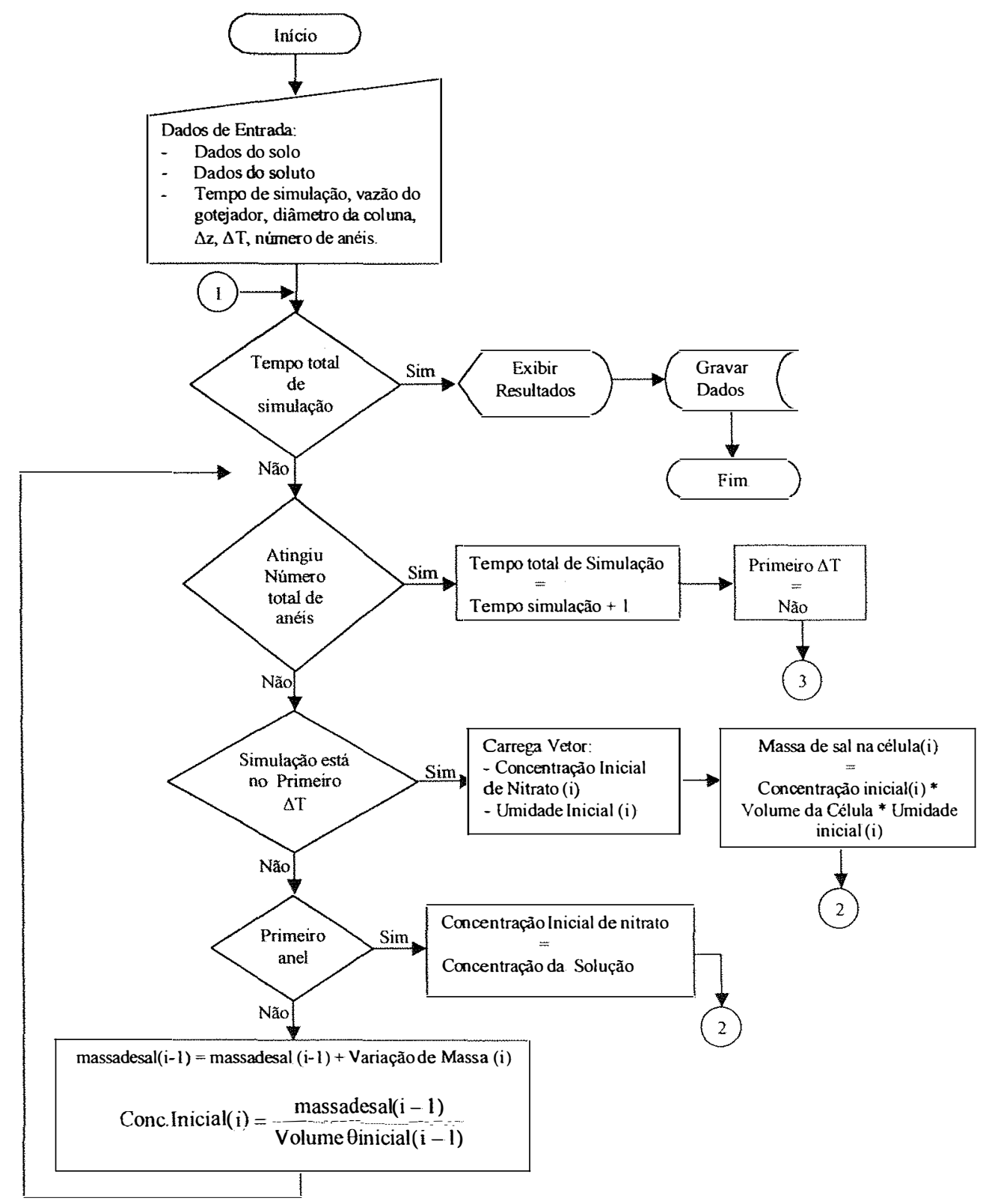

Figura 1 - Fluxograma do modelo proposto 

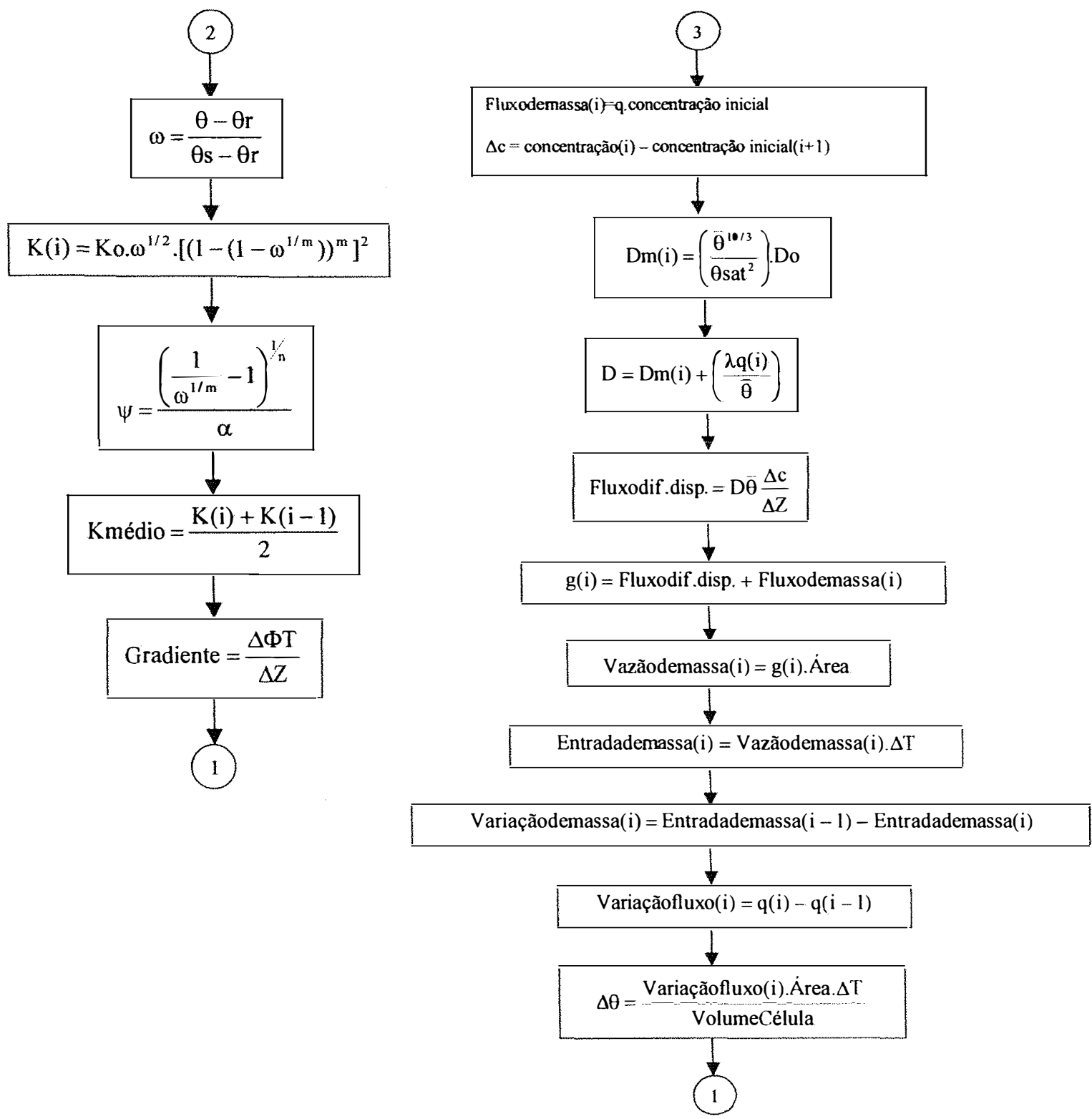

Figura 2 - Sub-rotinas do modelo proposto 


\section{Simulação da dinâmica de solutos e água}

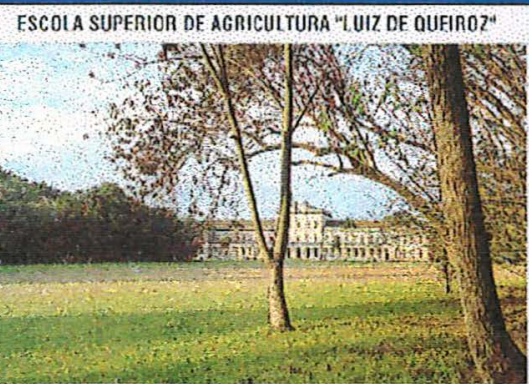

\section{Autores:}

Jarbas Honorio de Miranda

e-mail: jhmirand @carpa ciagri.usp.br

Sergio Nascimento Duarte

(a)

e-mail: snduarte@carpa ciagri.usp.br

\section{Menu Principal}

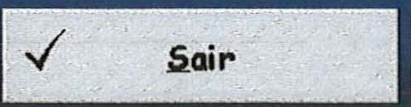

I] Informaģôes

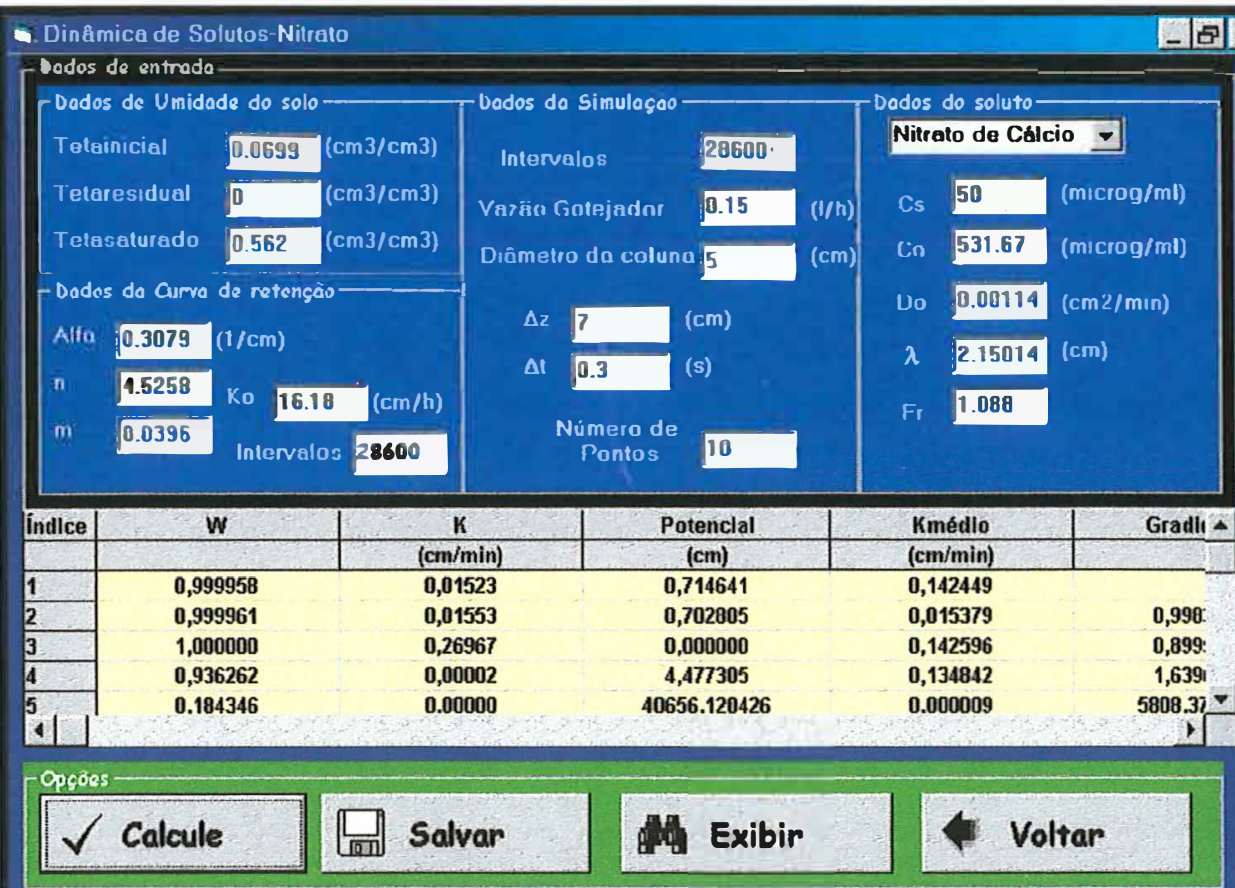

(b)

Figura 3 - Tela inicial (a) e Tela de entrada e saída de resultados do modelo (b) 


\subsection{Condução do experimento em laboratório}

A parte experimental desse trabalho consistiu de um experimento de laboratório, que objetivou validar o modelo proposto. $\mathrm{O}$ experimento foi conduzido no Laboratório de Física do Solo do Departamento de Engenharia Rural da Escola Superior de Agricultura "Luiz de Queiroz"- ESALQ/USP.

\subsubsection{Características do solo}

Nesse trabalho foram utilizados três tipos de materiais de solo, classificados e coletados nos municípios de Piracicaba-SP e Lavras-MG. As coletas foram realizadas em perfis característicos para cada tipo de solo a uma profundidade de 0 a $30 \mathrm{~cm}$.

Os materiais foram preparados em laboratório, secando-os e em seguida peneirando-os através de uma malha de $2 \mathrm{~mm}$. Os solos foram classificados como Latossolo Vermelho Amarelo, Fase arenosa, série "Sertãozinho" (Solo 1), Latossolo Vermelho Amarelo, Fase areno-argilosa (Solo 2) e Terra Roxa Estruturada (Solo 3).

O Quadro 1 apresenta as características físico-hídricas e o Quadro 2 os parâmetros da curva de retenção segundo o modelo de Genuchten (1980) dos três solos submetidos à simulação.

\begin{tabular}{|c|c|c|c|c|c|c|c|}
\hline \multirow[b]{2}{*}{ Tipo de Solo } & \multicolumn{3}{|c|}{ Textura } & \multicolumn{2}{|c|}{ Densidade } & \multirow[b]{2}{*}{$\begin{array}{c}\text { Porosidade } \\
\text { (\%) }\end{array}$} & \multirow[b]{2}{*}{$\begin{array}{c}\mathrm{Ko} \\
\left(\mathrm{cm} \mathrm{h}^{-1}\right)\end{array}$} \\
\hline & $\begin{array}{c}\text { Areia } \\
\text { (\%) }\end{array}$ & $\begin{array}{l}\text { Silte } \\
(\%)\end{array}$ & $\begin{array}{c}\text { Argila } \\
(\%)\end{array}$ & Global & Partículas & & \\
\hline Solo 1 & 69,5 & 12,0 & 18,5 & 1,56 & 2,575 & 39,41 & 18,19 \\
\hline Solo 2 & 55,0 & 7,0 & 38,0 & 1,26 & 2,515 & 49,90 & 16,18 \\
\hline Solo 3 & 12,0 & 25,0 & 63,0 & 1,33 & 2,580 & 48,44 & 8,73 \\
\hline
\end{tabular}

Quadro 1 - Características físico-hídricas dos três solos submetidos à simulação 


\begin{tabular}{|c|c|c|c|c|c|}
\hline \multirow{2}{*}{ Tipo de solo } & \multicolumn{5}{|c|}{ Parâmetros da Curva de Retenção } \\
\cline { 2 - 6 } & $\begin{array}{c}\theta \mathbf{r} \\
\left(\mathbf{c m}^{\mathbf{3}} \mathbf{c m}^{-3}\right)\end{array}$ & $\begin{array}{c}\theta \mathbf{s} \\
\left(\mathbf{c m}^{\mathbf{3}} \mathbf{c m}^{-\mathbf{3}}\right)\end{array}$ & $\begin{array}{c}\boldsymbol{\alpha} \\
\left(\mathbf{c m}^{-1}\right)\end{array}$ & $\mathbf{n}$ & $\mathbf{m}$ \\
\hline Solo 1 & 0,162 & 0,443 & 0,0449 & 3,6732 & 0,1119 \\
\hline Solo 2 & 0,164 & 0,562 & 0,1265 & 3,9898 & 0,1284 \\
\hline Solo 3 & 0,207 & 0,645 & 0,0429 & 1,4250 & 0,1995 \\
\hline
\end{tabular}

Quadro 2 - Parâmetros da curva de retenção, segundo o modelo de Genuchten (1980) dos três solos submetidos à simulação

3.2.2 Determinação das curvas de eluição e obtenção dos parâmetros de transporte do nitrato

Essa etapa foi desenvolvida no laboratório de Física do solo do Departamento de Engenharia Rural da ESALQ/USP, objetivando obter os parâmetros de transporte do nitrato nos três respectivos tipos de solo (Solo 1, Solo 2 e Solo 3). Um esquema foi montado em laboratório, composto pelos componentes apresentados pela Figura 4.

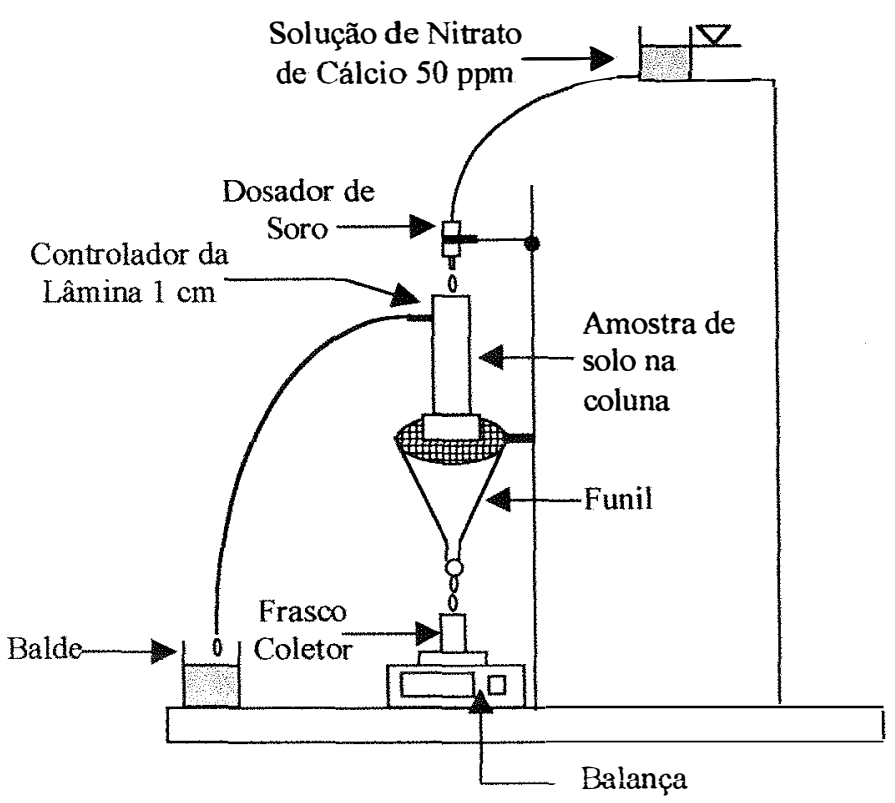

Figura 4 - Esquema para a coleta de solução que atravessa a coluna de solo, para a elaboração das curvas de eluição 


\subsubsection{Prepa ro da solução de nitrato}

O soluto utilizado na solução foi o Nitrato de Cálcio Tetrahidratado, $\mathrm{Ca}\left(\mathrm{NO}_{3}\right)_{2} \cdot 4 \mathrm{H}_{2} \mathrm{O}$, diluído a uma concentração de nitrato de $50 \mathrm{mg} \mathrm{L}^{-1}$. Para atingir esse valor foi necessário preparar uma solução padrão na qual foram colocados 19,032 g $\mathrm{Ca}\left(\mathrm{NO}_{3}\right)_{2} .4 \mathrm{H}_{2} \mathrm{O}$ por um litro de água, que resultou em uma solução que contém $10 \mathrm{~g} \mathrm{~L}^{-1}$ de $\mathrm{NO}_{3}$. A partir dessa solução padrão coletou-se $10 \mathrm{~mL}$ que foram completados com água destilada até atingir um volume de $2 \mathrm{~L}$.

\subsubsection{Aplicação da solução na coluna de solo}

A solução de nitrato de cálcio foi aplicada utilizando um dosador destes utilizados em hospitais para soro, com o objetivo de regular a vazão. A coluna de PVC foi confeccionada para o teste com as seguintes dimensões: $20 \mathrm{~cm}$ de altura e $5 \mathrm{~cm}$ de diâmetro. Na parte inferior da coluna foi colocado um círculo de manta sintética sobre uma tela fixada por um cap com rosca. Para manter uma lâmina constante de $1 \mathrm{~cm}$, na parte superior da coluna, foi instalada uma saída (ladrão) que retirava todo o excesso de água a um recipiente (balde). Para que o teste fosse iniciado era necessário primeiramente saturar a coluna com água destilada, processo esse realizado de forma lenta, no qual a coluna era colocada dentro de um balde e por gotejamento a água era adicionada, ao balde, até atingir uma altura aproximada de $2 / 3$ da coluna. Em seguida deixava-se o conjunto em repouso por um período de 24 horas e após esse prazo dava-se início ao teste deixando passar água destilada através da coluna de solo (também por volta de $24 \mathrm{~h}$ ), para que toda a quantidade de nitrato eventualmente presente no solo, que preenchia a coluna, fosse retirada. Atingido o fluxo constante, ocorria a troca do fornecimento de água para aplicação da solução de nitrato. A partir desse ponto começava-se a coleta dos volumes da solução que atravessavam a coluna de solo.

Os frascos coletores possuíam $15 \mathrm{ml}$ de volume, definidos em função do volume de poros, cujos valores estão em função do volume da coluna $\left(392,7 \mathrm{~cm}^{3}\right)$ e da porosidade do solo em questão (eq. 33). Cada frasco representava aproximadamente 0,08 volumes de poros. 
$\mathrm{VP}=\alpha \mathrm{V}$

em que

$\mathrm{VP}=$ volume de poros; $\mathrm{L}^{3}$;

$\alpha=$ porosidade do solo em questão, decimal; e

$\mathrm{V}=$ volume da coluna, $\mathrm{L}^{3}$.

O volume coletado foi controlado por uma balança eletrônica com precisão de 0,01 g. Ao atingir $15 \mathrm{~g}$ de solução trocava-se o frasco.

Visando um prévio conhecimento da tendência dos pontos na curva de eluição e com o objetivo de auxiliar no acompanhamento do teste, ou seja, na estimativa da concentração aproximada de nitrato na solução, foi elaborada uma curva de calibração que representava a concentração de nitrato em função da condutividade elétrica (CE) da solução. O valor da CE em torno de $0,12 \mathrm{dS} \mathrm{m}^{-1}$ representava de forma aproximada a concentração de $50 \mathrm{mg} \mathrm{L}^{-1}$. Então, quando atingia-se esse valor nos volumes coletados pelos frascos, o teste era finalizado e as amostras submetidas à análise em laboratório (Figura 5).

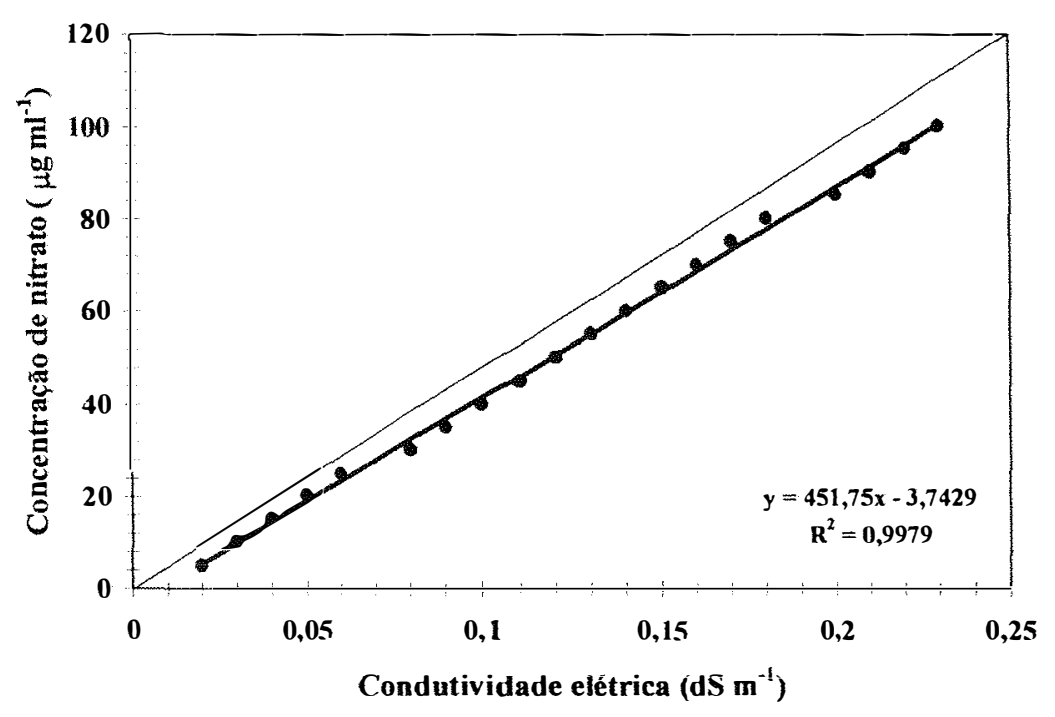

Figura 5 - Representação gráfica da concentração de nitrato em função da condutividade elétrica da solução 


\subsubsection{Obtenção dos parâmetros de transporte pelo modelo CXTFIT}

Para que os modelos possam determinar com uma certa precisão o movimento de solutos no solo, é necessário a determinação de alguns parâmetros de transporte relativos à cada tipo de solo, tais como, o coeficiente de dispersão (D), a dispersividade $(\lambda)$ e o fator de retardamento (R). Para a obtenção desses valores foi utilizado o modelo CXTFIT, desenvolvido pelo U.S. Salinity Laboratory - USDA Riverside-CA, versão 2.1 (atualizado em Novembro de 1998), escrito na linguagem de programação FORTRAN. Trata-se de um programa computacional para a estimativa de parâmetros de transporte de solutos por meio de concentrações obtidas em laboratório (chamado de problema inverso) ou para predizer concentrações de solutos em condições de escoamento permanente (chamado de problema direto) usando para isso as equações de conveç̧ão-dispersão. Para a obtenção de tais valores dos parâmetros, eram feitas tentativas, de modo a atingir um maior coeficiente de determinação, entre os dados experimentais e os simulados pelo modelo (Apêndice). Dessa maneira foram obtidos os valores dos parâmetros de transporte (Quadro 3) e as curvas de eluição foram plotadas (Figura 6).

\begin{tabular}{|c|c|c|c|c|}
\hline \multirow{2}{*}{ Tipo de Solo } & \multicolumn{3}{|c|}{ Parâmetros de transporte do nitrato } \\
\cline { 2 - 5 } & $\begin{array}{c}\mathbf{V} \\
\left(\mathbf{c m} \mathbf{~ m i n}^{-\mathbf{1}}\right)\end{array}$ & $\begin{array}{c}\mathbf{D} \\
\left(\mathbf{c m}^{\mathbf{2}} \mathbf{m i n}^{-1}\right)\end{array}$ & $\mathbf{R}$ & $\begin{array}{c}\boldsymbol{\lambda} \\
(\mathbf{c m})\end{array}$ \\
\hline Solo 1 & 0,9920 & 11,6800 & 1,340 & 11,77419 \\
\hline Solo 2 & 0,4649 & 0,9996 & 1,088 & 2,15014 \\
\hline Solo 3 & 0,2708 & 0,1042 & 1,572 & 0,38470 \\
\hline
\end{tabular}

Quadro 3 - Parâmetros de transporte do nitrato: velocidade da água nos poros (v), coeficiente de dispersão (D), fator de retardamento (R) e dispersividade $(\lambda)$, dos três solos submetidos à simulação

\subsubsection{Aplicação da solução na coluna segmentada}

Após a obtenção dos parâmetros de transporte do soluto nos diferentes tipos de solo, passou-se para a próxima etapa do experimento em laboratório, com o objetivo de obter as concentrações de nitrato ao longo de uma coluna segmentada. Para realizar essa etapa foi confeccionada uma coluna com as seguintes dimensões: $75 \mathrm{~cm}$ de altura e $5 \mathrm{~cm}$ de diâmetro. A coluna era dividida em 10 anéis com $7 \mathrm{~cm}$ de altura e o anel superior com $5 \mathrm{~cm}$, totalizando 11 anéis. 


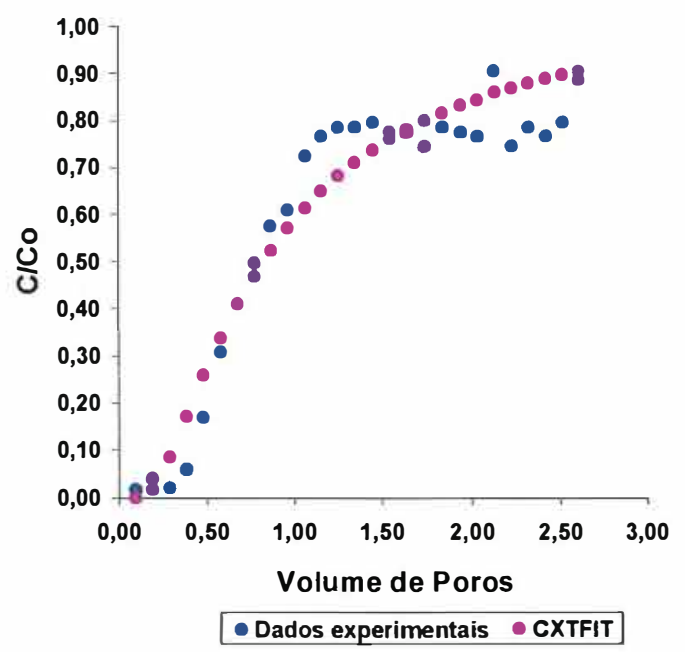

(a)

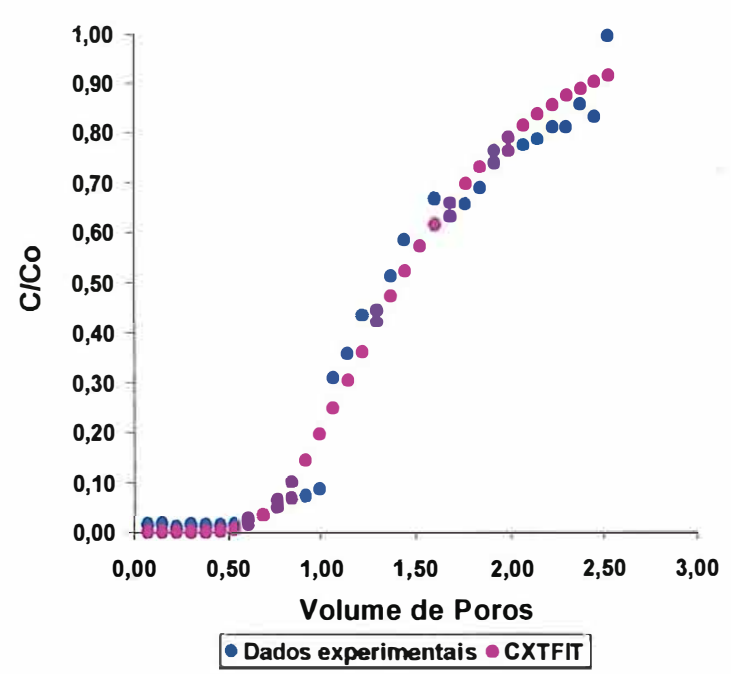

(b)

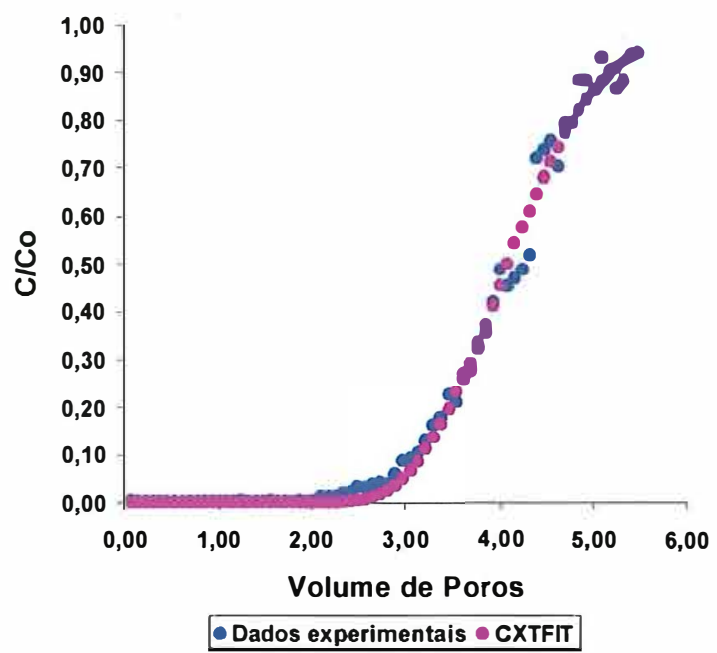

(c)

Figura 6 - Curvas de eluição obtidas para o Solo 1 (a), Solo 2 (b) e Solo 3 (c) 
$\mathrm{O}$ anel superior era um pouco menor, $5 \mathrm{~cm}$ de altura, com a função de proteção no momento da aplicação da solução e também para auxiliar na verificação da formação de uma lâmina da solução que estava sendo aplicada na superfície do solo na coluna, o que não era desejável. Este processo de certa forma auxiliava na regulagem da vazão do dosador de solução, que tinha que ser tal de modo que todo o volume aplicado infiltrasse na coluna, ou seja, em torno de $150 \mathrm{~mL} \mathrm{~h}^{-1}$. Para evitar vazamentos da solução entre os anéis, foi utilizado uma fita adesiva.

A coluna foi preenchida utilizando um volume conhecido do solo peneirado que foi submetido ao teste e pesada logo em seguida. A aplicação da solução de nitrato foi feita pelo dosador de soro por um tempo determinado e com uma vazão tal que, a frente de molhamento não atingisse o final da coluna e nem houvesse a formação de uma lâmina no primeiro anel da coluna. Passado o intervalo de tempo total de aplicação da solução, interrompia-se o fornecimento da solução e iniciou-se o procedimento de retirada dos anéis.

Os anéis foram desmontados e preparou-se uma pasta saturada com o solo que foi retirado. Em um primeiro instante determinou-se o valor da umidade do solo após o fornecimento da solução. A umidade foi medida pelo método gravimétrico. Como nos anéis inferiores a umidade foi menor, necessitou-se adicionar água destilada para facilitar a extração da solução. Com isso o valor da umidade foi alterado, necessitando-se determinar o novo valor para fazer o ajuste de acordo com a situação inicial. As pastas ficaram em repouso por 24 horas e depois por meio de filtro e bomba de vácuo retirou-se as soluções que seriam submetidas às análises em laboratório. Tanto as amostras relativas às curvas de eluição como também para a determinação da concentração de nitrato nas soluções das pastas de solo, foram submetidas ao método da Brucina (American Public Health Association, 1976), cujo princípio baseia-se no fato de que o nitrato reage com a Brucina, um alcalóide, em meio ácido, produzindo uma solução com coloração amarela. A cor produzida é proporcional a sua concentração na amostra, o que permite então a determinação por colorimetria. Os fatores que podem interferir na análise das amostras são: a coloração da amostra, presença de sedimentos em suspensão e tamanho das amostras. As amostras que contém altas concentrações de 
nitrato devem ser diluídas. As análises do nitrato foram feitas no Laboratório de Ecologia Aplicada do Departamento de Engenharia Florestal da ESALQ/USP.

Com o objetivo de validação do modelo foram comparados os resultados obtidos da concentração de nitrato do solo, com base em 3 repetições. Considerou-se como repetição os 3 tipos de solo de preenchimento da coluna. de preenchimento da coluna com cada tipo de solo. Nesse sentido o modelo considerou os pontos medianos de cada anel para comparação com os valores experimentais.

A coluna segmentada bem como a representação esquemática dos anéis na coluna podem ser observados pela Figura 7.
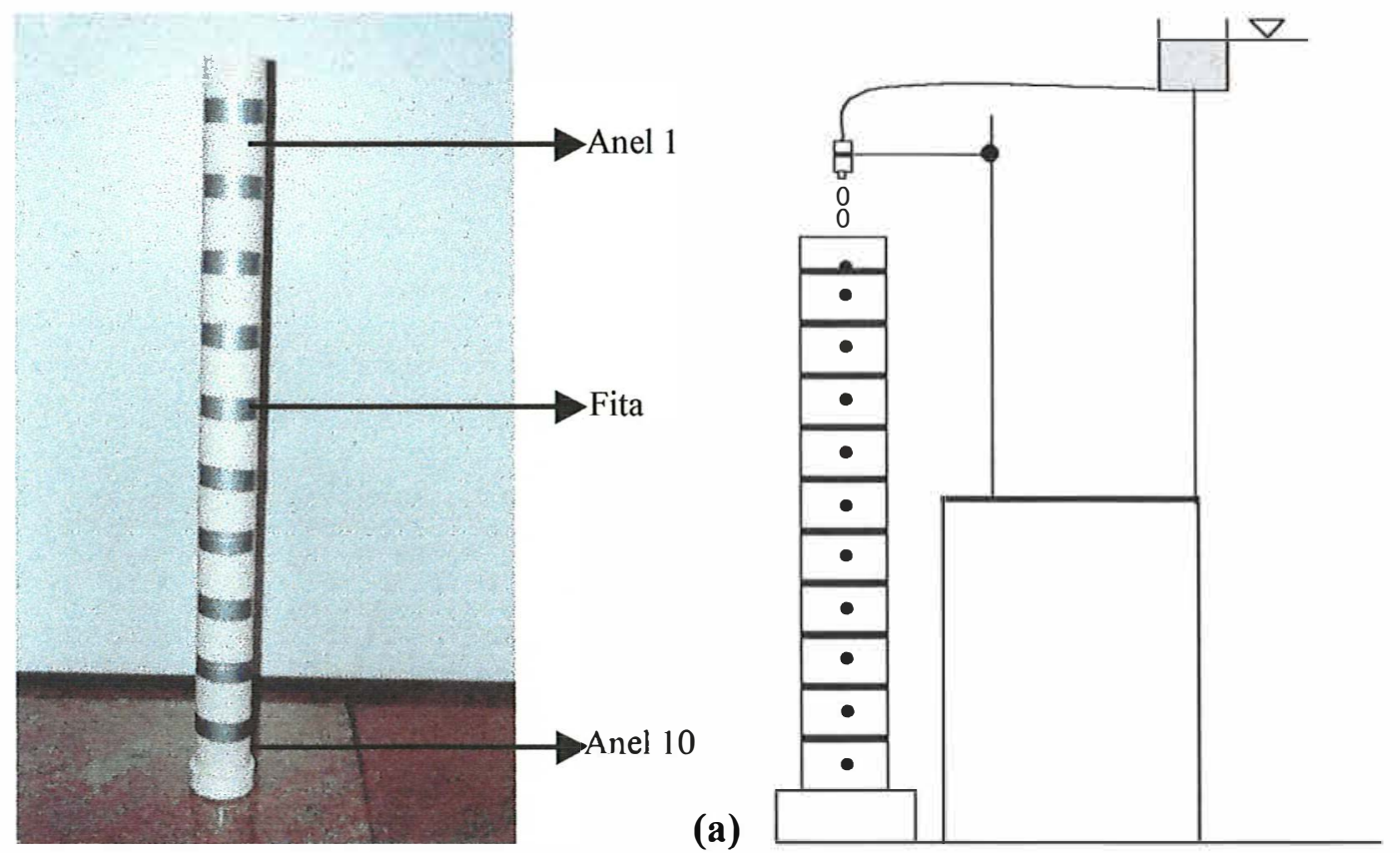

Figura 7 - Coluna utilizada para aplicar a solução e determinação da concentração de nitrato (a) e representação esquemática da aplicação da solução de nitrato na coluna com um dosador (b)

Os valores de entrada no modelo que dizem respeito à umidade inicial e à concentração inicial de nitrato no solo da coluna foram obtidos nos anéis que não foram atingidos pela frente de molhamento. Com relação ao intervalo de tempo utilizado na simulação, foi estipulado um intervalo de tempo $(\Delta \mathrm{T})$ igual a $0,3 \mathrm{~s}$, o qual, de acordo com o tempo de aplicação da solução, permitia estabelecer o número de intervalos. O 
incremento de profundidade $(\Delta Z)$ adotado foi igual a $7 \mathrm{~cm}$ de profundidade, isto é, igual à altura de cada anel.

\subsection{Análise de sensibilidade do modelo}

Os resultados de umidade do solo e de concentração de nitrato na coluna obtidos nas simulações foram submetidos a uma análise de sensibilidade e determinação do erro padrão (eq. 34) variando-se, individualmente, os seguintes parâmetros de entrada: condutividade hidráulica do solo saturado, umidade volumétrica do solo saturado, dispersividade, fator de retardamento, vazão do gotejador e umidade inicial do solo na coluna. Esses resultados simulados pelo modelo após as variações de cada parâmetro de entrada para o perfil de umidade e concentração de nitrato na coluna, foram comparados com aqueles obtidos com os dados experimentais para o Solo 2.

$e=\sqrt{\frac{\sum_{i=1}^{N}(y m(i)-y s(i))^{2}}{N}}$

em que

e = erro padrão;

ym(i) = valor padrão simulado pelo modelo;

ys $(i)=$ valor simulado pelo modelo variando o parâmetro de entrada; e

$\mathrm{N}=$ número de dados da simulação.

As variações aos parâmetros de entrada do modelo, para determinação do erro padrão, foram feitas tanto no sentido de acréscimos positivos, $+10 \%,+20 \%$, $+30 \%,+50 \%,+60 \%,+70 \%,+80 \%$ e $+90 \%$ quanto também nos negativos, $-10 \%$, $20 \%,-30 \%,-50 \%,-60 \%,-70 \%,-80 \%$ e $-90 \%$.

Para se verificar o efeito das variações nos perfis de umidade e de concentração de nitrato, aplicaram-se variações positivas de $+90 \%$ e negativas de -90 \%, nos parâmetros de entrada do modelo descritos anteriormente. 
Nas análises realizadas anteriormente a concentração da solução de nitrato aplicada apresentava-se menor que a concentração de nitrato no solo. Assim, a fim de verificar um efeito contrário à lixiviação do nitrato, o modelo foi submetido finalmente a uma análise de sensibilidade no sentido de prever aplicações de soluções de nitrato que apresentassem concentração superiores aos apresentados pelo solo que preencheu a coluna. Nesse caso, a solução aplicada apresentou uma concentração de $2.000 \mathrm{mg} \mathrm{L}^{-1}$. 


\section{RESULTADOS E DISCUSÃO}

Os resultados simulados pelo modelo serão abordados primeiramente em relação a sua validação, comparando-se os valores simulados de umidade do solo na coluna e os valores de concentração de nitrato presente no solo com os valores medidos nos respectivos anéis da coluna segmentada. $\mathrm{Na}$ seqüência será discutido o comportamento do modelo submetendo-o a uma análise de sensibilidade, supondo a aplicação de uma solução de nitrato de concentração inferior à concentração de nitrato no solo. Por fim serão discutidos os resultados da análise de sensibilidade, supondo a aplicação de uma solução de nitrato com concentração superior à presente no solo que preencheu a coluna.

\subsection{Validação do modelo comparando o perfil de umidade simulado em relação à média das três medições}

Os valores de umidade simulados pelo modelo apresentaram-se similares aos valores obtidos experimentalmente. De uma maneira geral os valores de umidade, em termos médios, obtidos em laboratório na coluna para os três tipos de solo, mantiveram-se constantes até uma profundidade aproximada de $45 \mathrm{~cm} \mathrm{e} \mathrm{em} \mathrm{seguida}$ reduziram-se, evidenciando que nos testes realizados em laboratório a frente de molhamento não atingiu os anéis na parte inferior da coluna (Figura 8).

Em relação ao Solo 1, por tratar-se de um solo arenoso, portanto com maior presença de macroporos, o que implica em uma menor retenção de água, os valores obtidos de umidade comparado com os outros solos foi menor, ou seja, em torno de $38 \%$ nas camadas superiores da coluna pelos dados experimentais e $44 \%$ para os valores simulados. Houve uma boa concordância entre os valores medidos e os simulados no que se refere à posição da frente de molhamento. 


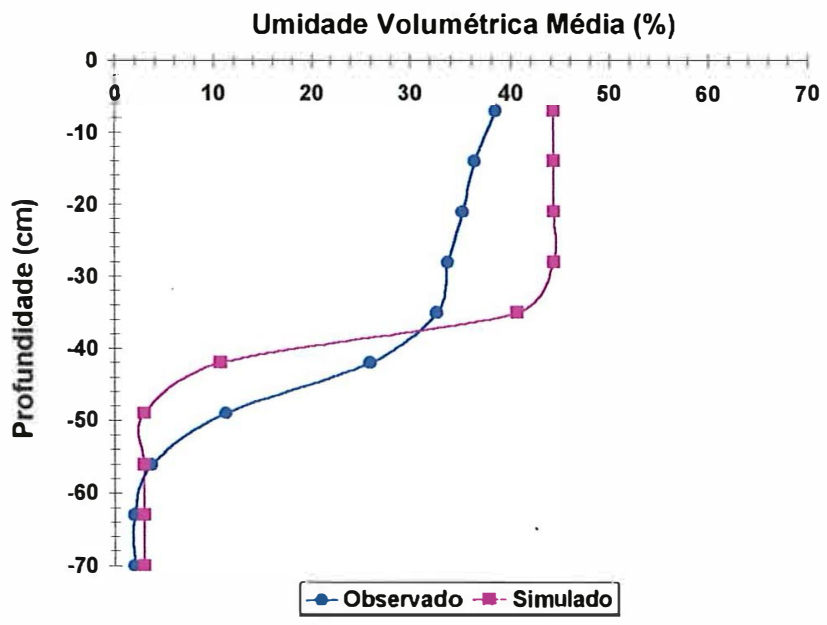

(a)

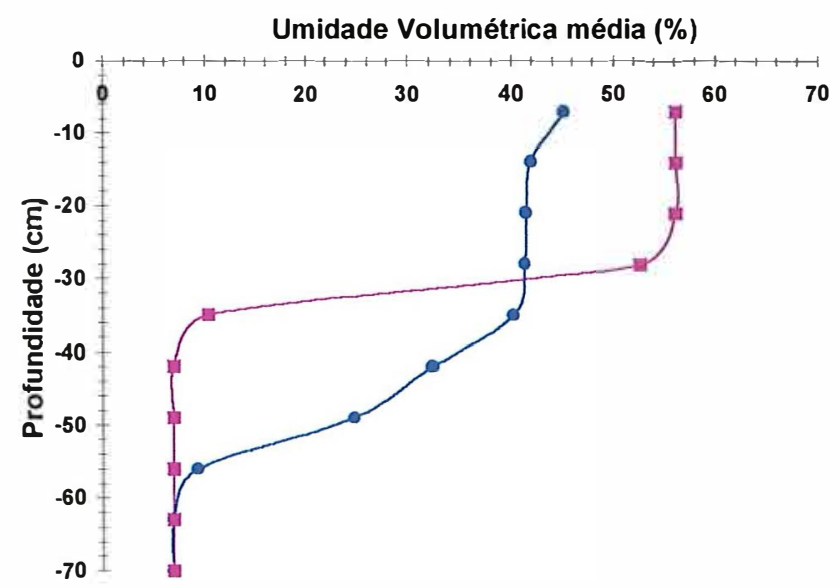

(b)

- Observado - - Simulado

Umidade Volumétrica Média (\%)

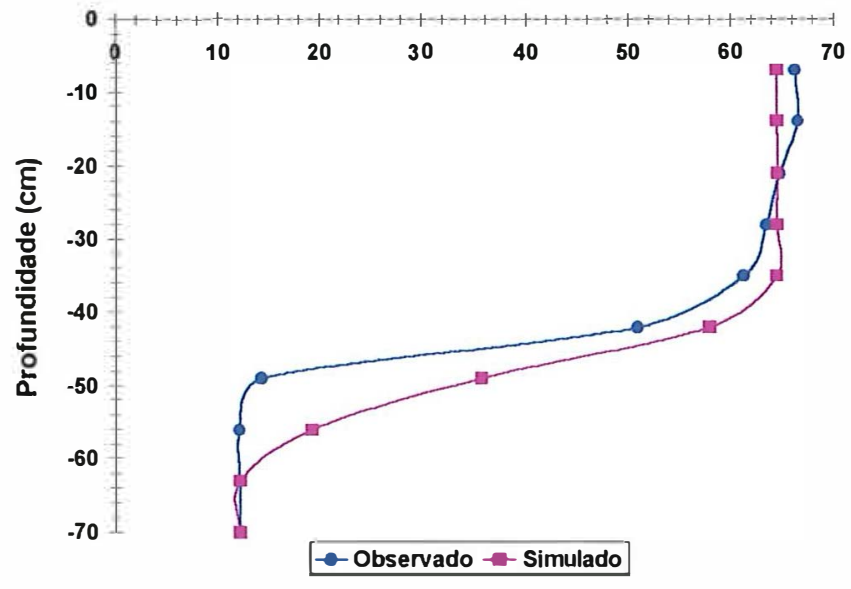

(c)

Figura 8 - Representação do perfil de umidade média de três repetições obtido em laboratório e pelo modelo para os solos: Solo 1 (a), Solo 2 (b) e Solo 3 (c) 
Para o Solo 2, houve um pequeno aumento, quando comparado com o Solo 1, por parte dos valores da umidade nos anéis superiores, obtidos tanto pelo modelo como também experimentalmente, ficando em torno de $44 \%$ para os dados experimentais e de $56 \%$ para os valores simulados. O perfil de umidade de acordo com os valores médios obtidos para o Solo 2, apresentou as maiores variações, principalmente para as profundidades de 32 a $56 \mathrm{~cm}$, devido ao fato de que a repetição 3 apresentou valores obtidos em laboratório bem semelhantes àqueles simulados pelo modelo e as outras 2 repetições apresentaram valores mais distintos, possivelmente influenciadas pelo preenchimento da coluna (Figura 9).

No Solo 3 obtiveram-se os maiores valores de umidade na zona de transmissão e as menores diferenças entre os valores medidos e os simulados. Cabe observar que os valores obtidos experimentalmente para o Solo 3, nos dois anéis superiores da coluna, apresentaram-se superiores aos da umidade volumétrica do solo saturado, o que pode ser devido a um erro de pesagem em laboratório.

\subsection{Simulação do perfil de umidade em relação às três repetições}

Da mesma forma que a simulação apresentada em relação à média, os parâmetros simulados de um modo geral ajustaram-se bem aos valores de umidade obtidos para cada repetição em laboratório. Cabe ressaltar que o modo de preenchimento da coluna, por mais criterioso que fosse, possivelmente provoca as variações apresentadas nos perfis de umidade. O comportamento do perfil de umidade mostrou-se aproximadamente constante até uma profundidade de cerca de $45 \mathrm{~cm}$, e abaixo desse valor ocorreu um decréscimo nos dados obtidos, evidenciando o fato da frente de molhamento não atingir o final da coluna. $O$ modelo simula melhor valores na saturação para os anéis superiores e nos anéis inferiores valores relacionados com a umidade inicial do solo (Figura 9).

Para o Solo 1 os valores de umidade medidos variaram de 38 a $42 \%$ para os anéis superiores da coluna e para os anéis a $40 \mathrm{~cm}$ de profundidade a variação de umidade aumentou, justamente devido ao deslocamento da frente de molhamento. A simulação aproximou a umidade dos dados experimentais. 


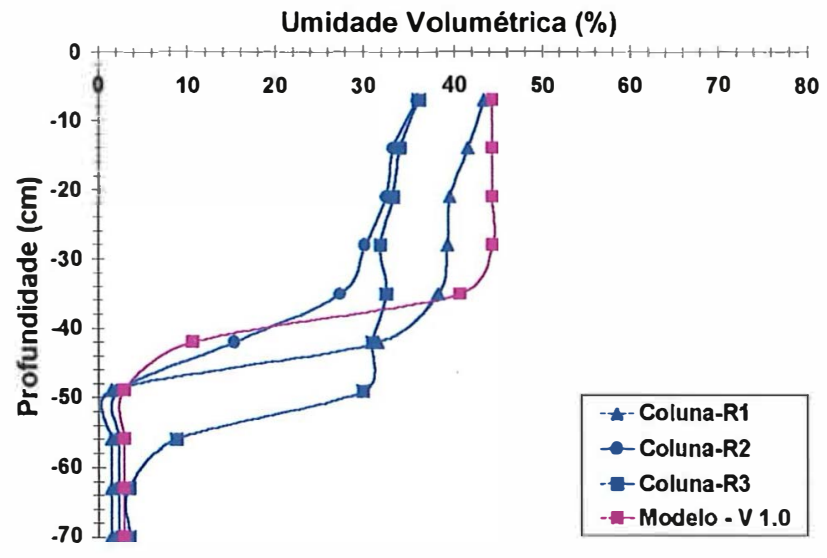

(a)

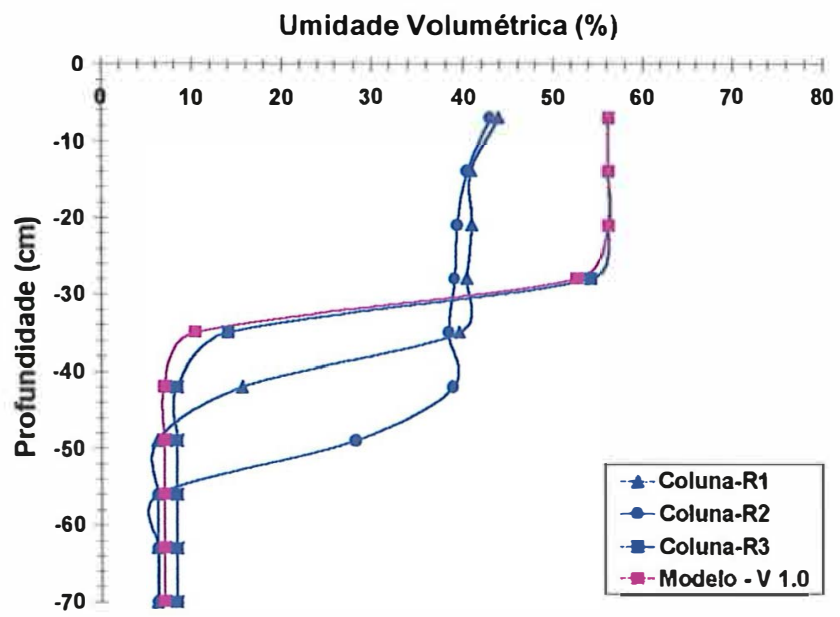

(b)

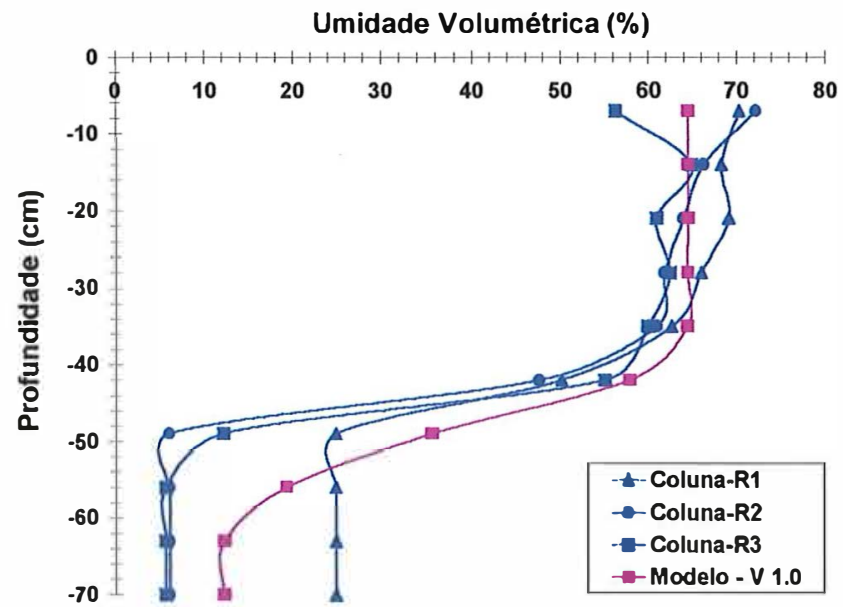

(c)

Figura 9 - Representação do perfil de umidade obtido em laboratório em 3 repetições e pelo modelo para os solos: Solo 1 (a), Solo 2 (b) e Solo 3 (c) 
Em relação ao Solo 2, houve pouca variação em profundidade do perfil de umidade medido em laboratório para as repetições 1 e 2 , cujas maiores diferenças obtidas ocorreram a partir dos $45 \mathrm{~cm}$.

No Solo 2 o modelo praticamente apresentou o mesmo comportamento dos dados observados no laboratório para a repetição 3, mantendo os valores de umidade nos anéis superiores próximos da saturação, isto é, em torno de $56 \%$, enquanto que os dados obtidos em laboratório para as repetições 1 e 2 ficaram em torno de $46 \%$.

Para o Solo 3, que possui a textura mais argilosa, os resultados obtidos em laboratório do perfil de umidade foram praticamente os mesmos e as maiores diferenças obtidas foram observadas a partir de $50 \mathrm{~cm}$. Isso deve-se ao fato de que a umidade inicial do solo na repetição 1 apresentou-se mais elevada do que a umidade nas repetições 2 e 3 . Os valores variaram de $6 \%$ para as repetições 2 e 3 e de $24 \%$ para a repetição 1. Porém a tendência com relação aos valores obtidos experimentalmente e os simulados pelo modelo, foi praticamente a mesma.

\subsection{Validação do modelo comparando o perfil de concentração de nitrato simulado em relação à média das três medições}

Os resultados obtidos para o movimento do nitrato na coluna serão apresentados e discutidos em função dos valores simulados pelo modelo e pelas análises de laboratório. Os valores da concentração de nitrato resultantes das análises em laboratório serão discutidos em função de valores médios e de três repetições que foram realizadas para cada coluna preenchida com cada tipo de solo. Primeiramente serão discutidos os valores da concentração de nitrato em termos médios (Figura 10).

Pelos valores avaliados no Solo 1, segundo os dados medidos em laboratório, nota-se a ocorrência de um processo de lixiviação, evidenciando-se dessa forma um processo de lavagem do solo principalmente das camadas superiores para as inferiores, no qual o aumento de nitrato tornou-se evidente à medida em que a frente de molhamento atingia os anéis inferiores da coluna, variando de $8 \mathrm{mg} \mathrm{L}^{-1}$ nos anéis superiores a $104 \mathrm{mg} \mathrm{L}^{-1}$ nos anéis inferiores. 


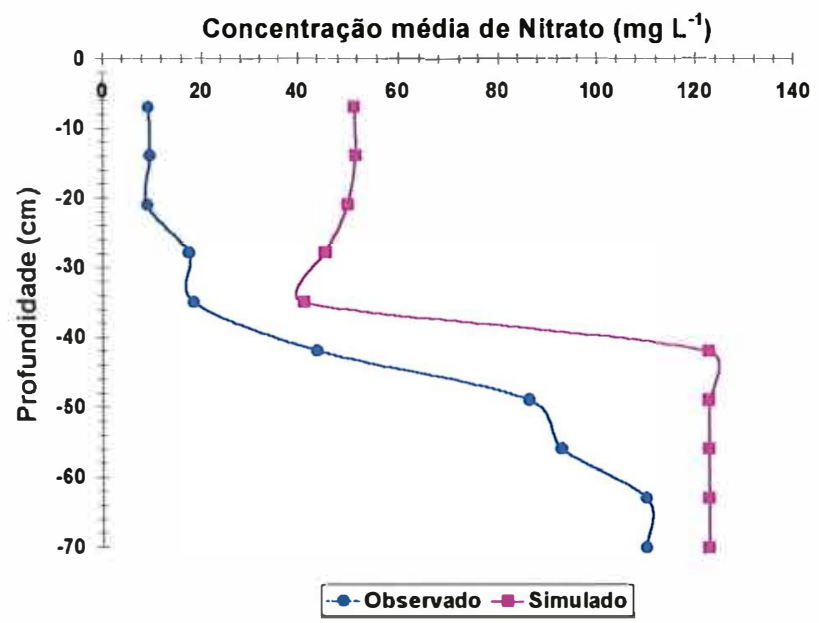

(a)

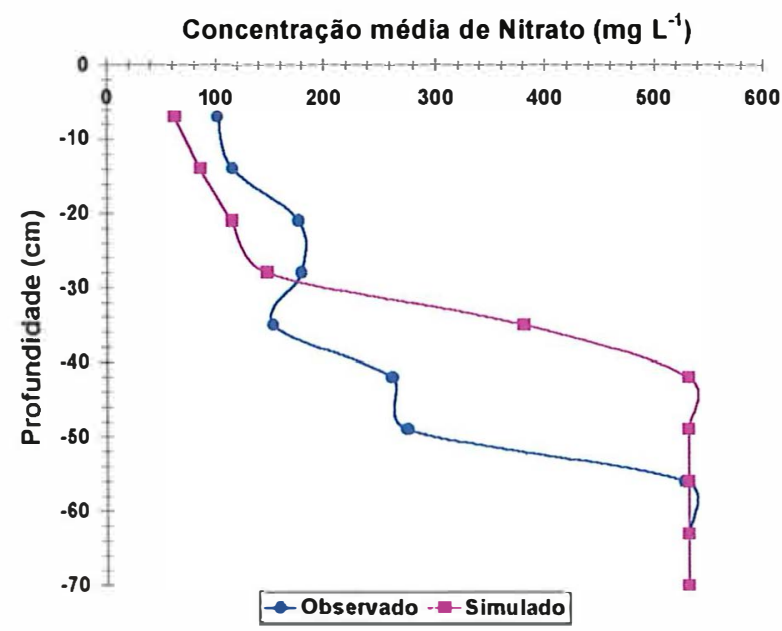

(b)

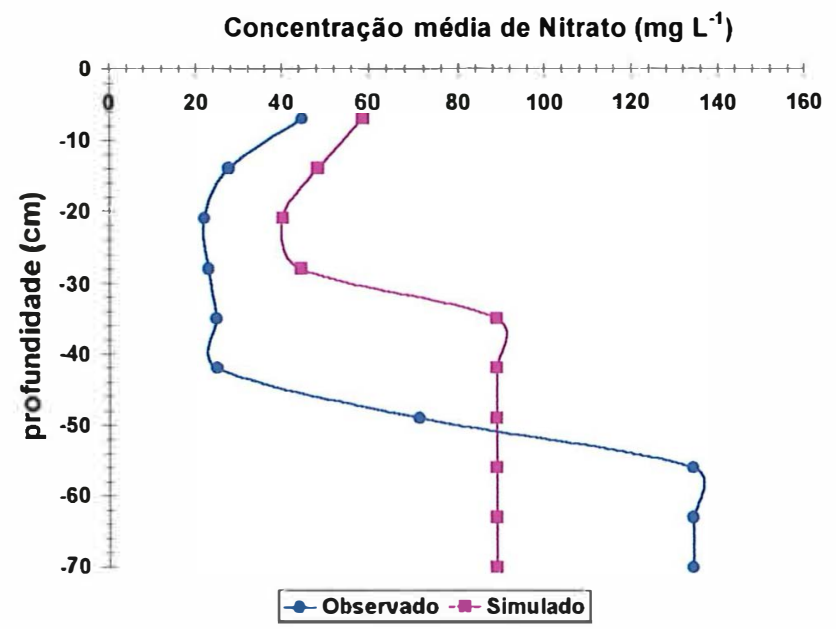

(c)

Figura 10 - Representação do perfil de concentração de nitrato obtido em laboratório em relação à média de 3 repetições e pelo modelo para os solos: Solo 1 (a), Solo 2 (b) e Solo 3 (c) 
A simulação também mostrou-se com capacidade de predizer esse efeito da lixiviação já que os anéis superiores mantiveram valores de concentração de nitrato em torno de $46 \mathrm{mg} \mathrm{L}^{-1}$ e variaram até atingir concentrações de $122 \mathrm{mg} \mathrm{L}^{-1}$ nos anéis inferiores. Os valores simulados ajustaram-se melhor àqueles obtidos em laboratório, principalmente na profundidade de $64 \mathrm{~cm}$. Isso deve-se ao fato de que o perfil de umidade nessa profundidade ter coincidido com os valores simulados, conforme foi apresentado na Figura 9.

Para o solo 2, os valores simulados de concentração de nitrato, apresentaram a mesma tendência dos valores medidos, em termos médios. De uma maneira geral os valores obtidos na simulação para a concentração de nitrato nos anéis superiores e inferiores ajustaram-se muito bem com os valores obtidos em laboratório. Observou-se uma maior concentração inicial de nitrato do que no Solo 1. O processo de lixiviação se fez presente de forma que até a profundidade de $35 \mathrm{~cm}$ os valores de concentração de nitrato obtidos em laboratório variaram pouco. No caso da simulação a maior variação ocorreu a partir de $28 \mathrm{~cm}$ até cerca de $42 \mathrm{~cm}$, o qual coincidiu com o perfil de umidade que apresentou as maiores variações nessa profundidade.

No solo 3, o comportamento do modelo também apresentou tendência semelhante aos valores obtidos em laboratório, principalmente até a uma profundidade de $30 \mathrm{~cm}$. O processo de lixiviação tornou-se evidente nos valores medidos em laboratório principalmente nas camadas de 14 a $42 \mathrm{~cm}$. Nessa situação, a umidade do solo nos anéis superiores mantiveram-se na saturação (Figura 9) o que provocou de certa forma uma lavagem do nitrato. Nos anéis medianos a diferença entre os valores medidos e simulados foi maior.

\subsection{Simulação do perfil de nitrato em relação às três repetições}

Para evidenciar o comportamento de cada solo em relação ao movimento do nitrato foram feitas repetições como pode ser observado na Figura 11. De uma maneira geral o Solo 1 apresentou a maior variação entre essas. Nesse tipo de solo, a repetição 3 apresentou praticamente a mesma concentração de nitrato ao longo de toda a coluna, não acontecendo o mesmo para as outras repetições. 


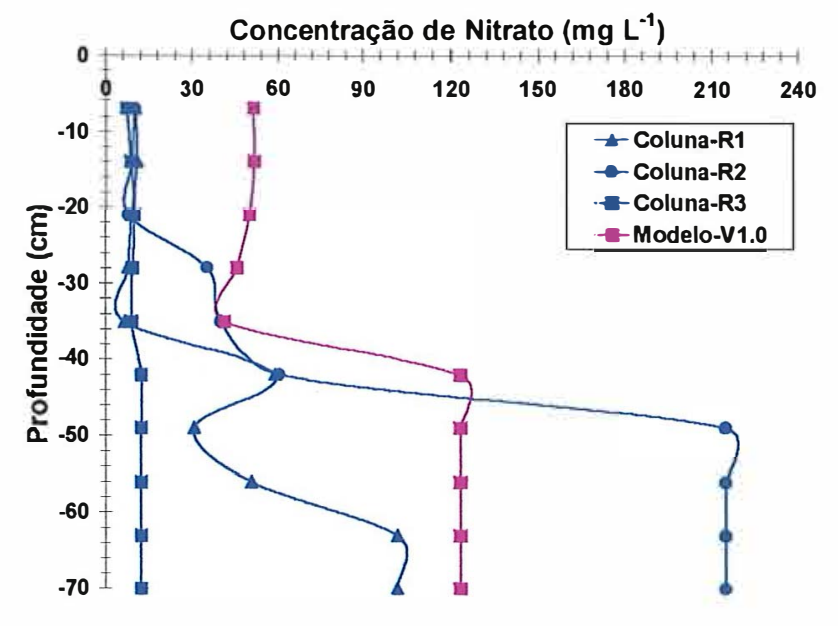

(a)

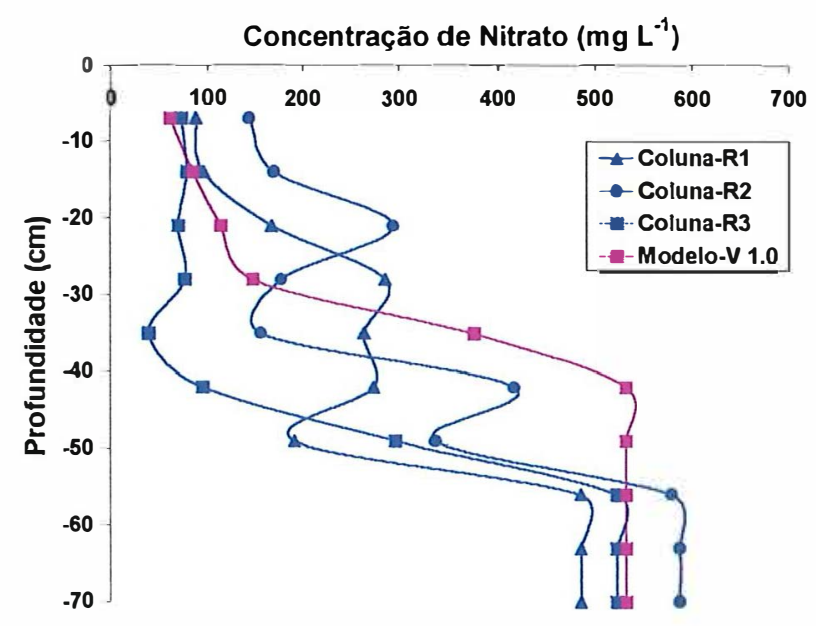

(b)

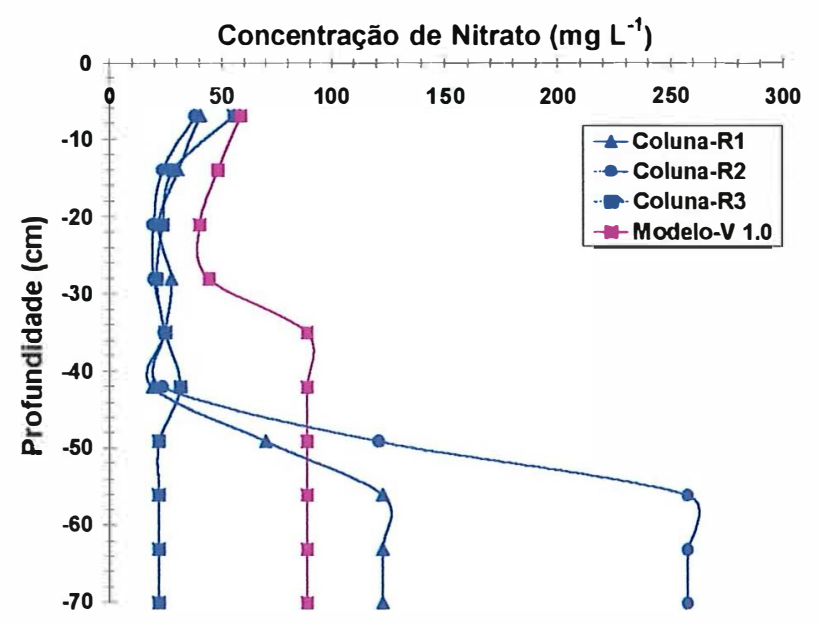

(c)

Figura 11 - Representação do perfil de concentração de nitrato obtido em laboratório em 3 repetições e simulado pelo modelo para os solos: Solo 1 (a), Solo 2 (b) e Solo 3 (c) 
Para o mesmo solo nota-se que as repetições mantiveram um valor constante até aproximadamente $20 \mathrm{~cm}$ e logo em seguida a concentração aumentou devido ao fato da frente de molhamento não ter atingido o final da coluna. Da mesma forma a simulação realizada mostrou que os valores permaneceram constantes até uma profundidade de $35 \mathrm{~cm}$ e depois foram crescendo atingindo um valor médio de $120 \mathrm{mg}$ $\mathrm{L}^{-1}$.

No caso do Solo 2, com exceção na profundidade por volta de $35 \mathrm{~cm}$, os valores apresentaram o mesmo comportamento do Solo 1, e nesse caso os valores da simulação ajustaram-se bem com aqueles obtidos em laboratório. Com relação à concentração de nitrato, entre os três tipos de solo analisados, o Solo 2 apresentou o maior valor médio inicial desse componente, ou seja $531,67 \mathrm{mg} \mathrm{L}^{-1}$.

Para o Solo 3 os valores medidos da concentração de nitrato permaneceram aproximadamente constantes até a uma profundidade de $42 \mathrm{~cm}$. A partir desse ponto, nas repetições 1 e 2 , houve um acréscimo desse valor evidenciando que a frente de molhamento já não estava mais atingindo os anéis inferiores da coluna. $O$ comportamento do modelo foi bastante semelhante ao obtido em laboratório pois a partir de 7 até $28 \mathrm{~cm}$ o valor da concentração sofreu um pequeno decréscimo em profundidade em todas as repetições e o modelo simulou esse efeito.

De um modo geral, as relações obtidas entre a concentração de nitrato e o perfil de umidade encontrado em cada coluna, evidenciaram um comportamento direto dos valores obtidos entre os dois perfis, nos quais foi notado que à medida que a coluna apresentava uma maior porcentagem de umidade, menores eram os valores de concentração de nitrato presentes na coluna de solo.

\subsection{Influência da variação dos parâmet ros de entrada do modelo na simulação da umidade do solo na coluna e concentração de nitrato}

Nessa etapa serão discutidos os valores obtidos nas simulações do modelo reduzindo e acrescendo alguns parâmetros de entrada relativos ao solo e ao movimento de nitrato, tais como: condutividade hidráulica do solo saturado, umidade volumétrica do solo saturado, dispersividade, fator de retardamento, vazão do gotejador 
e umidade inicial do solo que preenche a coluna. Primeiramente serão abordados os resultados de simulação relativos à umidade do solo na coluna e em seguida à concentração de nitrato.

\subsubsection{Análise de sensibilidade dos parâmetros de simulação na representação do perfil de umidade}

A análise de sensibilidade do modelo foi feita para verificar o efeito da variação dos parâmetros de entrada sobre as simulações do modelo com relação aos perfis de concentração de nitrato e umidade no solo da coluna. Os parâmetros de entrada sofreram variações de $-90 a+90 \%$, e os efeitos foram analisados calculando-se o erro padrão em relação aos resultados obtidos com os dados originais.

Observando-se a Figura 12 verifica-se que na faixa de $\pm 90 \%$ de variação da umidade volumétrica do solo saturado o modelo ficou ligeiramente mais sensível à variação negativa deste parâmetro. Nota-se também que o efeito da variação foi maior do que o da condutividade hidráulica do solo saturado, para variações positivas e negativas.

A variação da condutividade hidráulica mostrou-se mais sensível a elevadas variações negativas, ou seja, reduzindo o seu valor de aproximadamente - 90 \%. Para variações positivas desse parâmetro o modelo foi pouco sensível, com o erro permanecendo praticamente constante.

Na Figura 13 verifica-se que a simulação reduzida de $90 \%$ do valor da umidade volumétrica do solo saturado apresentou valores constantes é iguais à umidade inicial do solo na coluna, devido a redução aplicada a esse parâmetro ter sido muito alta. No aumento de $90 \%$ os principais aspectos observados dizem respeito aos anéis superiores, os quais são mais atingidos pela aplicação da solução, e também ao fato de que o modelo assume sempre como valor máximo no perfil de umidade àquele correspondente ao ponto de saturação. Nota-se também que aumentando-se o valor da umidade do solo saturado diminui a profundidade de alcance da frente de molhamento. 


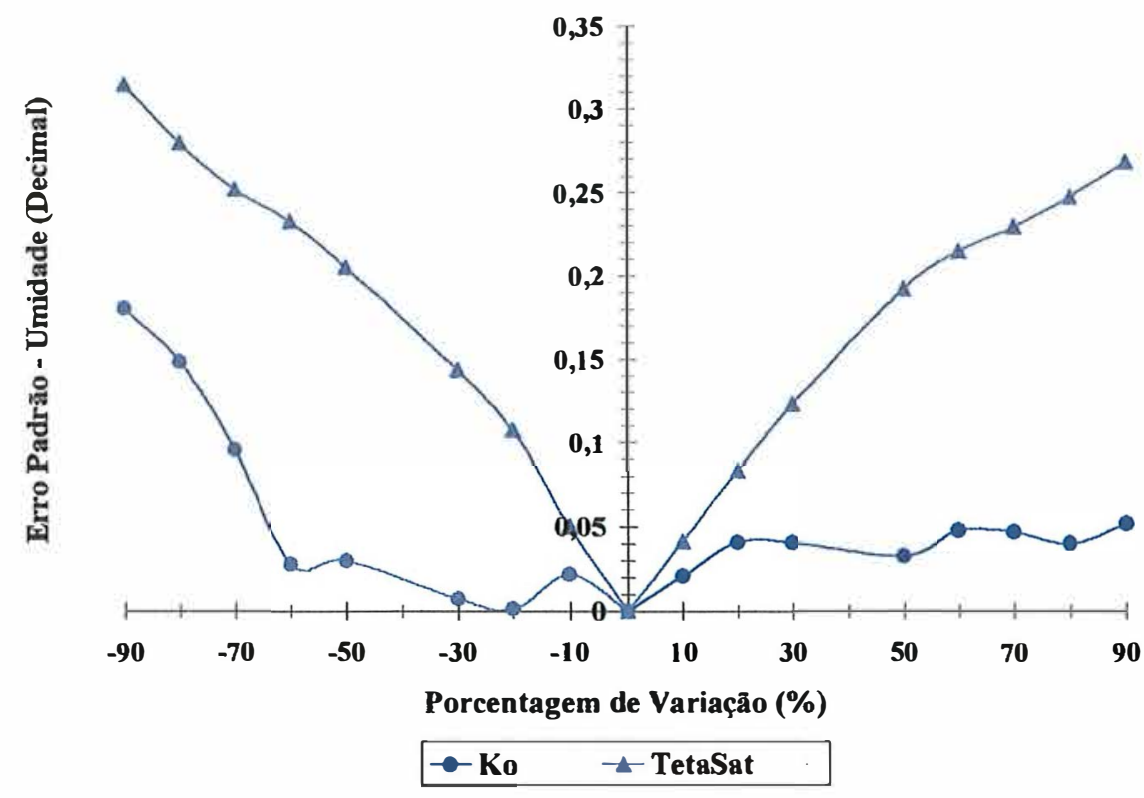

Figura 12 - Representação esquemática da análise de sensibilidade do modelo em relação à simulação do perfil de umidade do solo na coluna, aplicando de $-90 \%$ a $+90 \%$ de variação nos parâmetros de entrada, condutividade hidráulica do solo saturado e umidade volumétrica do solo saturado para o Solo 2

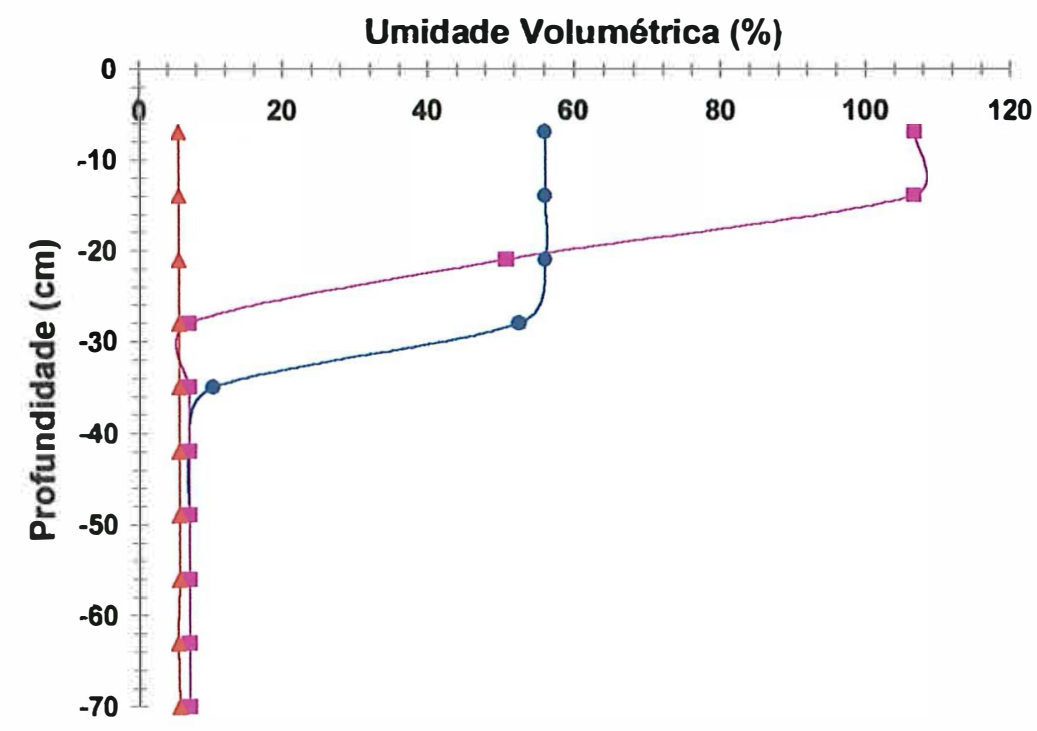

- Modelo V $1.0-$ Tetasat $+90 \%-$ Tetasat $-90 \%$

Figura 13 - Representação do perfil de umidade simulado para o Solo 2 comparado com outras duas simulações aumentando e reduzindo de $90 \%$ o parâmetro de entrada umidade volumétrica do solo saturado 
Pela Figura 14 pode-se observar que o maior efeito nos valores simulados foi verificado quando a condutividade hidráulica foi reduzida de $90 \%$. Essa redução influenciou diretamente no movimento da água no solo da coluna acarretando uma diminuição da profundidade atingida pela frente de molhamento, em torno de 28 $\mathrm{cm}$. Por outro lado, o aumento de $90 \%$ do valor da condutividade propiciou um ligeiro aumento dessa profundidade, em torno de $42 \mathrm{~cm}$.

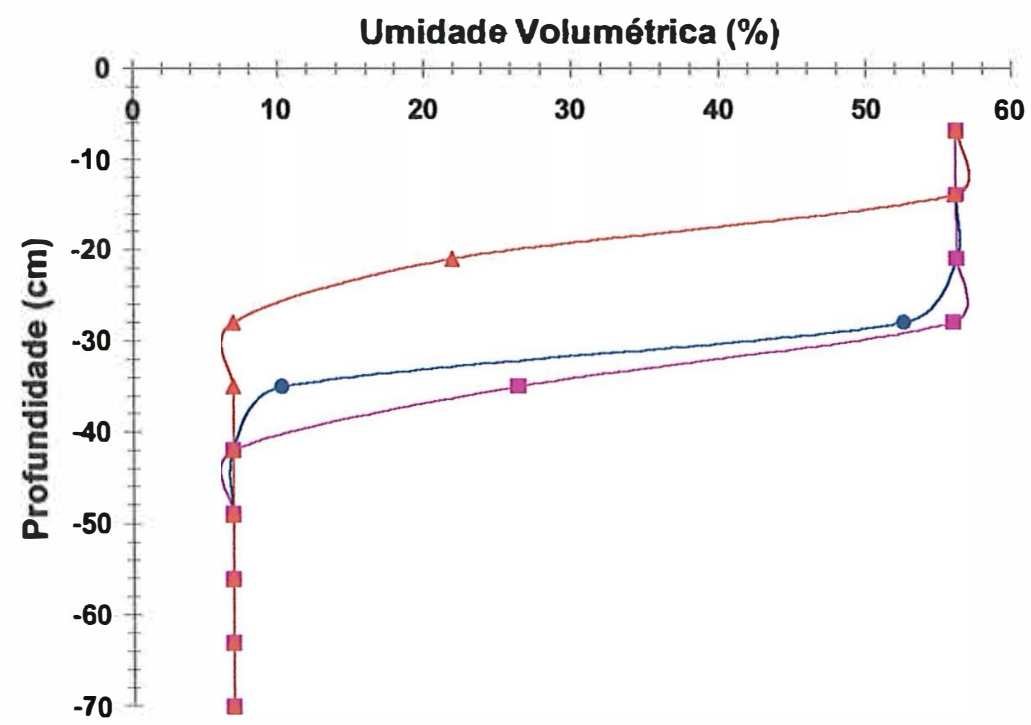

Modelo V $1.0-$ Ko $+90 \%-K o-90 \%$

Figura 14 - Representação do perfil de umidade simulado para o Solo 2 comparado com outras duas simulações aumentando e reduzindo de $90 \%$ o parâmetro de entrada condutividade hidráulica do solo saturado

Observando-se a Figura 15 verifica-se que dentre os dois parâmetros de entrada testados para verificar as suas influências na simulação, ou seja, a vazão do gotejador e a umidade inicial do solo que preencheu a coluna, aquele que mais acarretou variação no erro padrão foi justamente a vazão do gotejador, mostrando-se ser um parâmetro bastante influente na simulação pois, variações negativas ou positivas, evidenciaram uma sensibilidade do modelo, principalmente com relação a variações negativas. Isso justifica de certa forma, a aplicação da solução utilizando-se um dosador 
de soro, o qual mantinha a carga constante de solução a ser aplicada e dessa maneira obtinha-se uma vazão constante ao longo da aplicação da solução de nitrato na coluna.

A umidade inicial do solo na coluna, tanto para variações negativas quanto positivas apresentou o mesmo comportamento para os erros padrões. Quanto maiores foram as variações aplicadas, maiores foram os valores dos erros padrões. Como o modelo simula um processo de infiltração vertical na coluna, a grandeza da umidade inicial do solo influencia diretamente nesse processo.

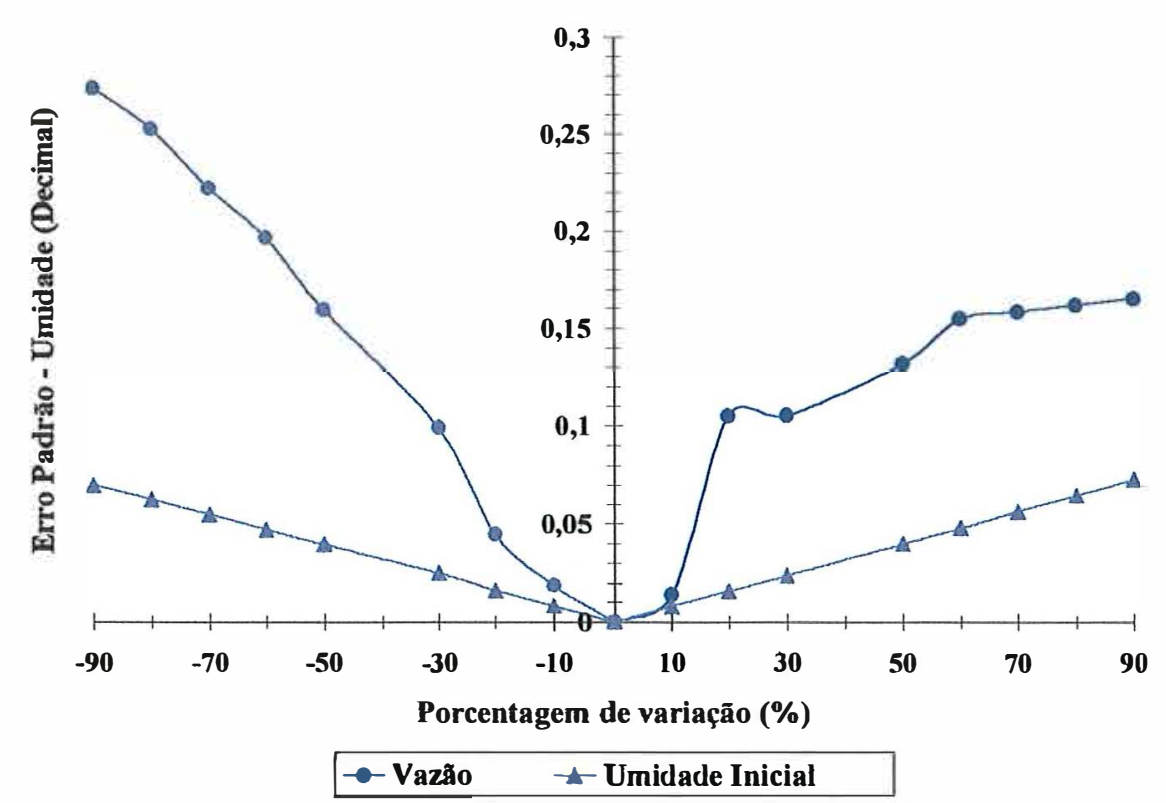

Figura 15 - Representação esquemática da análise de sensibilidade do modelo em relação à simulação do perfil de umidade do solo na coluna, aplicando de $-90 \%$ a $+90 \%$ de variação nos parâmetros de entrada, vazão do gotejador e umidade inicial do solo que preencheu a coluna para o Solo 2

Observando-se a Figura 16 verifica-se que a influência da variação da vazão do gotejador na simulação mostrou-se bem evidente, principalmente nos anéis superiores. Quando foi reduzida de $90 \%$ a vazão de aplicação da solução na coluna, a umidade volumétrica permaneceu distante do valor da saturação evidenciando, que não houve volume de solução suficiente para que a umidade atingisse valores elevados. Ainda nessa situação, já a partir do segundo anel, a umidade praticamente permaneceu 
constante e igual à umidade do solo que preenchia a coluna, mostrando que a frente de molhamento não atingiu os anéis inferiores.

Com o aumento da vazão do gotejador em quase o dobro do seu valor, o processo de infiltração ficou bem evidente, o que de certa forma, influenciou no movimento do nitrato que será discutido mais adiante. A frente de molhamento nesse caso atingiu a profundidade de $35 \mathrm{~cm}$, praticamente 2 anéis abaixo da simulação feita com os dados originais.

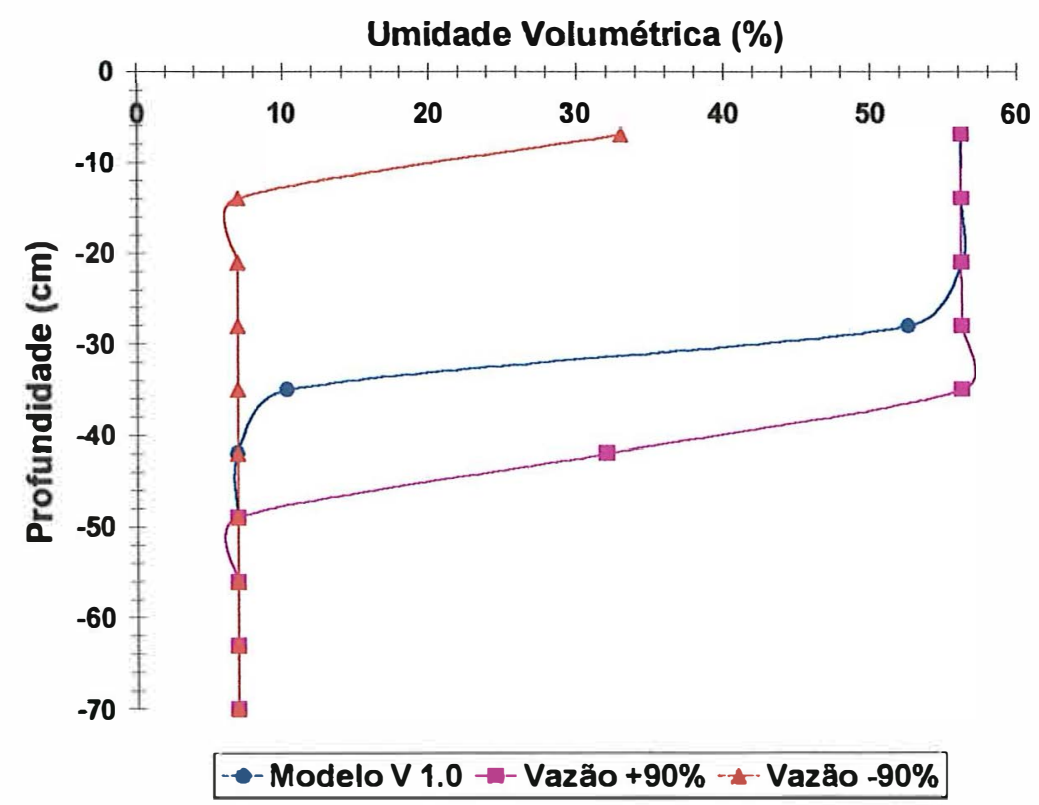

Figura 16 - Representação do perfil de umidade simulado para o Solo 2 comparado com outras duas simulações aumentando e reduzindo de $90 \%$ o parâmetro de entrada vazão do gotejador

Com relação à simulação da umidade do solo variando a umidade inicial, notou-se que principalmente para os anéis inferiores a variação foi mais expressiva. Observou-se também que aumentando-se a umidade inicial de $90 \%$ há um ligeiro acréscimo na profundidade da frente de molhamento (Figura 17). 


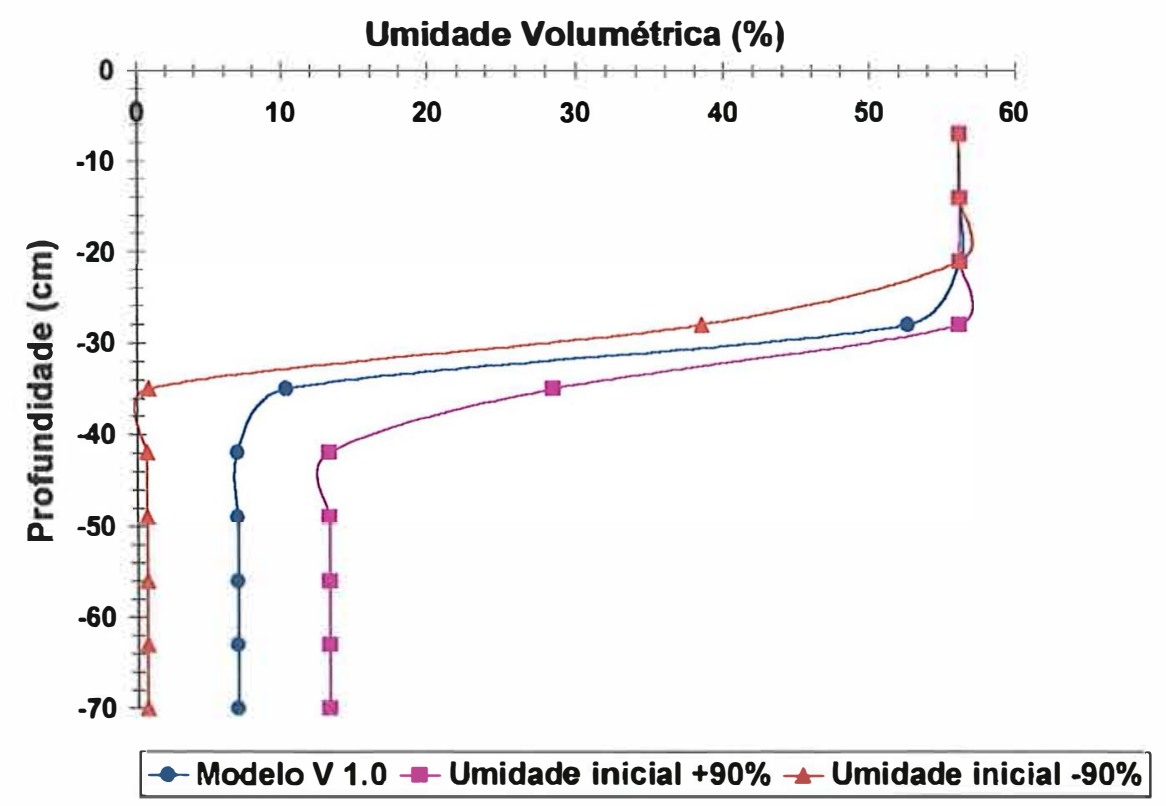

Figura 17 - Representação do perfil de umidade simulado para o Solo 2 comparado com outras duas simulações aumentando e reduzindo de $90 \%$ o parâmetro de entrada umidade inicial do solo que preenche a coluna

\subsubsection{Análise de sensibilidade dos parâmetros de simulação na representação do perfil de concentração de nitrato}

Seguindo o mesmo comportamento já evidenciado para a umidade, o modelo apresentou os maiores erros de simulação da concentração de nitrato para os aumentos da umidade volumétrica do solo saturado e para variações negativas da condutividade hidráulica do solo saturado. Isso deve-se ao fato de que o nitrato acompanha a dinâmica da solução no solo. Nessa situação os valores da umidade volumétrica do solo saturado que sofreram variações negativas, apresentaram maiores erros em relação às variações positivas desse mesmo parâmetro. Com variações de -10 $\%$ e de +20 a $+30 \%$ os erros padrões foram iguais para os dois parâmetros (Figura 18). 


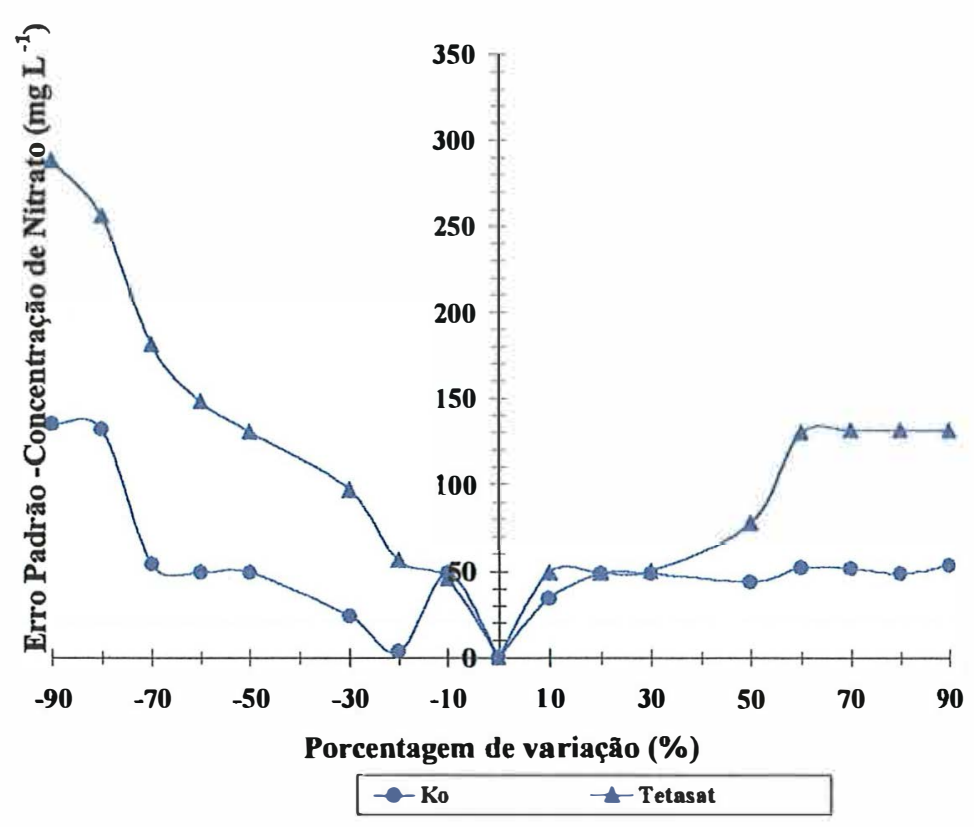

Figura 18 - Representação esquemática da análise de sensibilidade do modelo em relação à simulação da concentração de nitrato, aplicando de -90 \% a +90 \% de variação nos parâmetros de entrada, condutividade hidráulica do solo saturado e umidade volumétrica do solo saturado para o Solo 2

Observando-se a Figura 19 verifica-se que na análise do parâmetro de entrada, condutividade hidráulica do solo saturado, as simulações que tiveram os valores reduzidos de 90 \% apresentaram maior variação em relação à simulação com os dados originais, influenciando de certa forma no deslocamento da frente de molhamento para os anéis inferiores, o que provoca uma manutenção de altas concentrações de nitrato nos anéis superiores, pois aos $28 \mathrm{~cm}$ de profundidade já obteve-se o mesmo valor de concentração inicial de nitrato presente no solo.

O perfil de umidade do solo que preenche a coluna assume papel de importância principalmente quando simulado com redução de $90 \%$ dos valores originais. O modelo evidenciou que o movimento do nitrato no solo é influenciado pelo movimento da solução no solo, observado pelos dados discutidos anteriormente com relação à umidade. Quando se reduziu o valor da umidade volumétrica do solo saturado de $90 \%$, o perfil manteve valores de concentração de nitrato igual ao da solução de aplicação, pois a frente de molhamento deslocou-se em maior profundidade, devido a um menor espaço poroso necessário à saturação da coluna. 


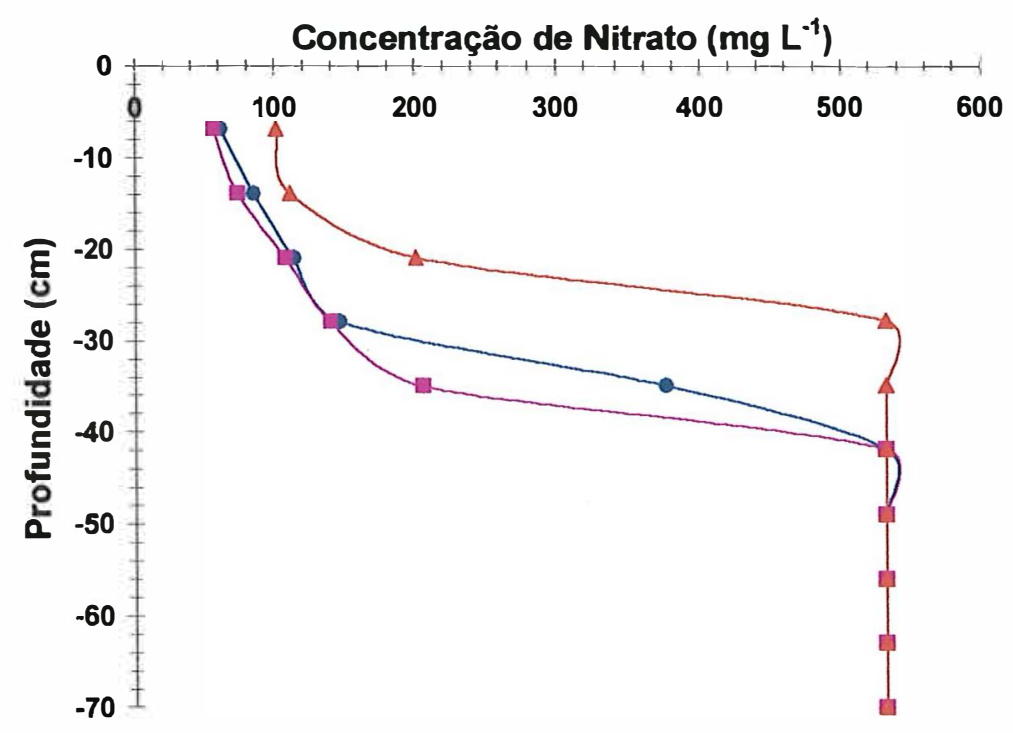

Modelo - V $1.0-\mathrm{Ko}+90 \%-\mathrm{Ko}-90 \%$

Figura 19 - Representação do perfil de concentração de nitrato simulado para o Solo 2 comparado com outras duas simulações aumentando e reduzindo de $90 \%$ o parâmetro de entrada condutividade hidráulica do solo saturado

De forma inversa, o aumento da umidade volumétrica do solo saturado causou uma diminuição do avanço da frente de lixiviação (Figura 20).

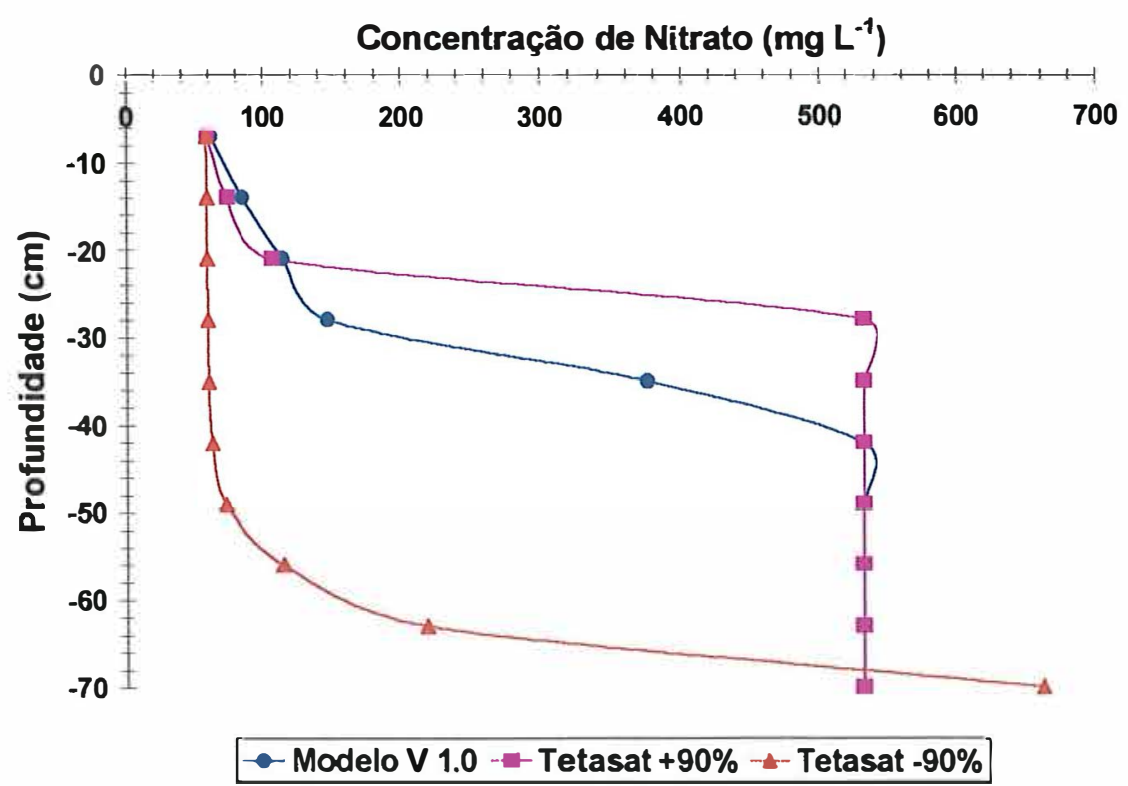

Figura 20 - Representação do perfil de concentração de nitrato simulado para o Solo 2 comparado com outras duas simulações aumentando e reduzindo de $90 \%$ o parâmetro de entrada umidade volumétrica do solo saturado 
Os parâmetros de entrada do modelo, dispersividade e fator de retardamento, apresentaram influência apenas na determinação da concentração de nitrato, pois com relação à simulação do perfil de umidade, as variações que foram testadas não acarretaram nenhuma variação em relação aos dados originais. Com relação à simulação da concentração de nitrato observa-se na Figura 21 que dentre estes dois parâmetros aquele mais sensível às variações foi o fator de retardamento, principalmente às variações negativas (- $90 \%$ ).

Aplicando-se variações positivas tanto na dispersividade quanto no fator de retardamento, até o valor máximo de $+90 \%$, praticamente não houve diferenças entre os valores simulados. Mesmo para variações negativas a dispersividade apresentou valores baixos de erros padrões, mostrando que o modelo não é sensível às variações deste dado de entrada. Já o fator de retardamento mostrou-se bastante sensível às variações negativas as quais provocaram uma elevação considerável do erro padrão.

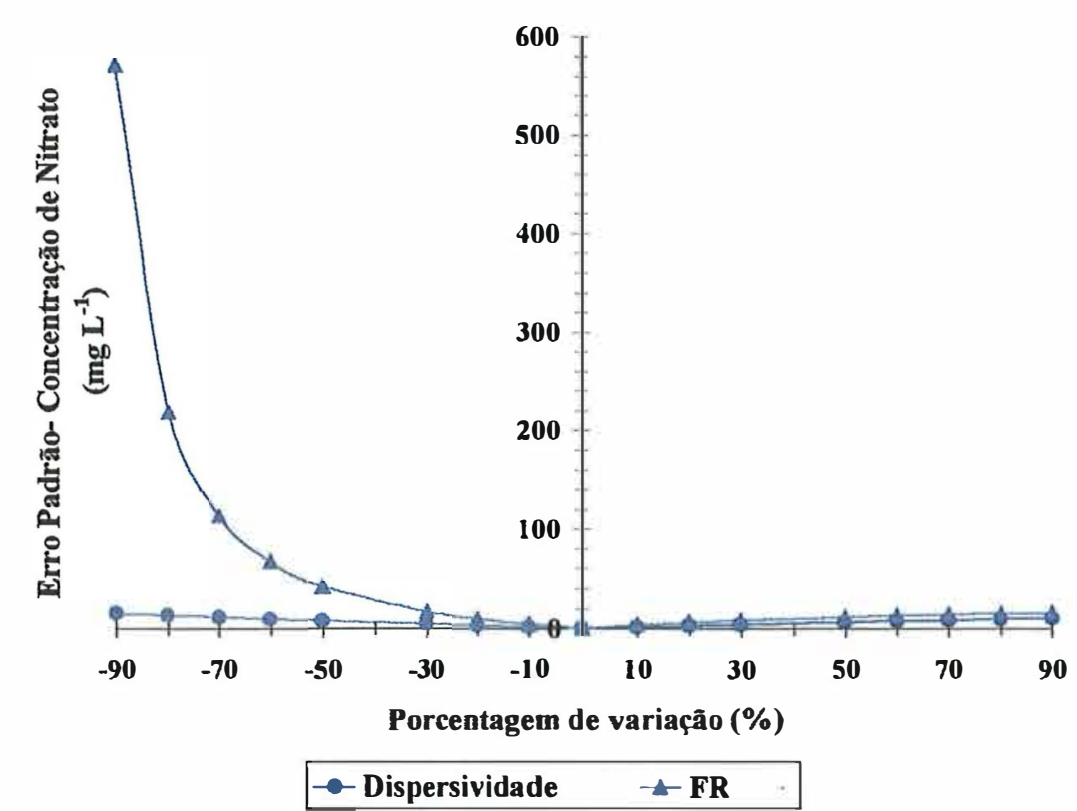

Figura 21 - Representação esquemática da análise de sensibilidade do modelo em relação à simulação da concentração de nitrato, aplicando de $-90 \%$ a +90 \% de variação nos parâmetros de entrada, dispersividade e fator de retardamento para o Solo 2 
A dispersividade é um parâmetro obtido pela relação entre o coeficiente de dispersão e a velocidade da água no poro do respectivo solo. Quanto maior a dispersividade, maior a diferença entre a velocidade média da solução nos poros e a velocidade da solução dentro de poros individuais, ou seja, a frente de lixiviação tornase mais dispersa. Na Figura 22, nota-se que o aumento da dispersividade causou um ligeiro aumento da lixiviação junto à frente de umedecimento.

$\mathrm{O}$ fator de retardamento também é chamado de coeficiente de partição pois representa a razão entre a concentração dos solutos nas fases sólida e líquida. Aumentando-se o fator de retardamento aumenta-se a adsorção, o que pode ser notado pela ligeira diminuição da concentração de nitrato nos primeiros anéis da Figura 23.

De forma inversa, quando o fator de retardamento diminui e assume valores menores que 1, há uma passagem de soluto adsorvido para a fase líquida, o que pode ser evidenciado pelo aumento da concentração de nitrato nos primeiros anéis, principalmente naquele localizado a $35 \mathrm{~cm}$ de profundidade.

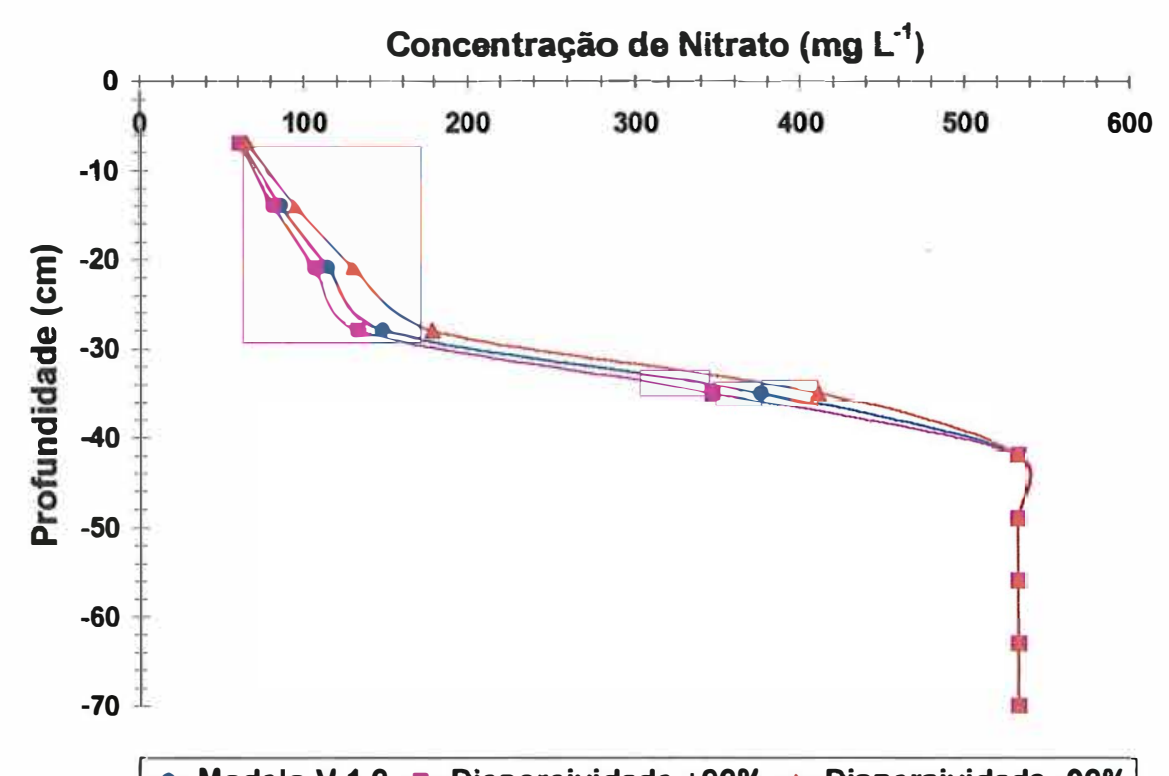

Figura 22 - Representação do perfil de concentração de nitrato simulado para o Solo 2 comparado com outras duas simulações aumentando e reduzindo de $90 \%$ o parâmetro de entrada dispersividade 


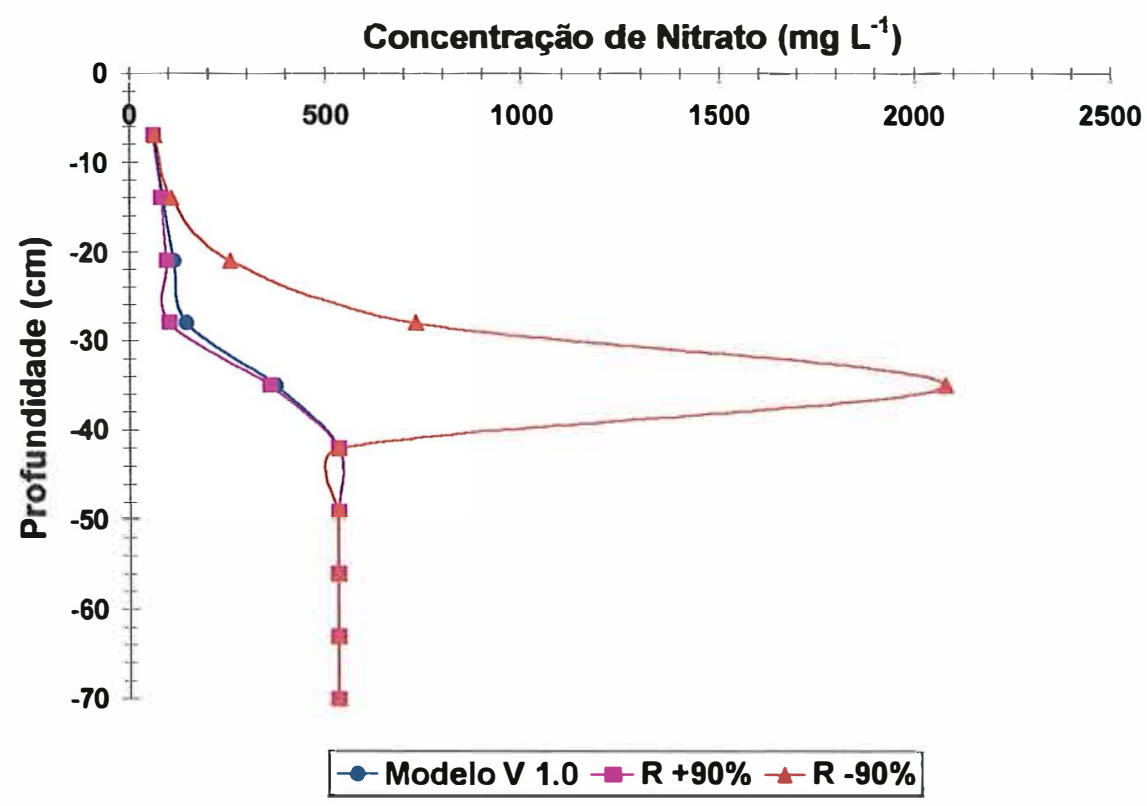

Figura 23 - Representação do perfil de concentração de nitrato simulado para o Solo 2 comparado com outras duas simulações aumentando e reduzindo de $90 \%$ o parâmetro de entrada fator de retardamento

Para a simulação da concentração de nitrato, sem dúvida, a vazão do gotejador é o parâmetro mais importante na simulação, pois tanto em relação às variações negativas $(-90 \%)$ bem como variações positivas (+90 \%) deste parâmetro o modelo mostrou-se bastante sensível.

A umidade inicial do solo que preencheu a coluna também assume um valor expressivo, pois quando são aplicadas variações negativas, ou seja, quanto menor o valor da umidade inicial do solo, o processo de infiltração se destaca, provocando uma lixiviação do nitrato para os anéis inferiores, causando um aumento do erro padrão em relação aos dados originais simulados (Figura 24).

A vazão do gotejador é um fator muito importante na simulação, justificando o fato do uso de um dispositivo de aplicação da solução de nitrato (dosador de soro). Portanto, o objetivo principal da utilização desse dosador, imitando um gotejador, foi justamente manter a carga constante e dessa forma aplicar uma vazão uniforme ao longo do tempo de aplicação. 


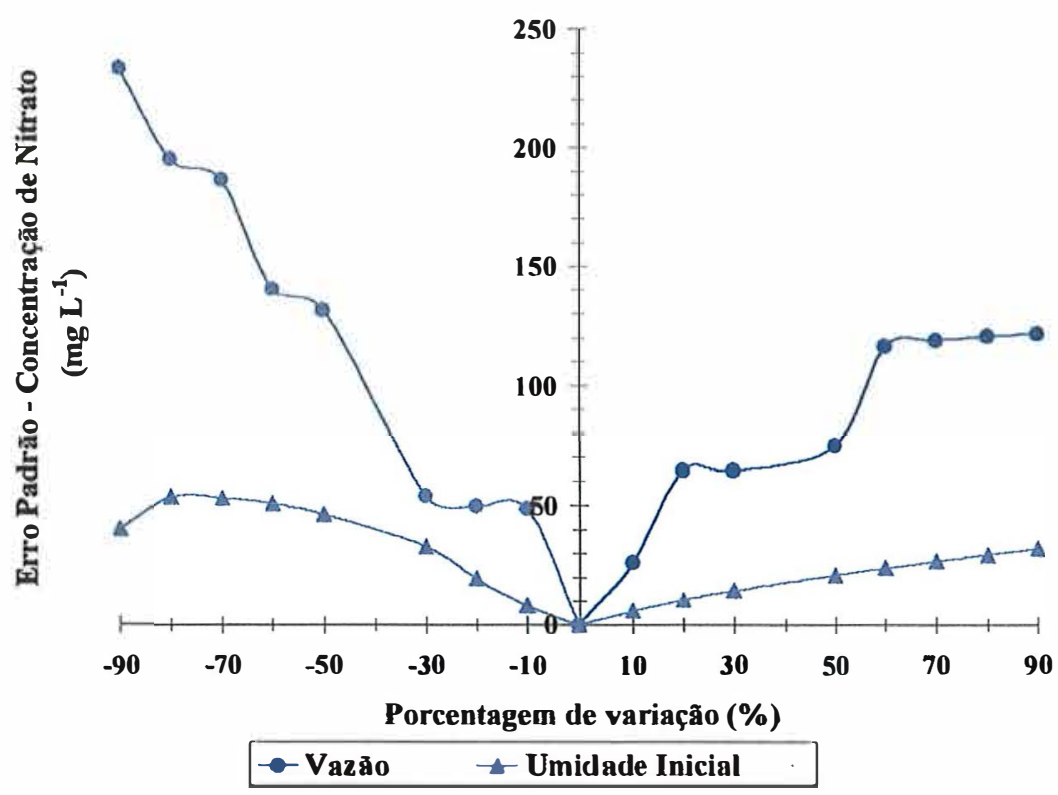

Figura 24 - Representação esquemática da análise de sensibilidade do modelo em relação à simulação da concentração de nitrato, aplicando de $-90 \%$ a +90 \% de variação nos parâmetros de entrada, vazão do gotejador e umidade inicial do solo que preencheu a coluna para o Solo 2

Pelos resultados obtidos na simulação, nota-se que quando a vazão do gotejador foi reduzida, houve uma tendência de simular altos valores de concentrações de nitrato, principalmente nos anéis superiores, mostrando que com a baixa aplicação de solução, a dinâmica da mesma foi devidamente alterada, e com isso o deslocamento da solução ficou comprometido, permanecendo a coluna como se estivesse na situação inicial.

Quando empregou-se uma vazão maior do que a simulada originalmente, ocorreu uma maior lixiviação de nitrato, o que pode ser observado principalmente nos anéis superiores. Então com o aumento de 90 \% a principal diferença encontrada foi justamente para os anéis que se encontravam na parte mais baixa da coluna, ou seja, a frente de molhamento alcançou as camadas inferiores da coluna, deslocando a concentração de nitrato para uma profundidade de $40 \mathrm{~cm}$ (Figura 25). 


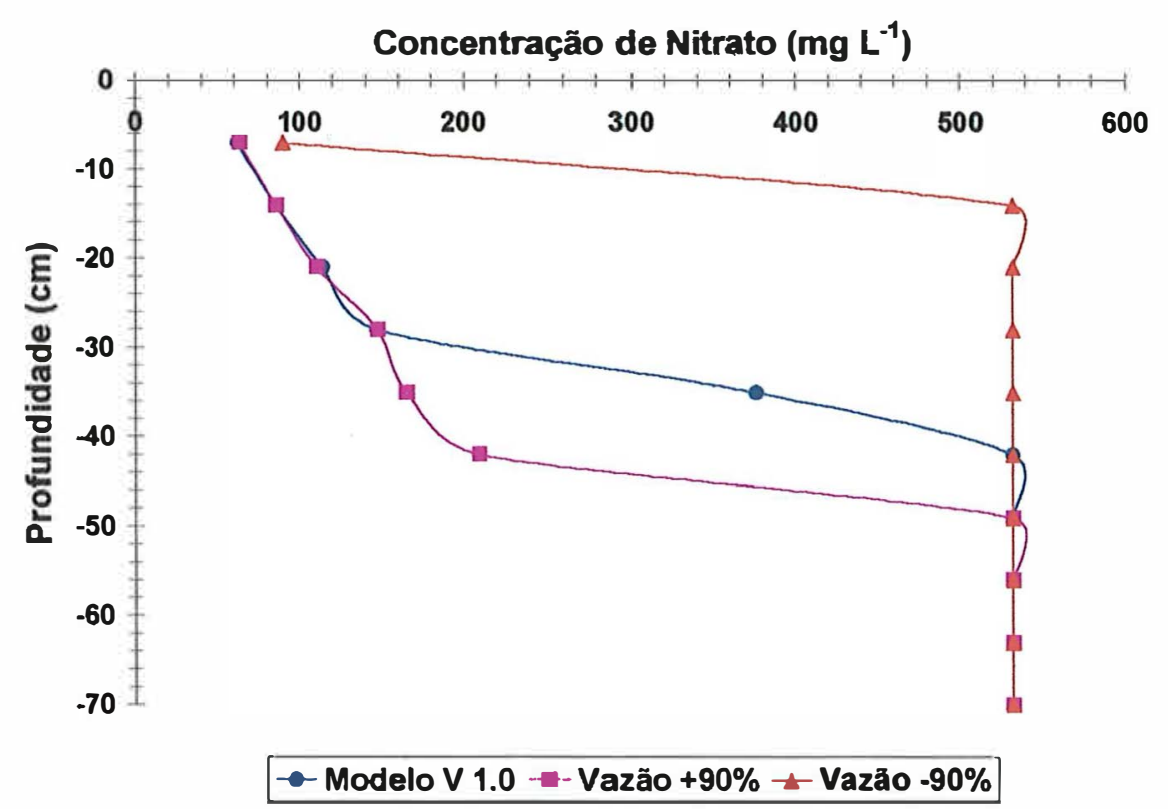

Figura 25 - Representação do perfil de concentração de nitrato simulado para o Solo 2 comparado com outras duas simulações aumentando e reduzindo de $90 \%$ o parâmetro de entrada vazão do gotejador

Na Figura 26, pelos resultados simulados, observa-se que quanto mais úmido o solo, menor é o efeito da lixiviação, ou seja, maior é o volume de solução passível de ser lixiviada. De forma contrária, quando a umidade inicial é baixa (reduzida de 90 \%), menor é o volume de solução disponível e, conseqüentemente, maior o efeito da lavagem nos anéis superiores.

\subsection{Análise de sensibilidade do modelo supondo a aplicação de uma solução de concentração superior à concentração do solo}

Nessa etapa serão discutidos os resultados obtidos pela simulação, aplicando-se uma solução com concentração de $2.000 \mathrm{mg} \mathrm{L}^{-1}$ de nitrato a qual é superior àquela presente no Solo 2 que é de $531,7 \mathrm{mg} \mathrm{L}^{-1}$. Em uma análise geral, observou-se que o incremento da concentração de nitrato na solução, apenas teve influência na simulação da concentração de nitrato ao longo da coluna, não causando nenhuma variação no perfil simulado para a umidade. Portanto serão discutidos apenas aspectos relacionados com o perfil da concentração de nitrato. 


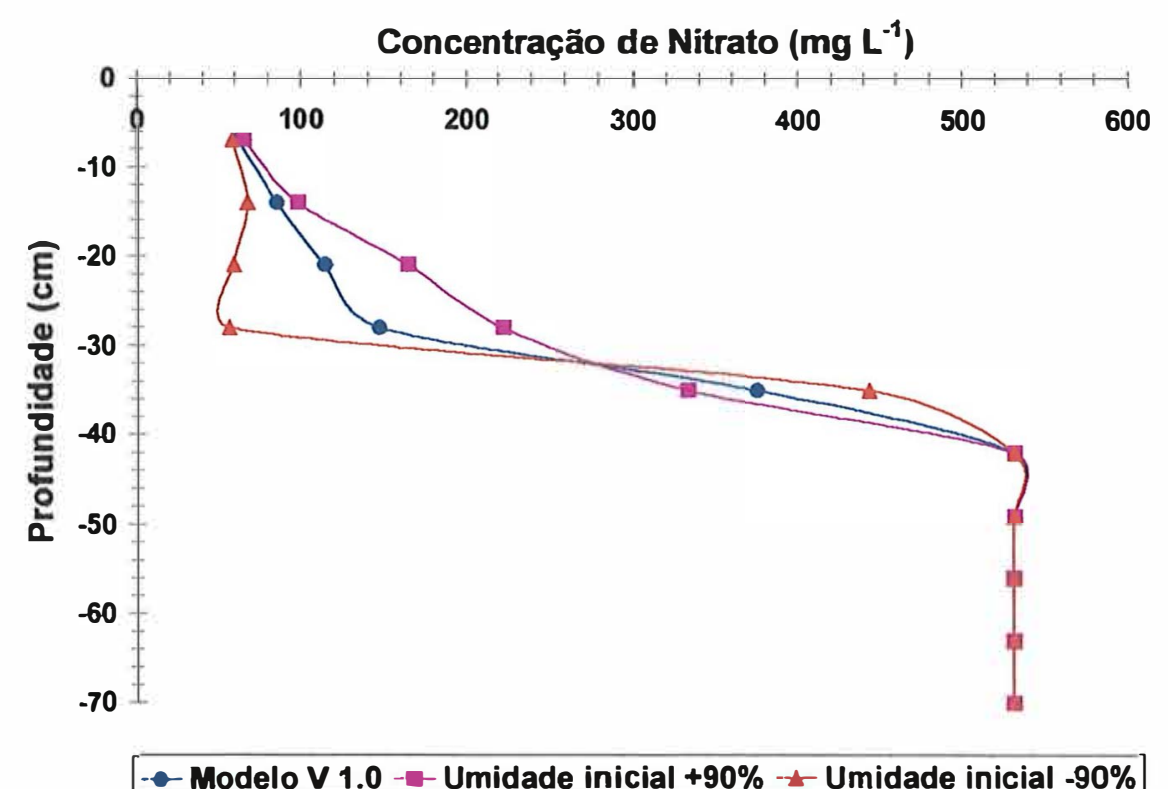

Figura 26 - Representação do perfil de concentração de nitrato simulado para o Solo 2 comparado com outras duas simulações aumentando e reduzindo de $90 \%$ o parâmetro de entrada umidade inicial do solo que preenche a coluna

Os valores que serão discutidos a seguir estão relacionados com a condutividade hidráulica e umidade volumétrica do solo saturado. Como já foi observado anteriormente, o modelo apresentou os maiores erros de simulação da concentração de nitrato em relação à redução dos valores da umidade volumétrica do solo saturado e para variações negativas da condutividade hidráulica do solo saturado. Isso deve-se ao fato de que o nitrato acompanha a dinâmica da solução no solo.

Pode-se observar também que o erro padrão atingiu o seu valor máximo para uma redução da umidade volumétrica do solo saturado em - $80 \%$, e apresentou uma redução quando aplicou-se uma redução de - $90 \%$. No caso da condutividade hidráulica do solo saturado, nota-se que as variações tanto positivas quanto negativas acarretaram erros que permaneceram constantes. Somente a partir de variações negativas de $-80 \%$, o modelo mostrou-se mais sensível (Figura 27). 


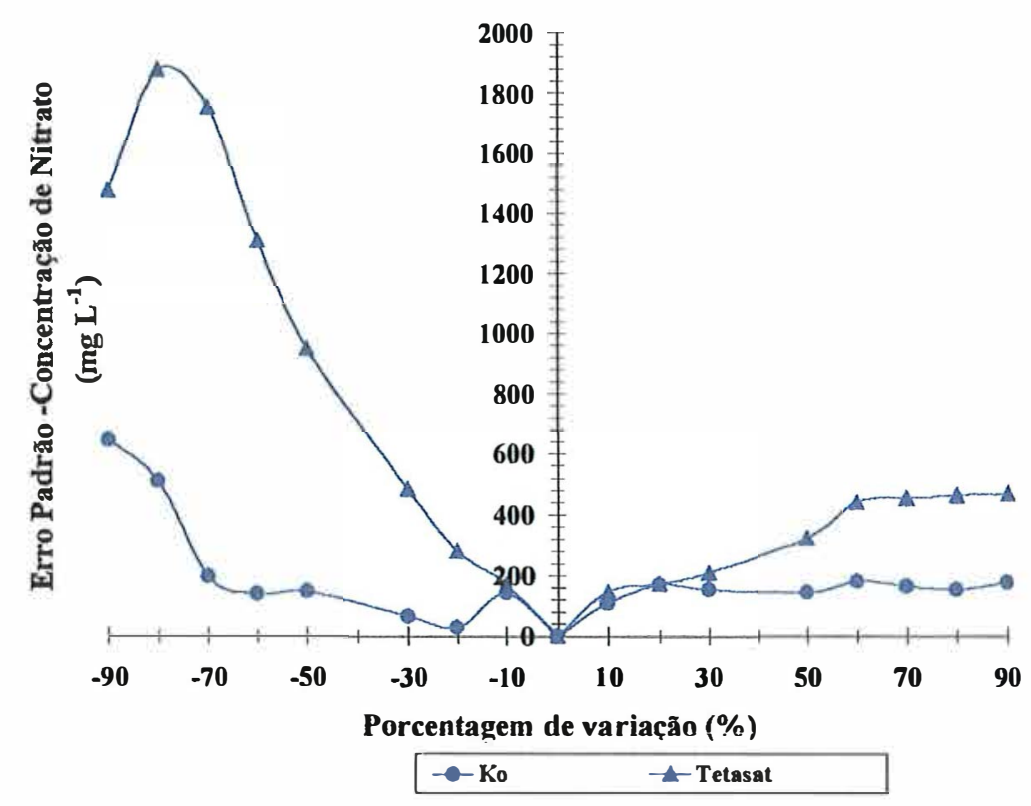

Figura 27 - Representação esquemática da análise de sensibilidade do modelo em relação à simulação da concentração de nitrato, aplicando de $-90 \%$ a +90 \% de variação nos parâmetros de entrada, condutividade hidráulica do solo saturado e umidade volumétrica do solo saturado, aplicando-se uma solução de $2.000 \mathrm{mg} \mathrm{L}^{-1}$, para o Solo 2

O comportamento da dinâmica da solução do solo influenciando no perfil de concentração de nitrato pode ser observado claramente pela simulação, na qual as variações negativas da condutividade hidráulica do solo saturado são responsáveis por um acúmulo expressivo nos anéis superiores, praticamente o dobro da concentração de nitrato. Para as variações positivas desse parâmetro, o modelo apresentou comportamento semelhante na simulação realizada com os dados originais (Figura 28).

As variações provocadas no parâmetro umidade volumétrica do solo saturado, evidenciam que nas simulações realizadas com reduções de $-90 \%$, ocorreu um acúmulo da concentração de nitrato, principalmente a $60 \mathrm{~cm}$ de profundidade. Esse fato deve-se à alta redução do parâmetro umidade volumétrica do solo saturado, o qual propiciou um avanço da solução. Como o solo já possuía uma concentração inicial de nitrato, esse acúmulo aconteceu exatamente até aonde a frente de molhamento atingiu na coluna. Com esses valores, observa-se claramente que há uma estreita relação entre a movimentação do nitrato com a dinâmica da solução na coluna (Figura 29). 


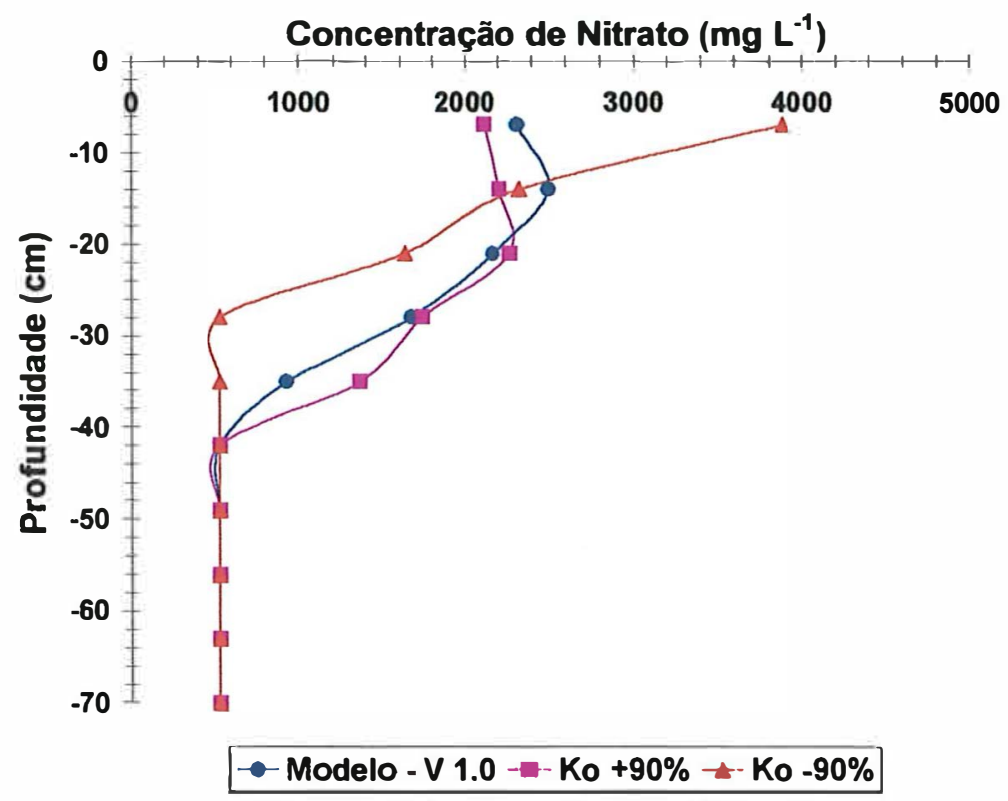

Figura 28 - Representação do perfil de concentração de nitrato simulado para o Solo 2, aplicando-se uma solução de $2.000 \mathrm{mg} \mathrm{L}^{-1}$, comparado com outras duas simulações aumentando e reduzindo de $90 \%$ o parâmetro de entrada condutividade hidráulica do solo saturado

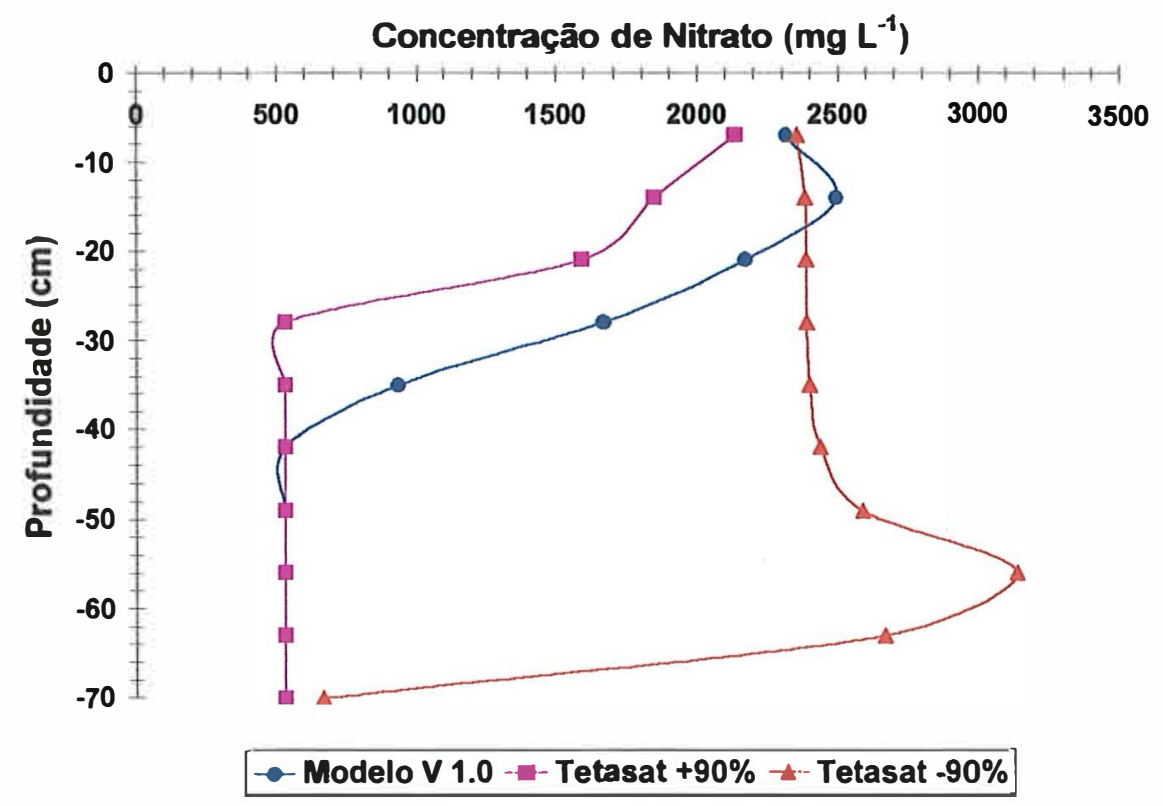

Figura 29 - Representação do perfil de concentração de nitrato simulado para o Solo 2 , aplicando-se uma solução de $2.000 \mathrm{mg} \mathrm{L}^{-1}$, comparado com outras duas simulações aumentando e reduzindo de 90 \% o parâmetro de entrada umidade volumétrica do solo saturado 
Com relação ao fator de retardamento observa-se que os maiores erros padrões foram obtidos quando aplicaram-se variações negativas para esse parâmetro. Com variações positivas os erros foram muito menores do que na situação anterior. As variações negativas do fator de retardamento atingiram os maiores valores quando se reduziu em torno de 90 \% a grandeza desse parâmetro (Figura 30 ).

Já em relação ao parâmetro dispersividade o modelo foi pouco sensível, tanto a variações positivas quanto às negativas.

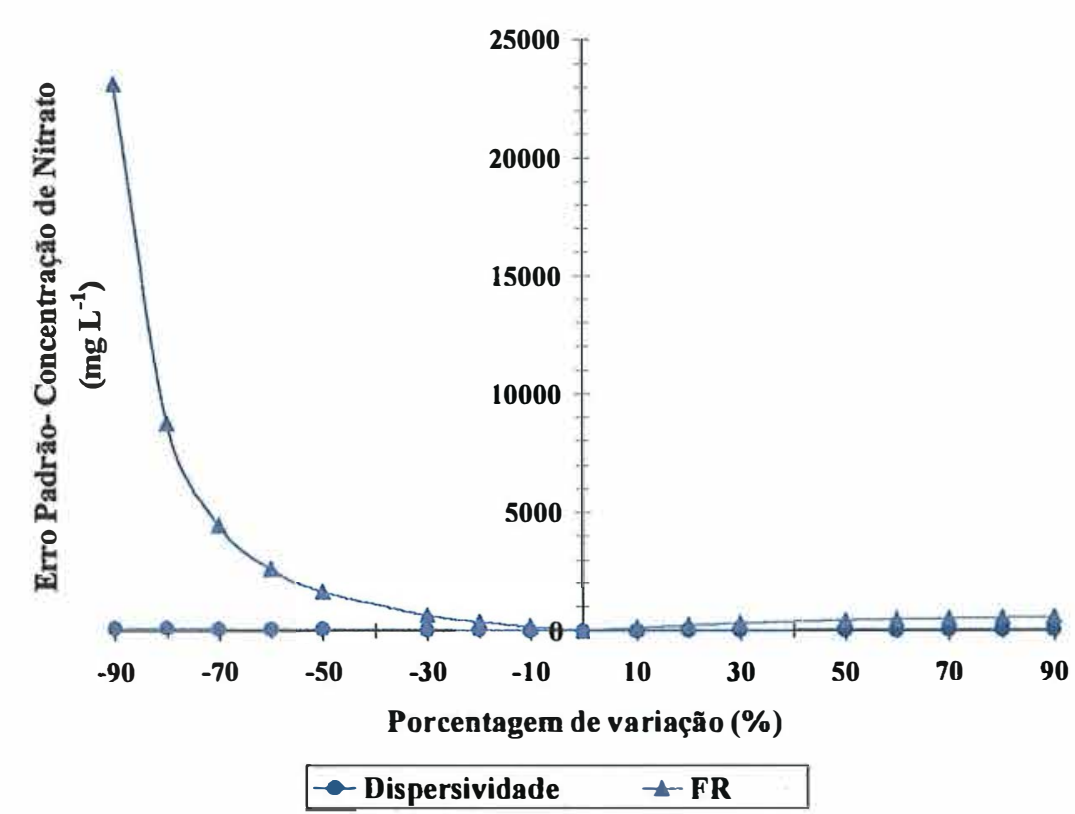

Figura 30 - Representação esquemática da análise de sensibilidade do modelo em relação à simulação da concentração de nitrato, aplicando de $-90 \%$ a +90 \% de variação nos parâmetros de entrada, dispersividade e fator de retardamento, aplicando-se uma solução de $2.000 \mathrm{mg} \mathrm{L}^{-1}$, para o Solo 2

No caso da dispersividade, confrontando-se com o perfil de concentração de nitrato (Figura 31), observa-se que realmente não houve praticamente nenhuma variação sensível.

Para o fator de retardamento, pode-se observar claramente pelo perfil de concentração do nitrato, principalmente quando reduziu-se o seu valor de $90 \%$, que houve um acréscimo elevado da concentração, atingindo valores por volta de $70.000 \mathrm{mg}$ $\mathrm{L}^{-1}$ aos $35 \mathrm{~cm}$ de profundidade na coluna (Figura 32). Evidencia-se que com essa 
redução desse parâmetro, ao longo do tempo houve um acúmulo do nitrato na solução do solo, principalmente nessa região da coluna, o que provocou o aumento no erro padrão na simulação conforme visto anteriormente.

Analisando-se os erros padrões devidos às variações provocadas nos parâmetros de entrada vazão do gotejador e umidade inicial do solo que preencheu a coluna, observou-se que os maiores valores de erro padrão alcançados foram relativos à vazão do gotejador, tanto para variações positivas quanto negativas, apresentando uma ordem de grandeza no erro padrão semelhante (Figura 33). De uma maneira geral, as variações provocadas na vazão do gotejador foram mais relevantes do que as variações provocadas à umidade inicial do solo. No caso da umidade inicial do solo que preencheu a coluna, praticamente não houve nenhuma variação expressiva, tanto para variações positivas quanto variações negativas (Figura 33).

Pela Figura 34, o perfil da concentração de nitrato auxilia na compreensão dos valores obtidos nos erros padrões, pois quando simulou-se a concentração de nitrato com um incremento da vazão do gotejador de $+90 \%$, houve um acréscimo expressivo na concentração de nitrato na coluna, principalmente para a profundidade de $35 \mathrm{~cm}$. Para valores reduzidos da vazão do gotejador, o que implica em uma baixa aplicação da solução de nitrato no solo, apenas o primeiro anel apresentou concentração próxima daquela aplicada pela solução e a partir do segundo anel, o perfil retorna praticamente para a condição inicial do solo, ou seja, por volta de $531,7 \mathrm{mg} \mathrm{L}^{-1}$.

Diante das variações provocadas para o parâmetro umidade inicial do solo que preenche a coluna, observou-se que acréscimos e reduções nos seus valores não foram suficientes para provocar uma variação na simulação da concentração de nitrato pelo modelo em relação aos dados originais. Apenas observou-se um ligeiro acréscimo da concentração de nitrato, principalmente para os anéis superiores quando se reduziu a umidade inicial do solo em $90 \%$ (Figura 35 ). 


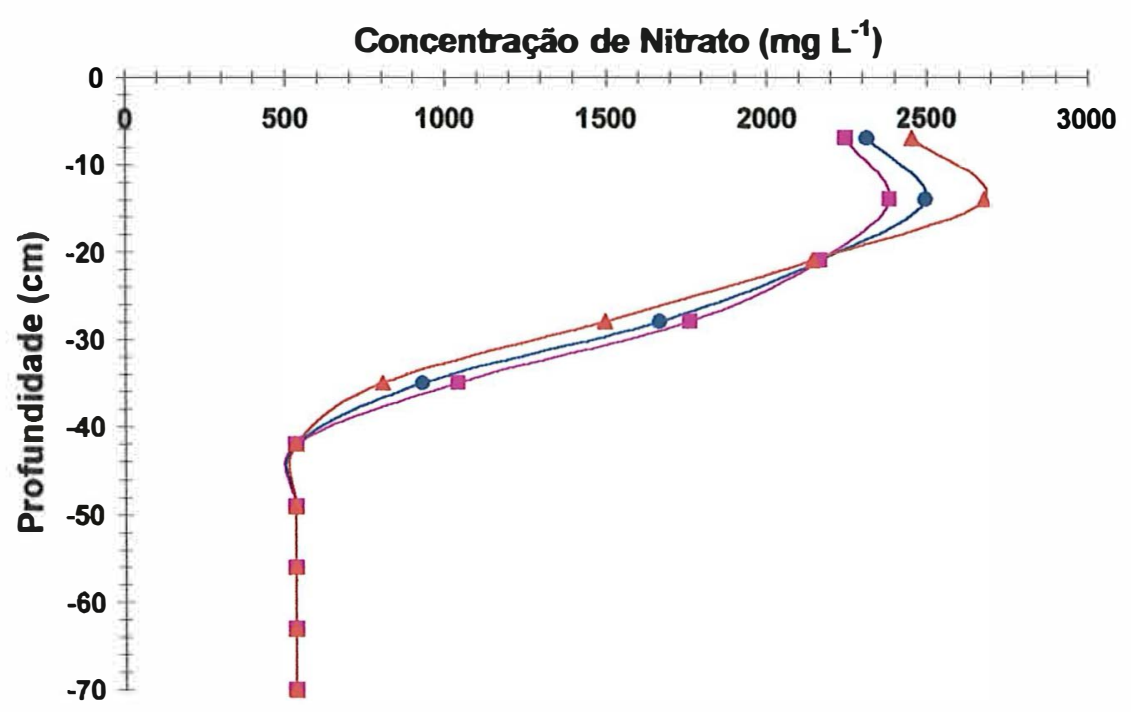

- Modelo V 1.0 - Dispersividade $+90 \%$ - Dispersividade $-90 \%$

Figura 31 - Representação do perfil de concentração de nitrato simulado para o Solo 2 , aplicando-se uma solução de $2.000 \mathrm{mg} \mathrm{L}^{-1}$, comparado com outras duas simulações aumentando e reduzindo de 90 \% o parâmetro de entrada dispersividade

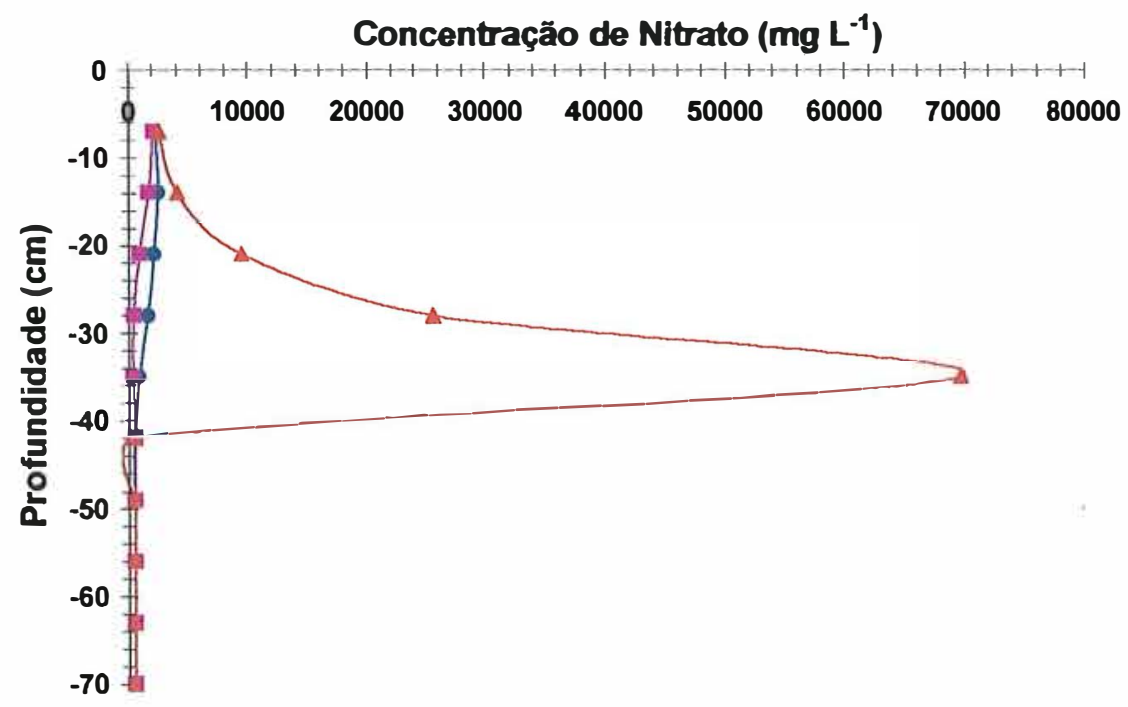

Modelo V $1.0-R+90 \%+-R-90 \%$

Figura 32 - Representação do perfil de concentração de nitrato simulado para o Solo 2, aplicando-se uma solução de $2.000 \mathrm{mg} \mathrm{L}^{-1}$, comparado com outras duas simulações aumentando e reduzindo de $90 \%$ o parâmetro de entrada fator de retardamento 


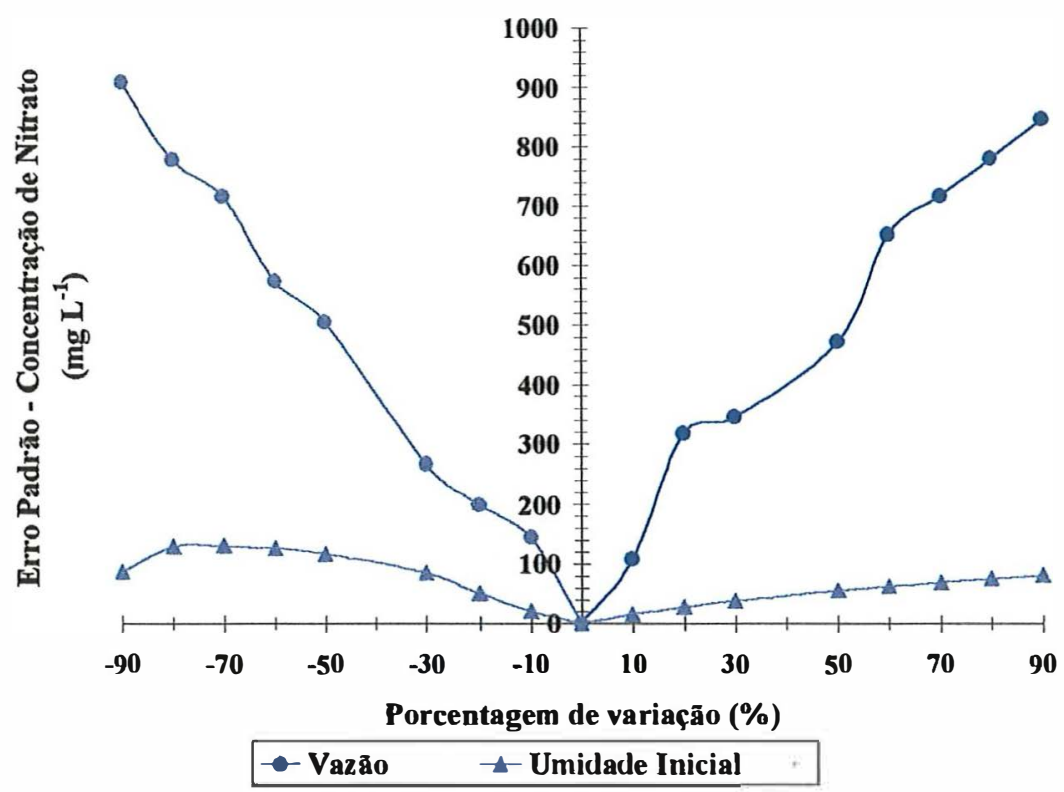

Figura 33 - Representação esquemática da análise de sensibilidade do modelo em relação à simulação da concentração de nitrato, aplicando de $-90 \%$ a +90 \% de variação nos parâmetros de entrada, vazão do gotejador e umidade inicial do solo que preencheu a coluna, aplicando-se uma solução de $2.000 \mathrm{mg} \mathrm{L}^{-1}$, para o Solo 2

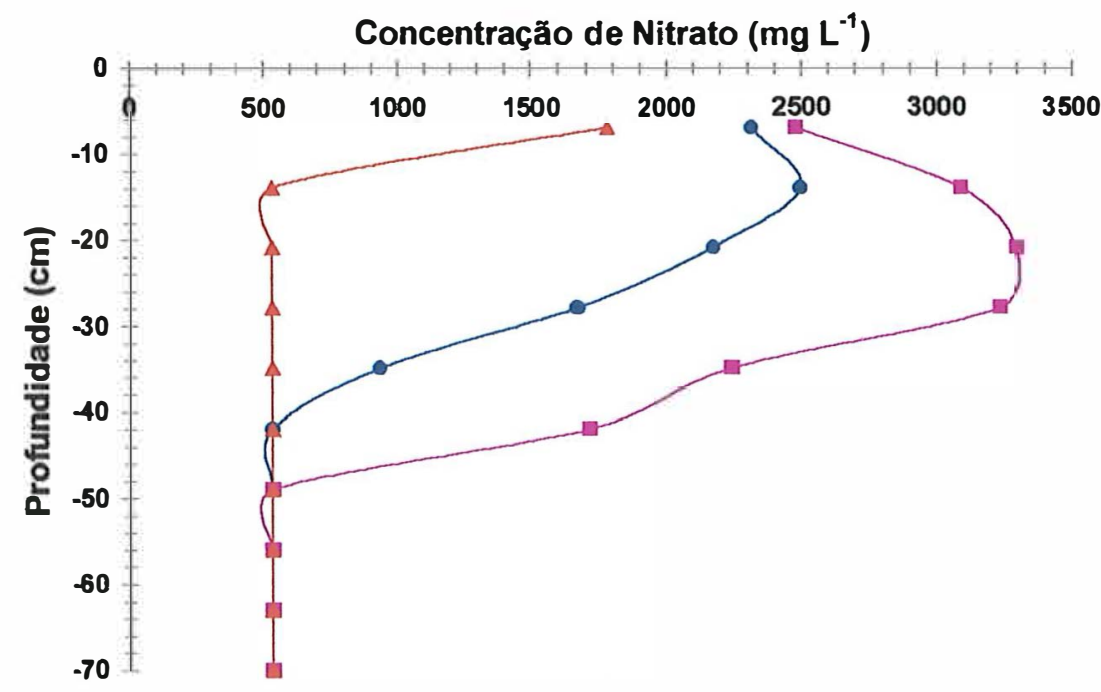

- Modelo V $1.0-$ Vazão $+90 \%-$ Vazão $-90 \%$

Figura 34 - Representação do perfil de concentração de nitrato simulado para o Solo 2, aplicando-se uma solução de $2.000 \mathrm{mg} \mathrm{L}^{-1}$, comparado com outras duas simulações aumentando e reduzindo de 90 \% parâmetro de entrada vazão do gotejador 


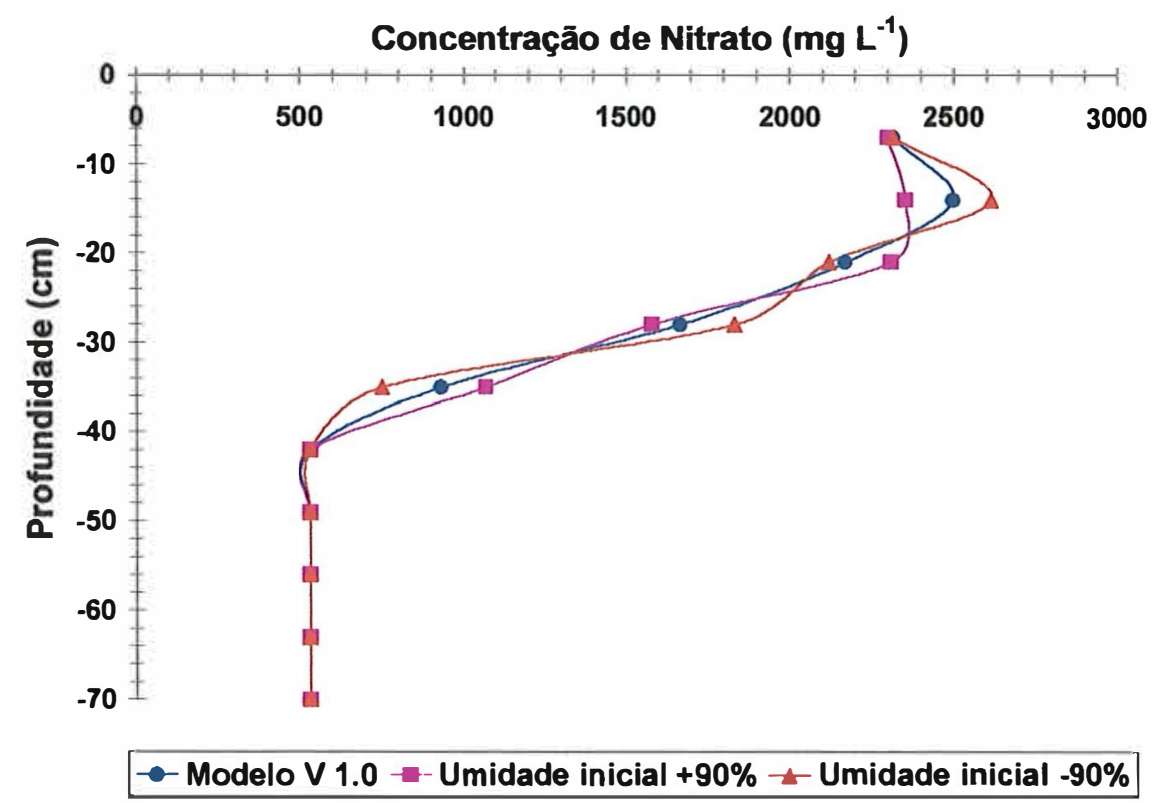

Figura 35 - Representação do perfil de concentração de nitrato simulado para o Solo 2, aplicando-se uma solução de $2.000 \mathrm{mg} \mathrm{L}^{-1}$, comparado com outras duas simulações aumentando e reduzindo de $90 \%$ o parâmetro de entrada umidade inicial do solo que preenche a coluna

\subsection{RECOMENDAÇÕES FINAIS}

O modelo mostrou ser uma ferramenta importante para predizer o deslocamento da concentração de nitrato e permitiu levantar algumas sugestões de trabalhos futuros tais como:

- Na etapa de validação, aplicar uma solução de nitrato não no sentido de lixiviação mas de acumulação desse componente no solo;

- Aplicar métodos numéricos para a simulação em direções bidimensionais e tridimensionais do movimento de nitrato prevendo a formação de bulbos e faixas molhadas; e

- Envolver outros elementos do meio, tais como, a extração do nitrato pelas plantas, reação química do nitrato com outros elementos presentes no solo, dentre outros. 


\section{CONCLUSÕES}

Os resultados obtidos pelas simulações da concentração de nitrato na coluna, bem como o perfil de umidade no solo que preencheu a coluna, permitiram as seguintes conclusões:

- O modelo permitiu prever a tendência do movimento unidirecional do nitrato em colunas verticais de solo não saturado, e também a distribuição do perfil de umidade;

- Quanto à simulação do perfil de umidade do solo o modelo mostrou-se bastante sensível a variações na umidade de saturação, na vazão do emissor e na condutividade hidráulica do solo saturado;

- Variações no fator de retardamento e na dispersividade não interferiram na simulação do perfil de umidade do solo;

- Quanto à simulação da concentração de nitrato na coluna o modelo mostrou-se bastante sensível às variações na umidade de saturação, na vazão do emissor e a variações negativas na condutividade hidráulica do solo saturado e no fator de retardamento; $\mathrm{e}$

- Variações na dispersividade tiveram um pequeno efeito sobre a simulação do perfil de concentração de nitrato. 


\section{REFERÊNCIAS BIBLIOGRÁFICAS}

AMERICAN PUBLIC HEALTH ASSOCIATION. American Water Works Association and Water Pollution Control Federation. Standard methods for the examination of water and wastewater. 14. ed. Washington, 1976. $1193 \mathrm{p}$.

BARTHOLOMEW, W.V.; CLARK, F.E. Soil nitrogen. Madison: American Society of Agronomy, $1965.615 \mathrm{p}$.

BEAR, J. Dynamics of fluids in porous media. New York: American Elsevier, 1972. $764 \mathrm{p}$.

BIGGAR, J.W.; NIELSEN, D.R. Miscible displacement: II. Behavior of tracers. Soil Science Society of America, v.26, n.2, p.125-128, 1962.

BLACKMER, A. M. Losses and transport of nitrogen from soils. In: D'ITRI, F.M.; WOLFSON, L. M. (Ed.) Rural groundwater contamination. Chelsea: Lewis Publ., 1987, p. 85-103.

BOTREL, T.A. Simulação da distribuição espacial da água em solo irrigado com gotejador. Piracicaba, 1988. 61p. Tese (Doutorado) - Escola Superior de Agricultura "Luiz de Queiroz", Universidade de São Paulo.

BRANDT, A.; BRESLER, E; DINER, N.; BEM-ASHER, I.; HELLER, J.; GOLDBERG, D. Infiltration from a trickle source. I Mathematical models. Soil Science Society of America Proceedings, v.35, p.675-682, 1971.

BRESLER, E. Two-dimensional transport of solutes during nonsteady infiltration from a trickle source. Soil Science Society of America Proceedings, v.39, p.604-613, 1975 .

BRESLER, E. Convective and pore scale dispersive solute transport in unsuturated heterogeneous fields. Water Resources Research, v.37, n.6, p.1683-1693, 1981.

BRESLER, E.; McNEAL, B.L.; CARTER, D.L. Saline and sodic soils: principledynamics-modeling. New York: Springer Verlag, 1982. $236 \mathrm{p}$. 
BROOKS, R.H.; COREY, A.T. Hydraulic properties of porous media. Fort Collins: Colorado State University, 1964. 27 p. ( Hydrology Paper, 3).

CLEMENTE, R.S.; PRASHER, S.O.; BARRINGTON, S.F. Pestafade, a new pesticide fate and transport model: model development and verification. Transactions of the ASAE, v.36, n.2, p.357-367, 1993.

COSTA, S.N. Desenvolvimento de um modelo numérico para simulação do transporte de água e solutos no solo sob condições de escoamento não permanente na vertical. Viçosa, 1998. 153 p. Tese (Doutorado) - Universidade Federal de Viçosa.

DODDS, G.T.; MANDRAMOOTOO, C.A.; SEREM, V.K. Predicting nitrate-N leaching under different tillage systems using leachm and ntrm. Transactions of the ASAE, v.41, n.4, p.1025-1034, 1998.

FERREIRA, P.A.; MARTINEZ, M.A. Movimento e modelagem de sais no solo. In: GHEYI, H.R.; QUEIROZ, J.E.; MEDEIROS, J.F. de (Ed.) Manejo e controle da salinidade na agricultura irrigada. Campina Grande: UFPB, SBEA, 1997, cap.6, p.171-207.

GENUCHTEN, M. T. van. A closed-form equation for predicting the hydraulic conductivity of unsaturated soils. Soil Science Society of America Journal, v.44, n.3, p.892-898, 1980.

GENUCHTEN, M. T. van.; WIERENGA, P.J. Solute dispersion coefficients and retardation factors. In: BLACK, C.A. (Ed.) Methods of soil analysis. Madison: Soil Science Society of America, 1986. pt. 1: Physical and mineralogical methods: p.1025-1054. (American Society of Agronomy, 9)

HARLEMAN, D.R.F; RUMER, R.R. The dynamics of salt-water intrusion in porous media. Cambridge: MIT Press, 1962. 50 p. (Civil Engineering Department, 55).

HLLEL, D. Fundamentals of soil physics. New York: Academic Press, 1980. 413 p.

HOLDEN, N.M.; ROOK, J.A.; SCHOLEFIELD D. Testing the performance of a unidimensional solute transport model (LEACHC) using response surface methodology. Geoderma, v.69, p.157-173, 1996.

HUTSON, J.L.; WAGENET, R.J. LEACHM: Leaching estimation and chemistry model: a process-based model of water and solute movement, transformations, plant uptake and chemical reactions in the unsaturated zone; version 3.0. New York: Cornell University, 1992. $131 \mathrm{p}$. 
KIRDA, C.; NIELSEN, D.R.; BIGGAR, J.W. Simultaneous transport of chloride and water during infiltration. Soil Science Society of America Proceedings, v.37, n.3, p.339-345, 1973.

KUMAR, A.; KANWAR, R.S. Development and evaluation of DRAINAGE-N model for predicting $\mathrm{NO}_{3}-\mathrm{N}$ concentrations and losses in subsurface drainage water. Transactions of the ASAE, v.40, n.4, p.911-919, 1997.

KUMAR, A.; KANWAR, R.S; AHUJA, L.R. RZWQM simulation of nitrate concentrations in subsurface drainage from manured plots. Transactions of the ASAE, v.41, n.3, p.587-597, 1998.

LIBARDI, P.L. Dinâmica da água no solo. Piracicaba: USP, PCLQ, 1995, 497p.

MARTINEZ, M.A. Modeling subsurface drainage in clermont silt loam using finite element technique. West Lafayette, 1989. 173 p. Thesis (Ph.D) - Purdue University.

MELLO, F.A.F.; BRASIL SOBRINHO, M.O.C.; ARZOLLA, S.; SILVEIRA, R.I.; NETTO, A.C.; KIEHL, J. Fertilidade do solo. São Paulo: Ed. Distribuidora, 1984. 400 p.

MONTAS, H.J.; EIGEL, J.D.; ENGEL, B.A.; HAGHIGHI, K. Deterministic modeling of solute transport in soils with preferential flow pathways - Part 1. Model development. Transactions of the ASAE, v.40, n.5, p.1245-1256, 1997.

MONTAS, H.J.; EIGEL, J.D.; ENGEL, B.A.; HAGHIGHI, K. Deterministic modeling of solute transport in soils with preferential flow pathways - Part 2. Model validation. Transactions of the ASAE, v.40, n.5, p.1257-1265, 1997.

MUALEM, Y. A new model for predicting the hydraulic conductivity of unsaturated porus media. Water Resources Research, v.12, n.3, p.513-522, 1976.

NIELSEN, D.R.; BIGGAR, J.W. Miscible displacement in soils: I. Experimental Information. Soil Science Society of America, v.25, n. 1, p. 1-5, 1961.

NIELSEN, D.R.; BIGGAR, J.W. Miscible displacement: III. Theoretical Considerations. Soil Science Society of America, v.26, n.3, p.216-221, 1962.

OLIVEIRA, L.F.C. Modelo para transporte de solutos no solo e no escoamento superficial. Viçosa, 1999. 171 p. Tese (Doutorado) - Universidade Federal de Viçosa.

PREVEDELLO, C.L. Física do solo com problemas resolvidos. Curitiba: SAEAFS, 1996. 446p. 
REICHARDT, K. Dinâmica da matéria e da energia em ecossistemas. 2. ed. Piracicaba: ESALQ, 1996. 513p.

RICHARDS, L.A. (Ed.) Diagnosis and improvement of saline and alkali soils. Washington: United State Salinity Laboratory, 1954. 160 p. (USDA. Agriculture Handbook, 60).

SANTOS, C.R. Movimento vertical de nitrato, amônio, cloreto e potássio em colunas de solo irrigado. Viçosa, 1986. 66p. Dissertação (Mestrado em Engenharia Agrícola) Universidade Federal de Viçosa.

SCHWAB, G. O. Soil and water conservation enginnering. 2. ed. New York: John Wiley, 1966. $683 \mathrm{p}$.

SCHWAB, G. O.; FANGMEIER, D. D. Soil and water conservation enginnering. 4. ed. New York: John Wiley, 1993. 507 p.

SHIRMOHAMMADI, A. Simulation of nitrogen and phosphorus leaching in a structured soil using GLEAMS and a new submodel, "PARTLE". Transactions of the ASAE, v.41, n.2, p.353-360, 1998.

SINGH, P.; KANWAR, R.S. Simulating $\mathrm{NO}_{3}-\mathrm{N}$ transport to subsurface drain flows as affected by tillage under contiuous corn using modified RZWQM. Transactions of the ASAE, v.38, n.2, p.499-506, 1995.

STONE, K.C.; HUNT, P.G.; JOHNSON, M.H.; COFFEY, S.W. GLEAMS simulation of groundwater nitrate-N from row crop and swine wastewater spray fields in the eastern coastal plain. Transactions of the ASAE, v.41, n.1, p.51-57, 1998.

VOGEL, T.; GENUCHTEN, M. T. van; CISLEROVA, M. Effect of the shape of the soil hydraulic functions near saturation on variably-saturated flow predictions. Advances in Water Resources, 24, p.133-144, 2001.

VOGEL, T.; HUANG, K.; ZHANG, R.; GENUCHTEN, M. T. van. The HYDRUS code for simulating water flow, solute transport and heat movement in variablysaturated porous media, version 5.0. Riverside: U.S Salinity Laboratory, 1996. 131 p. (Research Report, 140). 
APÊNDICES 


\section{1) Resultados dos parâmetros de transporte obtidos pelo modelo CXTFIT}

\section{1) LATOSSOLO VERMELHO AMARELO Fase Arenosa, Série "Sertãozinho"}

a) Valores dos parâmetros utilizados na simulação

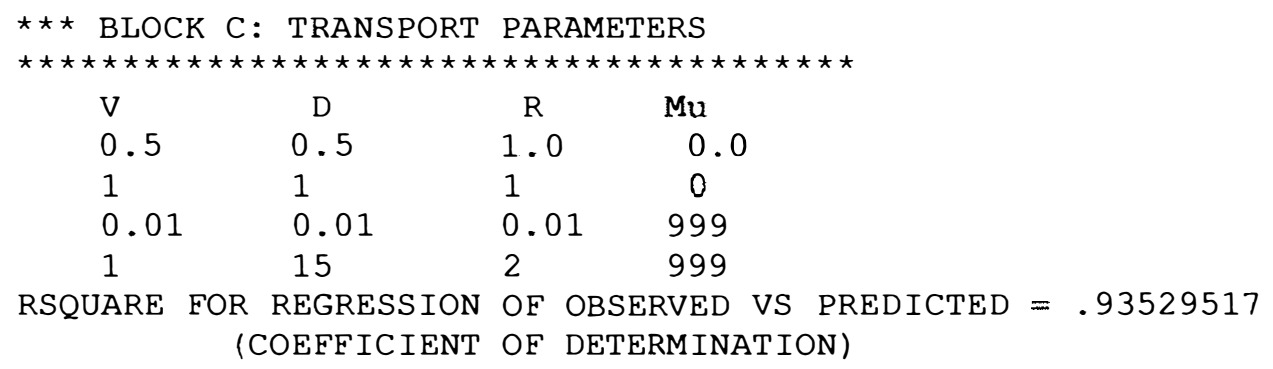


NON-LINEAR LEAST SQUARES ANALYSIS, FINAL RESULTS

\begin{tabular}{|c|c|c|c|c|c|}
\hline \multirow[b]{2}{*}{ NAME } & \multirow[b]{2}{*}{ VALUE } & \multirow[b]{2}{*}{ S.E.COEFF. T-VALUE } & \multicolumn{2}{|c|}{ 95\% CONFIDENCE } & LIMITS \\
\hline & & & LOWER & & UPPER \\
\hline $\mathrm{V} \ldots$ & $.1000 \mathrm{E}+01$ & $.1682 \mathrm{E}+02.5945 \mathrm{E}-01$ & $-.3372 \mathrm{E}+02$ & .35 & $572 E+02$ \\
\hline D.... & $.1249 \mathrm{E}+02$ & $.2020 \mathrm{E}+03.6183 \mathrm{E}-01$ & $-.4045 E+03$ & & $95 E+0$ \\
\hline R. . & $.1386 \mathrm{E}+01$ & $.2349 \mathrm{E}+02$ & $711 E+02$ & & \\
\hline
\end{tabular}

c) Segunda tentativa

Observações: Diminuiu o $r^{2}$ e os parâmetros atingiram o valor máximo da condição de contorno

\begin{tabular}{|c|c|c|c|}
\hline V & D & $\mathrm{R}$ & $\mathrm{Mu}$ \\
\hline 0.2 & 0.2 & 1.0 & 0.0 \\
\hline 1 & 1 & 1 & 0 \\
\hline 0.1 & 0.1 & 0.01 & 999 \\
\hline 1 & 15 & 2 & 999 \\
\hline
\end{tabular}

RSQUARE FOR REGRESSION OF OBSERVED VS PREDICTED $=.66284069$ (COEFFICIENT OF DETERMINATION)

MEAN SQUARE FOR ERROR (MSE) $=.3127 \mathrm{E}-01$

NON-LINEAR LEAST SQUARES ANALYSIS, FINAL RESULTS

\begin{tabular}{|c|c|c|c|c|}
\hline & & & \multicolumn{2}{|c|}{ 95\% CONFIDENCE LIMITS } \\
\hline NAME & VALUE & S.E.COEFE. T-VALUE & LOWER & UPPER \\
\hline V.... & $.1000 \mathrm{E}+01$ & $.7897 \mathrm{E}+02.1266 \mathrm{E}-01$ & $-.1620 \mathrm{E}+03$ & $1640 \mathrm{E}+03$ \\
\hline D.... & $.1500 \mathrm{E}+02$ & $.1155 \mathrm{E}+04.1299 \mathrm{E}-01$ & $-.2369 E+04$ & $2399 E+04$ \\
\hline $\mathrm{R} \ldots$ & $.2000 \mathrm{E}+01$ & $.1591 \mathrm{E}+03.1257 \mathrm{E}-01$ & $-.3263 E+03$ & $3303 E+03$ \\
\hline
\end{tabular}

d) Terceira tentativa

Observações: O fator de retardamento (R) ficou próximo de 1 mas diminuiu o $r^{2}$ e o parâmetro $D$ atingiu o valor máximo da condição de contorno

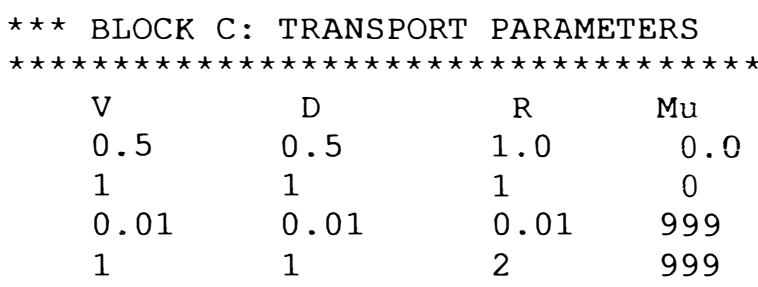


RSQUARE FOR REGRESSION OF OBSERVED VS PREDICTED $=.76223017$ (COEFFICIENT OF DETERMINATION)

MEAN SQUARE FOR ERROR (MSE) $=.2205 \mathrm{E}-01$

NON-LINEAR LEAST SQUARES ANALYSIS, FINAL RESULTS

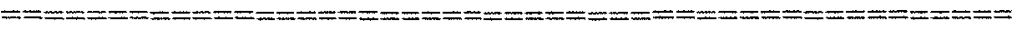

\begin{tabular}{lcccc} 
& & & \multicolumn{2}{c}{$95 \%$ CONFIDENCE LIMITS } \\
NAME & VALUE & S.E.COEFF. T-VALUE & LOWER & UPPER \\
V... & $.5402 \mathrm{E}+00$ & $.7337 \mathrm{E}+01.7362 \mathrm{E}-01$ & $-.1460 \mathrm{E}+02$ & $.1568 \mathrm{E}+02$ \\
D... & $.1000 \mathrm{E}+01$ & $.1164 \mathrm{E}+02.8590 \mathrm{E}-01$ & $-.2303 \mathrm{E}+02$ & $.2503 \mathrm{E}+02$ \\
R... & $.8501 \mathrm{E}+00$ & $.1159 \mathrm{E}+02.7333 \mathrm{E}-01$ & $-.2308 \mathrm{E}+02$ & $.2478 \mathrm{E}+02$
\end{tabular}

\section{2) LATOSSOLO VERMELHO AMARELO Fase Areno-Argilosa}

a) Valores dos parâmetros utilizados na simulação

Observações: Essa situação ficou melhor do que a situação atual, o parâmetro $D$ não atingiu o valor da condição de contorno $O R$ ficou mais próximo de 1 e o $r^{2}$ atingiu o maior valor das tentativas

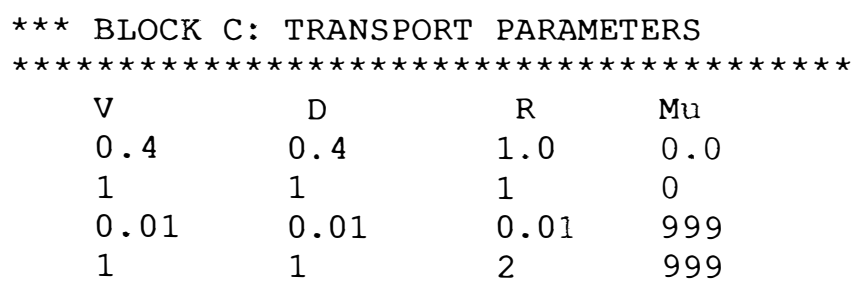

RSQUARE FOR REGRESSION OF OBSERVED VS PREDICTED $=.98276232$ (COEFFICIENT OF DETERMINATION)

MEAN SQUARE FOR ERROR (MSE) $=.2159 \mathrm{E}-02$

NON-LINEAR LEAST SQUARES ANALYSIS, FINAL RESULTS

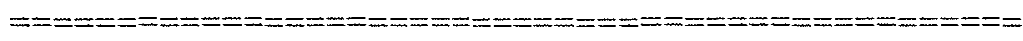

\begin{tabular}{lccccc} 
& & & & & \\
NAME & VALUE & \multicolumn{2}{c}{ S.E.COEFF. T-VALUE } & LOWER & UPENCE LIMITS \\
V... & $.4649 \mathrm{E}+00$ & $.2700 \mathrm{E}+01$ & $.1722 \mathrm{E}+00$ & $-.5049 \mathrm{E}+01$ & $.5979 \mathrm{E}+01$ \\
$\mathrm{D} \ldots$ & $.9996 \mathrm{E}+00$ & $.5147 \mathrm{E}+01$ & $.1942 \mathrm{E}+00$ & $-.9513 \mathrm{E}+01$ & $.1151 \mathrm{E}+02$ \\
R... & $.1088 \mathrm{E}+01$ & $.6347 \mathrm{E}+01.1715 \mathrm{E}+00$ & $-.1188 \mathrm{E}+02$ & $.1405 \mathrm{E}+02$
\end{tabular}


b) Primeira tentativa Observações: $O$ parâmetro $D$ atingiu o valor da condição de contorno mas o $R$ ficou próximo de $l$ e o $r^{2}$ atingiu o maior valor

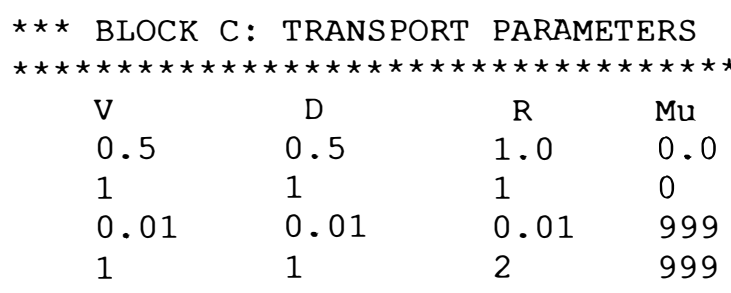

RSQUARE FOR REGRESSION OF OBSERVED VS PREDICTED $=.98173243$ (COEFFICIENT OF DETERMINATION)

MEAN SQUARE FOR ERROR (MSE) $=.2288 \mathrm{E}-02$

NON-LINEAR LEAST SQUARES ANALYSIS, FINAL RESULTS

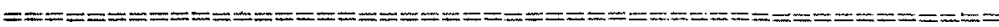

$\begin{array}{lccccc} & & & & & \\ \text { 95\% CONFIDENCE LIMITS } \\ \text { NAME } & \text { VALUE } & \text { S.E.COEFF. T-VALUE } & \text { LOWER } & \text { UPPER } \\ \text { V.... } & .5311 \mathrm{E}+00 & .2831 \mathrm{E}+01 & .1876 \mathrm{E}+00 & -.5251 \mathrm{E}+01 & .6313 \mathrm{E}+01 \\ \mathrm{D} \ldots . & .1000 \mathrm{E}+01 & .4647 \mathrm{E}+01 & .2152 \mathrm{E}+00 & -.8491 \mathrm{E}+01 & .1049 \mathrm{E}+02 \\ \text { R... } & .1242 \mathrm{E}+01 & .6650 \mathrm{E}+01.1868 \mathrm{E}+00 & -.1234 \mathrm{E}+02 & .1483 \mathrm{E}+02\end{array}$

C) Segunda tentativa

Observações: Essa situação não ficou boa, os parâmetros atingiram o valor da condição de contorno e o $r^{2}$ diminuiu

\begin{tabular}{|c|c|c|c|}
\hline V & D & $\mathrm{R}$ & $\mathrm{Mu}$ \\
\hline 1.0 & 1.0 & 1.0 & 0.0 \\
\hline 1 & 1 & 1 & 0 \\
\hline 0.1 & 0.1 & 0.1 & 999 \\
\hline 1 & 1 & 2 & 999 \\
\hline
\end{tabular}

RSQUARE FOR REGRESSION OF OBSERVED VS PREDICTED $=.84380051$ (COEFFICIENT OF DETERMINATION)

MEAN SQUARE FOR ERROR (MSE) $=.1956 \mathrm{E}-01$

NON-LINEAR LEAST SQUARES ANALYSIS, FINAI: RESULTS

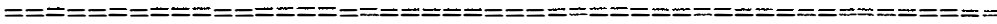

\begin{tabular}{lccccc} 
& & & \multicolumn{2}{c}{ 95\% CONFIDENCE LIMITS } \\
NAME & VALUE & S.E.COEFF. T-VALUE & LOWER & UPPER \\
V.... & $.1000 \mathrm{E}+01$ & $.9464 \mathrm{E}+01$ & $.1057 \mathrm{E}+00$ & $-.1833 \mathrm{E}+02$ & $.2033 \mathrm{E}+02$ \\
D... & $.1000 \mathrm{E}+01$ & $.7255 \mathrm{E}+01$ & $.1378 \mathrm{E}+00$ & $-.1382 \mathrm{E}+02$ & $.1582 \mathrm{E}+02$ \\
R.... & $.2000 \mathrm{E}+01$ & $.1899 \mathrm{E}+02$ & $.1053 \mathrm{E}+00$ & $-.3679 \mathrm{E}+02$ & $.4079 \mathrm{E}+02$
\end{tabular}


d) Terceira tentativa

Observações: Essa situação ficou próxima da ideal, mostrando que variando o valor dos parâmetros $V, D$ e $R$ a mudança nos valores não foi significativa e o $r^{2}$ não variou.

\begin{tabular}{|c|c|c|c|}
\hline V & D & $\mathrm{R}$ & $\mathrm{Mu}$ \\
\hline 0.2 & 0.2 & 0.2 & 0.0 \\
\hline 1 & 1 & 1 & 0 \\
\hline 0.01 & 0.01 & 0.01 & 999 \\
\hline 1 & 1 & 2 & 999 \\
\hline
\end{tabular}

RSQUARE FOR REGRESSION OF OBSERVED VS PREDICTED $=.98276232$

(COEFFICIENT OF DETERMINATION)

MEAN SQUARE FOR ERROR (MSE) $=.2159 \mathrm{E}-02$

NON-LINEAR LEAST SQUARES ANALYSIS, FINAL RESULTS

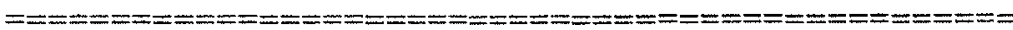

$\begin{array}{lccccc} & & & & & \\ \text { NAME } & \text { VALUE } & \text { S.E.COEFF. T-VALUE } & \text { CONFIDENCE LIMITS } \\ \text { LOWER } & \text { UPPER } \\ \text { D... } & .4603 \mathrm{E}+00 & .2673 \mathrm{E}+01 & .1722 \mathrm{E}+00 & -.4999 \mathrm{E}+01 & .5919 \mathrm{E}+01 \\ \text { R... } & .9896 \mathrm{E}+00 & .1077 \mathrm{E}+01 & .626 \mathrm{E}+01.1942 \mathrm{E}+00 & -.9417 \mathrm{E}+01 & .1140 \mathrm{E}+02 \\ & .6284 \mathrm{E}+01.1715 \mathrm{E}+00 & -.1176 \mathrm{E}+02 & .1391 \mathrm{E}+02\end{array}$

\section{3) TERRA ROXA ESTRUTURADA}

a) Valores dos parâmetros utilizados na simulação

\begin{tabular}{|c|c|c|c|}
\hline V & D & $\mathrm{R}$ & $\mathrm{Mu}$ \\
\hline 0.5 & 0.5 & 1.0 & 0.0 \\
\hline 1 & 1 & 1 & 0 \\
\hline 0.01 & 0.01 & 0.01 & 999 \\
\hline 1 & 1 & 2 & 999 \\
\hline
\end{tabular}

RSQUARE FOR REGRESSION OF OBSERVED VS PREDICTED $=.99176195$

(COEFFICIENT OF DETERMINATION)

MEAN SQUARE FOR ERROR (MSE) $=.9776 \mathrm{E}-03$

NON-LINEAR LEAST SQUARES ANALYSIS, FINAL RESULTS

\begin{tabular}{|c|c|c|c|c|}
\hline \multirow[b]{2}{*}{ NAME } & \multirow[b]{2}{*}{ VALUE } & \multirow[b]{2}{*}{ S.E.COEFF. T-VALUE } & 95\% CONFIDENCE & JCE LIMITS \\
\hline & & & LOWER & UPPER \\
\hline V.... & $.2708 E+00$ & $.3471 E+00$ & $-.4222 \mathrm{E}+00$ & $.9637 \mathrm{E}+00$ \\
\hline D.... & $.1042 E+00$ & $.6149 \mathrm{E}-01.1695 \mathrm{E}+01$ & $-.1850 \mathrm{E}-01$ & $.2270 \mathrm{E}+00$ \\
\hline R... & $.1572 E+01$ & $.2021 E+01.7776 E+00$ & $-.2463 E+01$ & $.5606 \mathrm{E}+01$ \\
\hline
\end{tabular}


b) Primeira tentativa

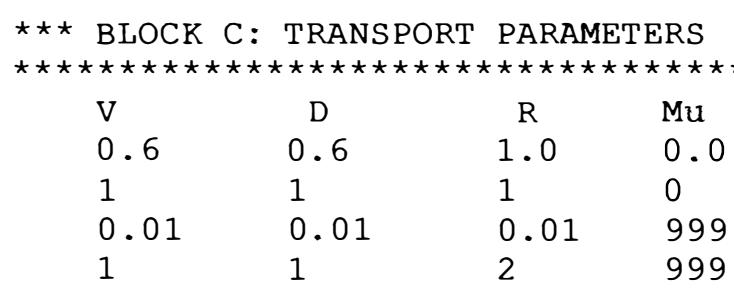

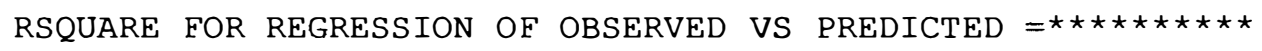
(COEFFICIENT OF DETERMINATION)

MEAN SQUARE FOR ERROR (MSE) $=.3576 \mathrm{E}+00$

NON-LINEAR LEAST SQUARES ANALYSIS, FINAL RESULTS

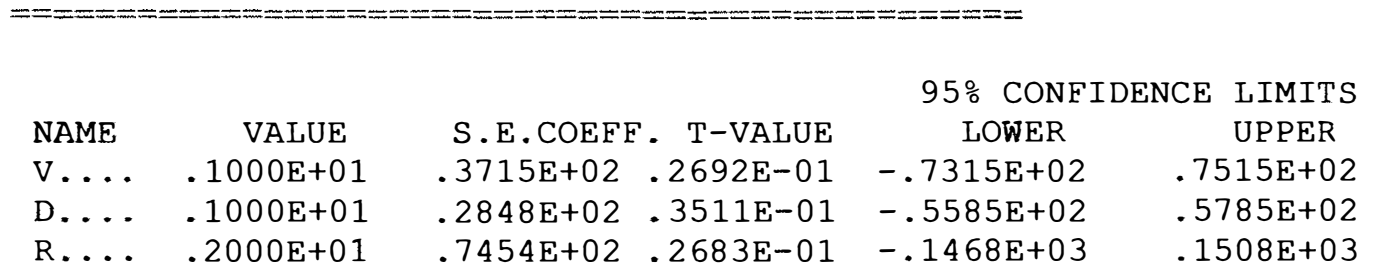

c) Segunda tentativa

\begin{tabular}{|c|c|c|c|}
\hline V & D & $\mathrm{R}$ & $\mathrm{Mu}$ \\
\hline 0.4 & 0.4 & 1.0 & 0.0 \\
\hline 1 & 1 & 1 & 0 \\
\hline 0.01 & 0.01 & 0.01 & 999 \\
\hline 1 & 1 & 1 & 999 \\
\hline
\end{tabular}

RSQUARE FOR REGRESSION OF OBSERVED VS PREDICTED $=.99175845$ (COEFFICIENT OF DETERMINATION)

MEAN SQUARE FOR ERROR (MSE) $=.9780 \mathrm{E}-03$

NON-LINEAR LEAST SQUARES ANALYSIS, FINAL RESULTS

\begin{tabular}{|c|c|c|c|c|}
\hline \multirow[b]{2}{*}{ NAME } & \multirow[b]{2}{*}{ VALUE } & \multirow[b]{2}{*}{ S.E.COEFF. T-VALUE } & \multicolumn{2}{|c|}{ 95\% CONFIDENCE LIMITS } \\
\hline & & & LOWER & UPPER \\
\hline V.... & $.7861 \mathrm{E}-01$ & $.1014 \mathrm{E}+00.7754 \mathrm{E}+00$ & $-.1237 \mathrm{E}+00$ & $.2810 \mathrm{E}+00$ \\
\hline D... & $.3053 E-01$ & $.1830 \mathrm{E}-01.1669 \mathrm{E}+01$ & $-.5991 \mathrm{E}-02$ & $.6705 \mathrm{E}-01$ \\
\hline R... & $.4563 E+00$ & $.5902 \mathrm{E}+00.7731 \mathrm{E}+00$ & $-.7219 \mathrm{E}+00$ & $.1634 \mathrm{E}+01$ \\
\hline
\end{tabular}


d) Terceira tentativa

Observações: Diminuiu o valor de $r^{2}$

$\star \star \star$ BLOCK C: TRANSPORT PARAMETERS

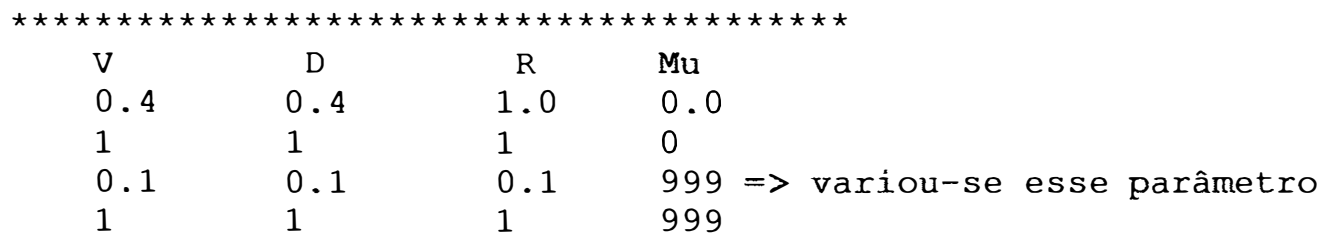

RSQUARE FOR REGRESSION OF OBSERVED VS PREDICTED $=.97487592$

(COEFFICIENT OF DETERMINATION)

MEAN SQUARE FOR ERROR (MSE) $=.2981 \mathrm{E}-02$

NON-LINEAR LEAST SQUARES ANALYSIS, FINAL RESULTS

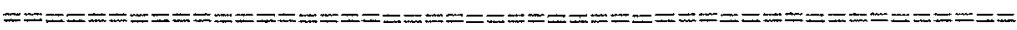

$\begin{array}{lccrcc} & & & 95 \% & \\ \text { NAME } & \text { VALUE } & \text { S.E.COEFF. T-VALUE } & \text { LOWER } & \text { UPPER } \\ \text { V.... } & .1319 \mathrm{E}+00 & .4909 \mathrm{E}+00 & .2687 \mathrm{E}+00 & -.8480 \mathrm{E}+00 & .1112 \mathrm{E}+01 \\ \text { D... } & .1000 \mathrm{E}+00 & .2692 \mathrm{E}+00 & .3715 \mathrm{E}+00 & -.4373 \mathrm{E}+00 & .6373 \mathrm{E}+00 \\ \text { R... } & .7615 \mathrm{E}+00 & .2844 \mathrm{E}+01 & .2677 \mathrm{E}+00 & -.4916 \mathrm{E}+01 & .6439 \mathrm{E}+01\end{array}$

e) Quarta tentativa

Observações: O valor de $r^{2}$ foi menor que a tentativa 1 mas deu um valor do fator de retardamento $(R)$ próximo de 1 , e o parâmetro $D$ ficou no limite da condição de contorno.

\begin{tabular}{|c|c|c|c|}
\hline V & D & $R$ & Mu \\
\hline 0.2 & 0.2 & 1.0 & 0.0 \\
\hline 1 & 1 & 1 & 0 \\
\hline 0.1 & 0.1 & 0.1 & 999 \\
\hline 1 & 1 & 1 & 999 \\
\hline
\end{tabular}

RSQUARE FOR REGRESSION OF OBSERVED VS PREDICTED $=.98505580$

(COEFFICIENT OF DETERMINATION)

MEAN SQUARE FOR ERROR (MSE) $=.1773 \mathrm{E}-02$

NON-LINEAR LEAST SQUARES ANALYSIS, FINAL RESULTS

\begin{tabular}{|c|c|c|c|c|}
\hline & & & \multicolumn{2}{|c|}{ 95\% CONEIDENCE LIMITS } \\
\hline NAME & VALUE & S.E.COEFF. T-VALUE & LOWER & UPPER \\
\hline $\mathrm{V} \ldots$. & $.1693 \mathrm{E}+00$ & $.3968 E+00.4268 E+00$ & $-.6226 E+00$ & $.9613 \mathrm{E}+00$ \\
\hline D.... & $.1000 \mathrm{E}+00$ & $.1513 \mathrm{E}+00.6611 \mathrm{E}+00$ & $-.2019 E+00$ & $.4019 \mathrm{E}+00$ \\
\hline R.... & $.9796 \mathrm{E}+00$ & $.2303 E+01.4254 E+00$ & $-.3618 E+01$ & $.5577 \mathrm{E}+01$ \\
\hline
\end{tabular}


f) Quinta tentativa

Observações: Apresentou $r^{2}$ menor que a repetição $1, e$ os parâmetros $D$ e fator de retardamento (R) ficaram no limite da condição de contorno.

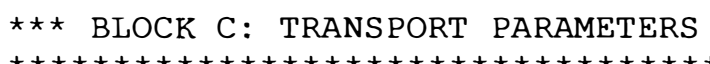

$\mathrm{V} \quad \mathrm{D} \quad \mathrm{R} \quad \mathrm{Mu}$

$0.20 .2 \quad 1.0 \quad 0.0$

$1 \quad 1 \quad 1 \quad 0$

$\begin{array}{llll}0.1 & 0.2 & 0.1 & 999\end{array}$

$\begin{array}{llll}1 & 1 & 1 & 999\end{array}$

RSQUARE FOR REGRESSION OF OBSERVED VS PREDICTED $=.94783508$

(COEFFICIENT OF DETERMINATION)

MEAN SQUARE FOR ERROR (MSE) $=.6190 \mathrm{E}-02$

NON-LINEAR LEAST SQUARES ANALYSIS, FINAL RESULTS

I=ニ=- $=$

\begin{tabular}{lccccc} 
& & & & \multicolumn{2}{c}{$95 \%$ CONFIDENCE LIMITS } \\
NAME & VALUE & S.E.COEFF. T-VALUE & LOWER & UPPER \\
V $\ldots .$. & $.1735 \mathrm{E}+00$ & $.1362 \mathrm{E}+01$ & $.1274 \mathrm{E}+00$ & $-.2546 \mathrm{E}+01$ & $.2893 \mathrm{E}+01$ \\
D.... & $.2000 \mathrm{E}+00$ & $.1284 \mathrm{E}+01$ & $.1558 \mathrm{E}+00$ & $-.2363 \mathrm{E}+01$ & $.2763 \mathrm{E}+01$ \\
R.... & $.1000 \mathrm{E}+01$ & $.7885 \mathrm{E}+01$ & $.1268 \mathrm{E}+00$ & $-.1474 \mathrm{E}+02$ & $.1674 \mathrm{E}+02$
\end{tabular}

